\title{
STRANGER DANGER!
}

\section{THE ROLE OF GHRELIN IN THE MODULATION OF SOCIAL BEHAVIOR}

\section{Su-Bin Park}

A Thesis submitted to the Faculty of Graduate \& Postdoctoral Affairs in partial fulfillment of the requirement of the degree of

\author{
Master of Science \\ in \\ Neuroscience \\ Carleton University \\ Ottawa, ON \\ C2017 - Su-Bin Park
}




\section{ABSTRACT}

Ghrelin is a gut-derived peptide hormone associated with feeding, energy balance, reward and the stress response. Among many of its identified functions, the role of ghrelin in anxiety has been particularly controversial with some authors reporting anxiogenic and others reporting anxiolytic effects of ghrelin receptor activity. In this thesis, we demonstrated that increasing ghrelin receptor activity in mice has anxiolytic effects in tests of anxiety involving stimuli with positive incentive value (i.e. palatable food or a novel conspecific mouse). We also found that this anxiolytic effect is mediated, at least in part, by ghrelin receptors in the ventral tegmental area. A role for ghrelin in social anxiety is particularly intriguing because social withdrawal and social anxiety are common symptoms of depression and there is strong evidence that ghrelin has other antidepressant properties. Depressive-like behaviors can be generated in mice by psychosocial stressors such as chronic social defeat. Thus we explored the possibility that treatment with the ghrelin agonist GHRP6 could prevent and/or alleviate stress-induced social anxiety when administered alone or in combination with the commonly prescribed antidepressant citalopram. We found that peripheral GHRP6 treatment was not sufficient to prevent or treat social withdrawal induced by chronic stress exposure. Chronic GHRP6 treatment, however, increased the number of immature neurons in the hippocampus. Furthermore, we found that chronic GHRP6 treatment reduced weight gain when administered alone as well as in combination with citalopram. Weight gain is a common side effect of antidepressant treatment thus the finding that GHRP6 can reduce these metabolic side effects has potential therapeutic potential. 


\section{ACKNOWLEDGEMENTS}

First and foremost, I would like to thank my supervisor Dr. Alfonso Abizaid for accepting me as his graduate student and for providing all the resources for me to complete my study. More importantly, his continuous support and encouragement allowed me to build confidence in my work. I would also like to thank Dr. Barbara Woodside for her valuable contribution to this thesis by sharing her knowledge and for all the countless edits/feedbacks that increased the quality of this thesis. I am also grateful to have her as my committee member. Likewise, I want to acknowledge the rest of my committee, Dr. Hymie Anisman and lain McKinnell for taking the time to read, correct and provide constructive feedback to further improve the quality of this thesis.

\section{"Art is I, Science is We" - Claude Bernard}

As the quote reflects, the work in this thesis is the final product of collaboration. With that being said, I would like to express my sincere gratitude to the Abizaid Lab family for all of their support and positive influence they had on my graduate study. Special shout out goes to Lindsay Hyland for the countless memories in and outside of the lab, as well as for helping me at times when I needed it most. I would also like to thank Samantha King for the opportunity to collaborate with her on her PhD work, as well as for all the contributions she have made to strengthen the work in this thesis. All the fat cells in my body are grateful for Rim Khazall, who looked after my ghrelin levels at stressful times during my graduate study. I'm also grateful for Alex Edwards, Cathy Nesbitt, Eliza Ali, and Dr. Marianne Klein for their friendship. I would also like to acknowledge Dr. Harry MacKay for his 24/7 facebook support line answering emergency research questions, as well as for all the advice and technical help he provided throughout my study.

Finally, I would like to thank my parents for their unconditional love and support. 25 years ago, my dad finished his graduate study and dedicated his thesis to my mom for all the sacrifices she made to support him. I would also like to dedicate my thesis to my mom, as her positivity and enthusiasm have been a great source of motivation for me to complete my degree.

- Su-Bin Park -

August 2017 


\section{LIST OF ABBREVIATIONS}

$\alpha-\mathrm{MSH}$ : $\alpha$-melanocyte stimulating hormone

5-HT: 5-hydroxytryotamine (serotonin)

AgRP: agouti related peptide

AAV-Cre: adeno-associated virus containing cre-recombinase

AAV-GFP: adeno-associated virus containing green fluorescent protein

ANOVA: analysis of variance

ARC: arcuate nucleus

BrDU: 5-bromo-2'-deoxyuridine

CART: cocaine and amphetamine regulated transcript

CIT: citalopram

CSDP: chronic social defeat paradigm

DA: dopamine

DCX: doublecortin

GABA: $\gamma$-aminobutyric acid

GC: glucocorticoid

GHRP6: growth hormone releasing hexapeptide (ghrelin agonist)

GHSR: growth hormone secretagogue receptor (ghrelin receptor)

GHSR KO: ghrelin receptor knock out

GOAT: ghrelin-o-acyltransferase

HPA axis: hypothalamus pituitary adrenal axis

JMV2959: ghrelin receptor antagonist

NAcc: nucleus accumbens

NPY: neuropeptide $Y$

NSFT: novelty suppressed feeding test

NTS: nucleus tractus solitarius

OFT: open field test

PFA: paraforaldehyde

POMC: propiomelanocortin

PVN: paraventricular nucleus

SSRI: selective serotonin reuptake inhibitor

TBC: transcriptional blcking cassette

Tukey's HSD: Tukey's honest significant differences

VTA: ventral tegmental area

WT: wild type

4. 


\section{CONTENTS}

CHAPTER 1 GENERAL INTRODUCTION..................................... 7

CHAPTER 2 MANIPULATION OF THE GHRELIN RECEPTOR AND ITS EFFECTS

ON ANXIETY.

- GENERAL METHODS

- Animals 18

- Cannula Implantation $\quad 19$

- $\quad$ Acute viral administration into the VTA 20

- Behavior tests 22

- Experimental designs 26

- Statistics 30

- RESULTS

- Experiment $1 \mathrm{a}$ and $1 \mathrm{~b} \quad 31$

- Experiment 2a and 2b 39

- DISCUSSION

CHAPTER 3 EFFECTS OF GHRELIN AGONIST GHRP6 ALONE AND IN COMBINATION WITH CITALOPRAM ON DEPRESSIVE SYMPTOMS EVOKED BY CHRONIC SOCIAL STRESS

- GENERAL METHODS

Animals $\quad 57$

Osmotic minipump implantation $\quad 57$

Citalopram administration $\quad 58$

Chronic social defeat paradigm 58

Behavior tests $\quad 59$

Immunohistochemistry $\quad 60$

Experimental designs $\quad 64$

- $\quad$ Statistics 67

- RESULTS

Experiment 3a 68

- Experiment 3b 73

- DISCUSSION 81

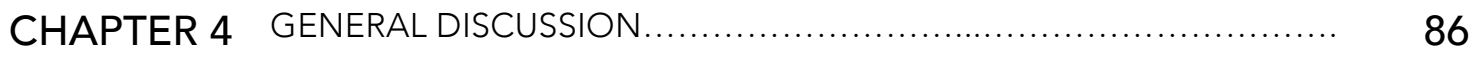

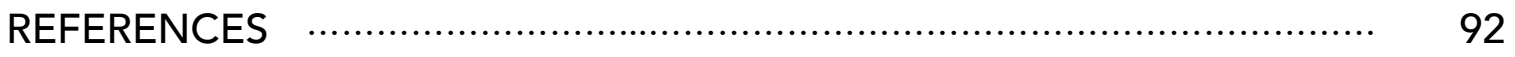

5. 


\section{LIST OF FIGURES}

2.A. Simplified demonstration of the Cre-LoxP application....................... 21

2.B. Open field test and novelty suppressed feeding test ...................... 24

2.C. The social interaction chamber......................................... 25

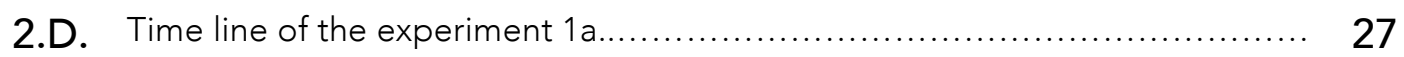

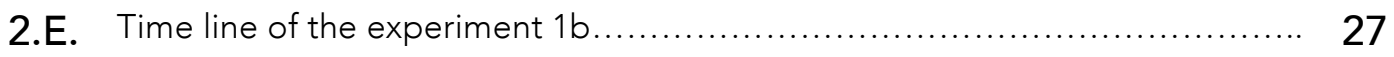

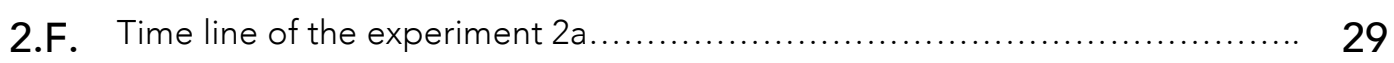

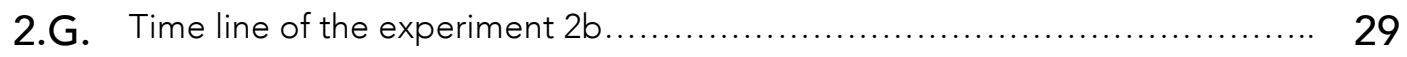

2.1. Social behavior measures of WT and GHSR-KO ......................... 32

2.2. Social behavior measures of vehicle and JMV2959........................ 33

2.3. Novelty suppressed feeding behaviors of WT and GHSR-KO ................ 35

2.4. Novelty suppressed feeding behaviors of vehicle and JMV2959............... 36

2.5. Behavior in the open field test of WT and GHSR-KO ....................... 38

2.6. Behavior in the open field test of vehicle and JMV2959.................... 38

2.7. Social behavior measures of saline v.s. JMV2959 into the VTA ............... 41

2.8. Social behavior measures of GFP v.s. CRE into the VTA .................... 42

2.9. Novelty suppressed feeding behaviors in saline v.s. JMV2959 into the VTA.... 44

2.10. Behavior in the open field test of saline v.s. JMV2959 into the VTA............ 44

2.11. Novelty suppressed feeding behaviors in GFP v.s. CRE into the VTA........... 45

2.12. Behavior in the open field test of GFP v.s. CRE into the VTA ................. 45

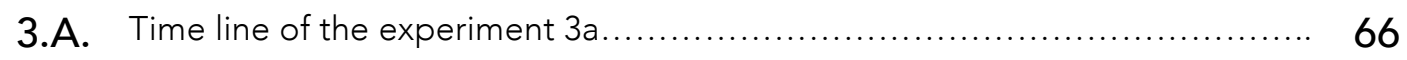

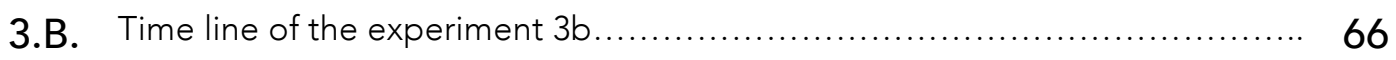

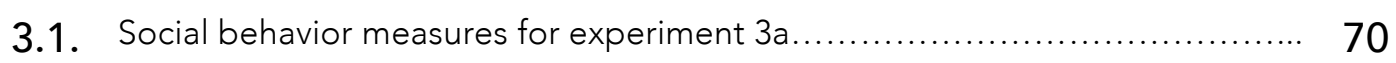

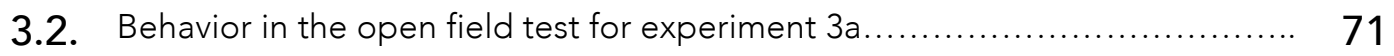

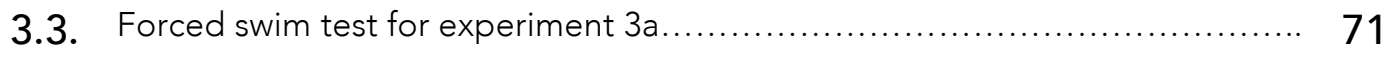

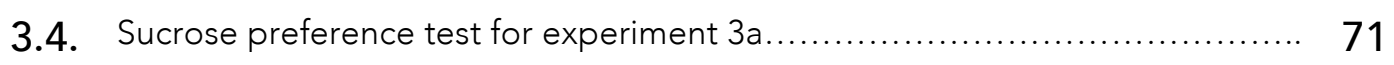

3.5. Body weight and chow, water and citalopram intake for experiment 3a....... 72

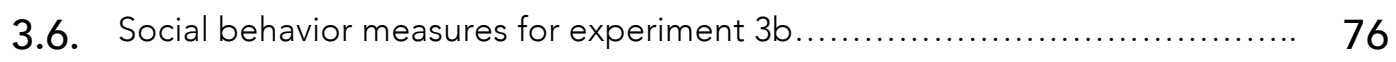

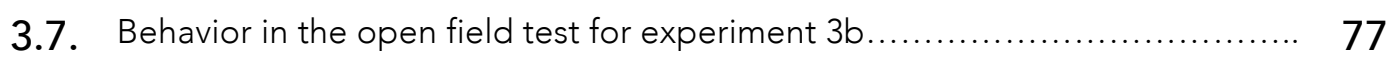

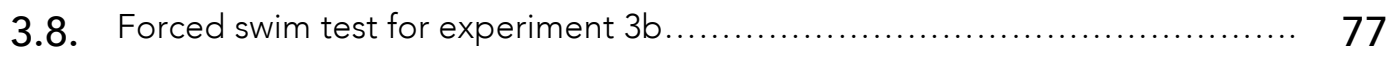

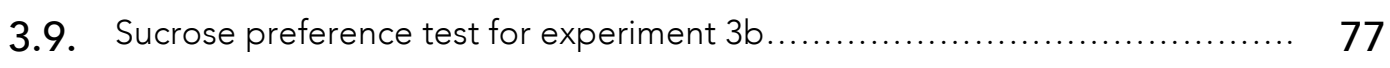

3.10. Mean DCX immunoreactivity in the dentate gyrus for experiment3b........... 78

3.11. Mean BrDU immunoreactivity in the dentate gyrus for experiment3b.......... 79

3.12. Body weight and chow, water and citalopram intake for experiment $3 b \ldots \ldots \ldots . \quad 80$ 


\section{CHAPTER 1}

\section{GENERAL INTRODUCTION}

Ghrelin is a 28 amino acid peptide hormone that has potent orexigenic (appetite-stimulating) effects (Kojima et al., 1999). It is primarily secreted by the enteroendocrine X/A like cells lining the wall of the stomach (Kojima et al., 1999). Ghrelin is an endogenous ligand for the growth hormone secretagogue receptor (GHSR) (Kojima et al., 1999; Dornonville de la Cour et al., 2001). Binding of ghrelin to the GHSR only occurs once a fatty acid side chain has been bound to its serine 3 residues which occurs in the presence of ghrelin $\bigcirc$-acyl transferase (GOAT) enzyme (Gutierrez et al., 2008; Yang et al., 2008). The non-acylated form of ghrelin, desacyl-ghrelin, does not bind to GHSR. Consistent with its orexigenic effects, serum ghrelin concentrations increase before meals and in response to fasting and chronic food restriction (Cummings et al., 2001; Toshinai et al., 2001; Gualillo et al., 2001). The GHSR is expressed in a number of organs and throughout the brain. It is especially abundant in the hypothalamus, an important central region in the control of food intake and energy balance (Guan et al., 1997; Elmquist et al., 1999; Wren et al., 2000). The expression of GHSR in the hypothalamus also increases in response to chronic food restriction (Kim et al., 2003).

Both central and peripheral ghrelin administration increase food intake and promote food-seeking behavior in humans and rodents (Wren et al., 2000; Wren et al., 2001; Tong et al., 2011; King et al., 2011; St.Onge et al., 2016). 
Ghrelin administration also increases preference for palatable foods such as those high in fat and/or sugar, whereas mice with a genetic mutation of the GHSR as well as those treated systemically with a GHSR antagonist show a decrease in preference for palatable food (Disse et al., 2010; Egecioglu et al., 2010; Perello et al., 2010; King et al., 2011; MacKay et al., 2016). Moreover, both fasted and sated mice show increased palatable food seeking behavior after exogenous ghrelin administration even in a novel environment (Lockie et al., 2017). This effect was abolished in animals injected intraperitoneally with glucose, supporting the idea that metabolic state (hunger vs satiety) influences the assessment of risk in foraging situations (Lockie et al., 2017).

The effects of ghrelin on food intake are mediated primarily through the actions of this hormone on receptors found in the hypothalamus and brain stem. Within the hypothalamus, GHSR expression is particularly dense in the arcuate nucleus (ARC). This region harbors two populations of neurons with parallel projections but opposing effects on food intake and energy balance (Kohno et al., 2003; Mondal et al., 2005; Grill, 2006; Zigman et al., 2006; Tschop et al., 2000). Neurons that stimulate appetite co-produce two potent orexigenic peptides, neuropeptide Y (NPY) and agouti related peptide (AGRP). Ghrelin stimulates these NPY/AGRP neurons to increase food intake and decrease energy expenditure (Stanley et al., 1986; Hagan et al., 2000; Sun et al., 2003; Holst and Schwartz, 2004; Abizaid and Horvath, 2008; Atasoy et al., 2012; Williams and Elmquist, 2012). The second set of neurons produces propiomelanocortin (POMC) and cocaine and amphetamine-regulated transcript (CART), and these neurons secrete $\alpha$-melanocyte stimulating hormone $(\alpha-M S H)$, a peptide that decreases appetite via inhibition of appetite stimulating signals and increases 
metabolic rate (Joseph et al., 1985; Elias et al., 1998; Kristensen et al., 1999; Marsh et al,. 1999; Bagnol et al., 1999; Grill et al., 2006; Abizaid and Horvath, 2008). The POMC/CART neurons do not express GHSR, but ghrelin indirectly inhibits these neurons by stimulating NPY/AGRP neurons to release GABA that ultimately inhibit the anorectic effect of POMC/CART neurons (Cowley et al., 2003; Abizaid and Horvath, 2008). Ghrelin also increases food intake via the stimulation of the vagus nerve and its afferents in the brain stem (Date et al., 2002; Faulconbridge et al., 2003; Williams et al., 2003; Abizaid and Horvath, 2008). Ghrelin receptors are found in the area postrema and nucleus of the solitary tract (NTS) and these are stimulated by peripheral ghrelin to modulate feeding (Faulconbridge et al., 2003; Zhang et al., 2004; Zhang et al,. 2005; Zigman et al., 2006; Solomon et al., 2006; Date et al., 2006; Fry and Ferguson, 2009).

Central GHSR expression, however, is not limited to regions of the brain typically involved with feeding. GHSR expression is also abundant in the substantia nigra, dorsal and medial raphe nuclei, basolateral amygdala, hippocampus, and the ventral tegmental area (VTA) (Guan et al., 1997; Zigman et al., 2006; Alvarez-Crespo et al., 2012). Like the hypothalamus, these regions are important centers for the modulation of feeding, but are also implicated in multiple physiological and behavioral processes including stress responses, and reward seeking behaviors.

The effects of ghrelin in the VTA have received a relatively large amount of attention because of the role of this area in regulating reward seeking mechanisms and responses to stress. Direct administration of ghrelin into the VTA increases food intake as well as food searching/anticipation of food delivery 
(Naleid et al., 2005; Abizaid et al., 2006; Skibicka et al., 2011). Preference for highly palatable foods such as those high in fat and/or sugar was enhanced by administration of ghrelin into the VTA but not when ghrelin was administered into the nucleus accumbens (NAcc) (King et al., 2011; Skibicka et al., 2012; Anderberg et al., 2016; St.Onge et al., 2016). Ghrelin also acts in the VTA to excite dopaminergic neurons resulting in increased dopamine (DA) turnover in the NAcc (Abizaid et al., 2006; Skibicka et al., 2011; Skibicka et al., 2013).

There is also evidence to suggest that ghrelin modulates behaviors that are aimed at obtaining non-food associated rewards. This includes increases in behaviors associated with sexual motivation and drug seeking. For instance, in male mice, administration of a ghrelin antagonist as well as genetic mutation of GHSR reduced sexual motivation and sexual behavior towards receptive female mice (Egecioglu et al., 2016). In our lab, we have also found that mutation of GHSR in male rats decreased anticipatory behavior prior to the presentation of a receptive female and resulted in a longer latency to approach a receptive female on initial exposure (Hyland et al., 2016). In addition, peripheral ghrelin treatment results in increases in the locomotor and reinforcing actions of cocaine, and these effects are attenuated in rodents with a genetic mutation of the GHSR or in the presence of a GHSR antagonist (Wellman et al., 2005; Davis et al., 2007; Wellman et al., 2008; Jerlhag et al., 2010; Abizaid et al., 2011; Clifford et al., 2012). Finally, acute ghrelin administration in rats produces increased exploration of a novel stimulus, a behavior that is correlated with increased dopamine release, and this effect was eliminated by intra-VTA GHSR antagonist treatment (Hansson et al., 2012). Importantly, a role for ghrelin receptor activity in response to novelty has also been reported in humans. Hansson and colleagues (2012) also 
reported that two human GHSR single nucleotide polymorphisms, rs2948694 and rs495225, were significantly associated with lower scores on the personality trait for novelty seeking behavior as assessed by the Temperament and Character Inventory.

Although the VTA has been studied primarily within the context of reward seeking behaviors, it is important to note that this region has been implicated in the responses to acute and chronic stressors, and plays a major role in the processes that lead to stress induced psychopathology (Cabib and PuglisiAllegra, 1996; Krishnan and Nestler, 2008; Friedman et al., 2014). For example, dopamine (DA) release from the VTA is increased after acute stressors, and dampened after chronic stressors (Anisman and Zacharko, 1990; Shanks et al., 1991). Moreover, chronic social defeat stress, a commonly used pre-clinical animal model of depression and anxiety, is associated with alterations in brain chemistry that are unique to the VTA and that may reflect a key role for this region in mediating the transition to these psychopathological states (Ortiz et al., 1996; Berton et al., 2006; Krishnan et al., 2007; Krishnan and Nestler, 2008; Chaudhury et al., 2013; Pena et al., 2017). Therefore, ghrelin receptors in this region may be important for processes other than reward seeking behaviors.

In addition to the VTA, the GHSR is expressed in other regions of the brain associated with the physiological, behavioral and emotional responses to stress. These include the hippocampus, pre-frontal cortex, basolateral amygdala and medial amygdala, lateral septum, dorsal raphe and paraventricular nucleus of the hypothalamus (PVN) (Guan et al., 1997; Zigman et al., 2006; Alvarez-Crespo et al., 2012). The localization of the GHSR in these regions and their function has 
not been fully established, but suggests that ghrelin is not only a feeding hormone but also one that plays a role in the responses to stressors. It is therefore not surprising that acute and chronic stressors result in an increase in plasma ghrelin concentrations (Asakawa et al., 2001; Kristensson et al., 2006; Shmidt et al., 2006; Rouach et al., 2007; Lutter et al., 2008; Zheng et al., 2009; Spencer et al, 2012; Patterson et al., 2013). Ghrelin may be secreted in these situations not only to promote metabolic homeostasis, but also to defend against potential long-term consequences of chronic exposure to stressors (Patterson et al., 2010; Spencer et al., 2012; Patterson et al., 2013). For instance, chronic stress and depressive like symptoms are associated with a decrease in hippocampal neurogenesis, and ghrelin treatment increases neurogenesis as well as having other antidepressant effects, particularly in defending against the metabolic and feeding deficits observed with depression (Diano et al., 2006; Moon et al., 2009; Patterson et al., 2010; Deng et al., 2010; Li et al., 2013; Patterson et al., 2013 Kent et al., 2015). In contrast, mice with mutations to the GHSR are more likely to develop stress induced depressive like symptoms, which include anhedonia, despair, social withdrawal, and disruptions of sleep (Lutter et al., 2008; Szentirmai et al., 2009; Patterson et al., 2010; Patterson et al., 2013; Spencer et al., 2014; Skov et al., 2017). Collectively, these data support the idea that ghrelin defends against the effects of chronic stress.

Given the antidepressant effect of ghrelin, one would suspect that ghrelin also exerts anxiolytic effects. Nevertheless, evidence in the literature on this topic is controversial. In some studies, ghrelin shows an anxiolytic effect where acute and chronic peripheral ghrelin administration reduced the time spent immobile during the forced swim test and produced anxiolytic effects on behavior in the 
open field, light dark chamber, and elevated plus maze in both mice and rats (Lutter et al, 2008; Spencer et al., 2012; Landrigan et al., 2016; Jensen et al., 2016). In contrast, Carlini and colleagues (2002) demonstrated that intracerebroventricular injection of ghrelin in rats increased freezing behavior and decreased the number of entries into the center of the open field test, and reduced the amount of time spent on the open arms in the plus-maze, suggesting an anxiogenic effect. Similarly, Kanehisa and colleagues (2006) reported that chronic central administration of ghrelin antisense oligonucleotides decreased the time animals spent on the open arms of an elevated plus maze, and reduced time spent in the light side of a light/dark chamber supporting an anxiogenic effect of ghrelin. In an excellent review of the role of ghrelin in stress, mood and anxiety regulation by Chuang and Zigman (2010), the authors argue that discrepancies in findings involve differences in drug dose, route of administration, timing of administration, and timing of behavioral test after administration. It is important to note that many studies conduct and refer to one type of anxiety test, and therefore examine only a limited range of behaviors that do not reflect the whole spectrum of anxiety. As such, the precise role of ghrelin in modulating anxiety like behaviors remains to be delineated.

The evidence reviewed above suggests that ghrelin modulates many behavioral and physiological processes in addition to its well-known function in the regulation of food intake. Ghrelin has been implicated in sex behavior and drug seeking as well as in stress and anxiety. Ghrelin's diverse functions may reflect the wide central distribution of its receptor GHSR. Of all its putative functions, studies examining the role of ghrelin in anxiety have generated particularly confusing outcomes with some authors reporting anxiogenic and 
some others reporting anxiolytic effects of GHSR activity. Thus, it is clear that further work is required to more precisely elucidate under which conditions GHSR activation modulates anxiety behavior.

Two sets of data from our lab suggest that ghrelin acts on its receptor in the VTA to reduce anxiety. The first set of data showed that GHSR mRNA expression in the VTA is increased in chronically stressed animals and the second evidence is that pharmacological blockade of GHSR in the VTA increased social anxiety in chronically stressed mice (Park et al., 2015; Wallace et al., 2015). On the basis of these data, together with evidence that GHSR activation, induces novelty-seeking and exploratory behaviors towards both food and non-food associated cues, we hypothesized that loss of function of GHSR would increase anxiety in tests of social approach and eating in a novel environment while having little effect in the open field test. In the first two studies presented in Chapter 2 of this thesis (Experiments 1a and 1b), we tested this hypothesis by comparing the behavior of mice given either saline or JMV2959 and that of wild type (WT) mice and mice with a genetic mutation of the ghrelin receptors (GHSRKO). In addition, we hypothesized that GHSR signalling in the VTA modulates anxiolytic responses during the behavior tests associated with incentive value (i.e. palatable food, opportunity to socialize). We tested this hypothesis by administering a GHSR antagonist (JMV2959) into the VTA of mice (Experiment 2a) and comparing their behavior with mice treated with saline using the same tests as described for Experiments 1a and 1b. Finally, in Experiment 2b, we tested the same hypothesis by comparing the behavior of the GHSR-null mice with GHSR-null mice in which GHSR was restored in the VTA using AAV-Crerecombinase.

14. 
If GHSR signaling does have anxiolytic effects, one would expect that ghrelin or ghrelin agonist treatment would improve stress induced social anxiety. In the experiments described in Chapter 3, we first tested the hypothesis that increasing GHSR activation by chronic administration of a ghrelin agonist (GHRP6) alone or in combination with a commonly used antidepressant (citalopram) would dampen the anxiogenic effects caused by chronic stress (Experiment 3a). In the final experiment (Experiment 3b), we tested the hypothesis that GHRP6 treatment alone or in combination with citalopram after chronic stress would alleviate the effects of chronic stress in a more effective manner than citalopram alone. 


\section{CHAPTER 2}

\section{MANIPULATION OF THE GHRELIN RECEPTOR AND ITS EFFECTS ON ANXIETY}

Ghrelin, a stomach derived orexigenic peptide, is an endogenous ligand for the growth hormone secretagogue receptor (GHSR) (Kojima et al., 2001). Within the brain, GHSRs are found most abundantly in the hypothalamus, consistent with the well-established role of ghrelin in food intake and metabolic regulation. Ghrelin receptors, however, are also located in several brain regions best known for their role in modulating emotional responses, and these include regions within the mesolimbic dopaminergic system that include the VTA, hippocampus, amygdala, and pre frontal cortex (Guan et al., 1997; Zigman et al., 2006; Alvarez-Crespo et al., 2012). This network as a whole is critical for a number of processes that include motivation, cognitive function and emotional regulation, and the presence of ghrelin receptors in these regions points to a role of ghrelin in modulating these functions. There is now extensive evidence related to this contention (refer to an excellent review by Muller et al., 2015).

In addition to feeding, ghrelin is released in response to acute and chronic stressors, and it may play an important role in the regulation of the behavioral 
and physiological responses to stressors. The mesolimbic system is particularly vulnerable to the effects of chronic exposure to stress and ghrelin may act on this system to mitigate some of the effects of chronic exposure to stressors, including the appropriate metabolic shift required to maximize energy utilization (Berton et al., 2006; Nestler and Carlezon, 2006; Patterson et al., 2010; Patterson et al., 2013). In behavioral studies, ghrelin improves symptoms associated with chronic stress like anhedonia, despair, and social anxiety, whereas decreased GHSR signaling is associated with vulnerability to chronic stressors (Lutter et al., 2008; Patterson et al., 2010; Patterson et al., 2013). While there seems to be a strong evidence for the antidepressant effects of ghrelin, the role of ghrelin in modulating anxiety remains less clear. There is evidence both showing that ghrelin decreases anxiety and that it has anxiogenic effects (Asakawa et al., 2001; Carlini et al., 2002; Kanehisa et al., 2006; Currie et al., 2012). In this chapter, we report results from a series of experiments examining, in detail, the role of GHSR signaling on behaviors associated with anxiety using an extensive battery of behavioral anxiety tests. These tests included a typically used behavioral screen to test for general anxiety (the open field test), as well as behavioral screens that pit the natural anxiogenic state associated with exposure to a environment that lacks enrichment against a stimuli that has a positive incentive value (a palatable food item or a novel con-specific). Given that GHSR signaling in the VTA is associated with increased reward seeking behaviors including behaviors associated with food and social rewards, we also present data examining the role of GHSR in the VTA mediating these processes. 


\section{GENERAL METHODS}

\section{Animals}

Male C57/BL6 mice purchased from Jackson Laboratory (Bar Harbor ME, USA) served as experimental subjects in Experiments $1 \mathrm{~b}$ and 2a. Male GHSR WT and GHSR KO mice served as experimental subjects in Experiments 1a. These mice, generated on a C57/BL6 background strain, originate from breeding pairs developed by Regeneron Pharmaceuticals Inc. (Tarryown NY, USA). Their phenotypic characterizations have been described previously (Pfluger et al., 2008). GHSR WT and GHSR LoxP/LoxP (referred as GHSR-null in this thesis) mice, generated on a C57/BL6 background strain, originate from breeding pairs developed by Jeffrey Zigman lab (The University of Texas Southwestern, Texas USA) served as subjects in experiment $2 \mathrm{~b}$. GHSR KO and GHSR-null mice both lack GHSR activity but they differ in how they were generated. For extensive review on how GHSR ${ }^{\text {LoxP/LoxP }}$ were generated as well as information on genotype and phenotypic characterizations, please refer to a paper by Zigman and colleagues (2005). All mice weighed 25-30g at the beginning of the experiment and were single-housed in standard plastic mouse cages $(27 \times 21 \times 14 \mathrm{~cm})$ in a temperature-controlled $\left(22 \pm 1^{\circ} \mathrm{C}\right)$ and humidity-controlled $(50 \pm 5 \%)$ environment on a $12 \mathrm{~h}$ light-dark cycle (lights on at 08:00h) with access to chow $(2.9 \mathrm{kcal} / \mathrm{g}$, with $70 \%$ of calories derived from carbohydrates) and water at ad libitum.

All experimental procedures were approved by the Carleton University Animal Care Committee and followed the guidelines of the Canadian Council on Animal Care.

18. 


\section{Cannula Implantation}

Mice were anesthetized with isoflurane mixed with oxygen (4\%) and injected s.c. with analgesic meloxicam (1 mg/kg, Metacam). All mice were secured onto a mouse stereotaxic apparatus (Kopf Instruments, Tujunga, CA). Surgiprep and Priviodine were applied to the scalp to provide sterilization, and tear gel was applied to the eyes to prevent dehydration. A midline incision was made on the skin covering the scalp. A 30-gauge stainless steel unilateral cannula (Plastics One model 330OP/DW/Spc) coupled to an osmotic minipump (Alzet pump model 1004; 4weeks, flow rate $0.11 \mathrm{ul} / \mathrm{hr}$ ) of assigned treatment using a polyethylene catheter was implanted into the VTA (AP-2.92, ML+/-0.7, DV-4.5). Dental cement was applied to secure the cannula. Once fully dried, the minipump was subcutaneously implanted after separating the skin from the hind back muscle using blunt dissection tools. The hind back area had large amount of fatty tissues, which minimized impact of minipump implantation on mobility. Silk surgical sutures were used to close all incisions, and polysporin $®$ (@) Johnson \& Johnson, New Jersey, USA) and 2\% lidocaine hydrochloride topical anaesthetic jelly (Xylocaine, AstraZeneca, CDMV, Saint-Hyacinthe, OC, Canada) was administered on the surgical sites to prevent bacterial infection and as siteanalgesic. Mice were allowed to recover from surgery in clean homecage with a heating pad and medicam $(1 \mathrm{mg} / \mathrm{kg})$ injected s.c.. The recovery of the animals was closely monitored through daily weight, chow and water intake measurement as well as behavioral checks. 


\section{Acute viral administration into the VTA}

All mice were anesthetized with isoflurane mixed with oxygen (4\%) and injected s.c. with analgesic meloxicam (1 mg/kg, Metacam). All mice were secured onto a mouse stereotaxic apparatus (Kopf Instruments, Tujunga, CA). Surgiprep and Priviodine were applied to the scalp to provide sterilization, and tear gel was applied to the eyes to prevent dehydration. A midline incision was made on the skin covering the scalp. A 30-gauge stainless steel unilateral cannula (Plastics One model 3300P/DW/Spc) was implanted into the VTA (AP-2.92, ML+/-0.7, DV4.5). The microsyringe connected to the cannula delivered the assigned drug at a flow rate of $0.5 \mathrm{ul}$ over 400 seconds. This procedure repeated to target VTA in the other hemisphere of the brain. Mice received a single, bilateral microinfusion of either GFP (AAV9.hSyn.eGFP.WPRE.bGH; purchased from uPenn Vector Core, Pennsylvania, USA) or AAV-Cre recombinase $(4.44 \mathrm{e} 9 \mathrm{GC} / \mathrm{ml}$; AAV9.hSyn.HI.eGFP-Cre.WPRE.SV40; purchased from uPenn Vector Core, Pennsylvania, USA). Simplified application diagram of the Cre-LoxP excision of transcription blocking cassette is described in Figure 2.A. Once the microinfusion was complete, the cannula was removed. Incision closure and postoperative procedures were as described for pump implantation 


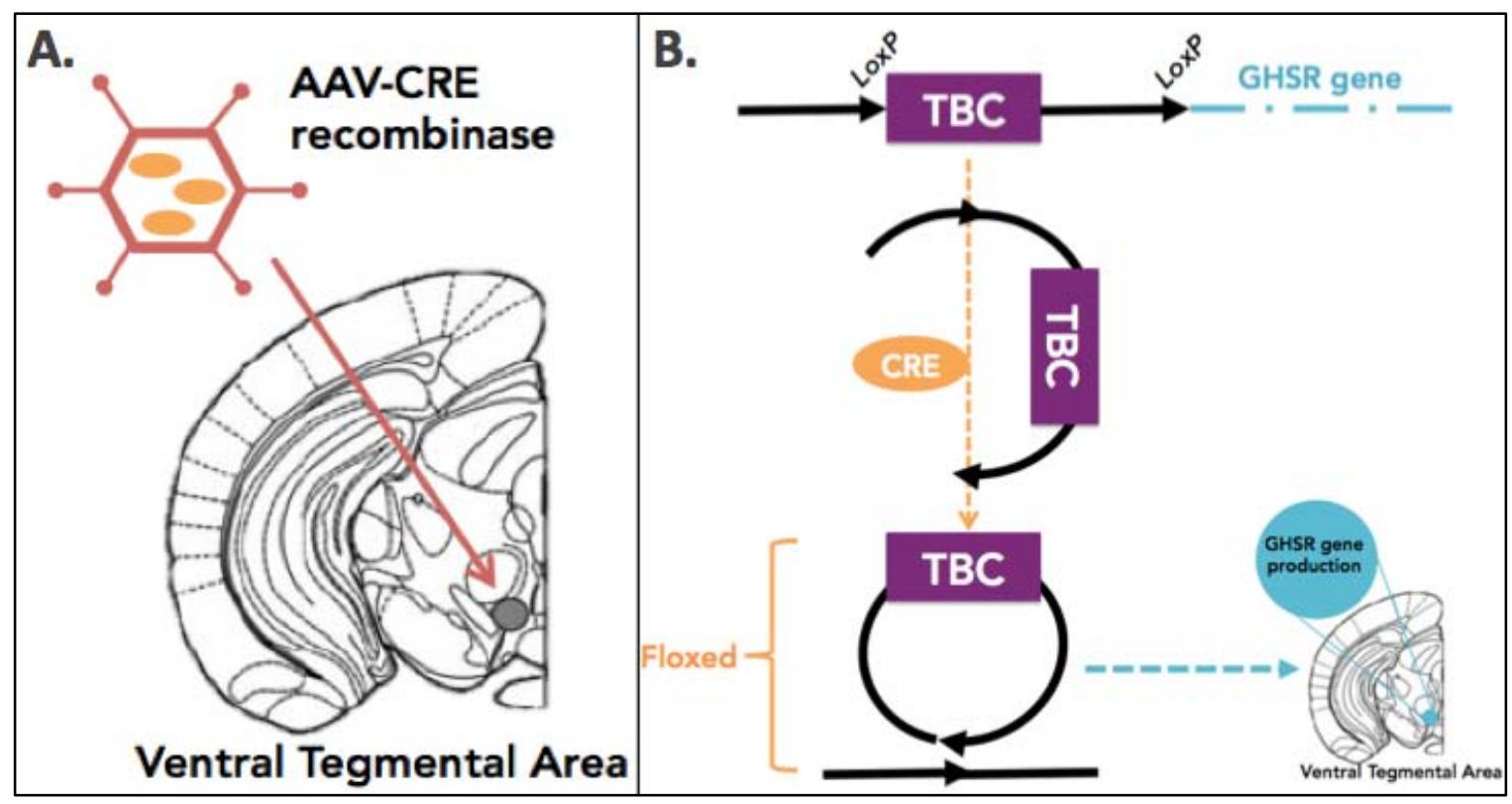

Figure 2.A. Simplified demonstration of the application of Cre-LoxP recombination using GHSR-null mice developed by Jeffrey Zigman lab (The University of Texas Southwestern, Texas USA). A. Cannula targeted the VTA in each hemisphere of the brain to administer AAV virus containing Crerecombinase. B. Administered cre-recombinase selectively binds to LoxP-flanked transcriptional blocking cassette (TBC) that were inserted into a putative intron, localized downstream of the transcriptional start site and upstream of the translational start site of the GHSR gene. Cre bound LoxP region of the gene will be removed containing the TBC, and thus the transcription and translation of the GHSR resumes in the GHSR null mice. 


\section{BEHAVIOR TESTS}

\section{Open field test (OFT)}

All mice were placed individually in the corner of the gridded $(10 \times 10 \mathrm{~cm})$ open field box (50x50x50 cm) (Figure 2.B.A.) and allowed to freely explore the field for 5 minutes. Animal activity during this time was video recorded and the time spent in the center of the box was used as a measure of anxiety. Anxious animals spontaneously prefer the periphery of the open field by walking close to the walls, a behavior known as thigmotaxis (Prut and Belzung, 2003).

\section{Novelty Suppressed Feeding Test (NSFT)}

Animals were pre-exposed to palatable food (cookie dough in Experiments 1a,b; high fat in Experiments 2a,b) for 48 hours then deprived for one day before the NSFT test. Following the OFT, palatable food was introduced in the center of the OFT arena (Figure 2.B.B.) for 5 minutes during which activity was video recorded. Latency to approach palatable food and number of times approaching palatable food was measured (Bodnoff et al., 1988).

\section{Social interaction test}

The social interaction test was conducted following the method of Tsuda and Ogawa (2012). All mice were habituated in a social interaction chamber (Figure 2.C.A) that contained a perforated cylinder (3.5"(d) by 7"(h); custom made from Plastics of Ottawa) as well as enrichment items such as red housing, 
nestlet and wooden block for 48 hours. On the test day, all enrichment except the perforated cylinder was removed from the chamber and mouse acclimatized to this condition for 30 minutes. A stranger mouse of the same strain was then placed into the centrally located perforated cylinder. Social activity was video recorded for 10 minutes. Latency to approach the stranger mouse, frequency of sniffing, stretching, and corner observation (Figures 2.C.B., 2.C.C., and 2.C.D. respectively) was quantified. See Tsuda and Ogawa (2012) for an extensive discussion of these social behavioral measures.

To avoid confounds due to the order of behavioral tests, in all experiments order of test presentation was counterbalanced across subjects within groups. 

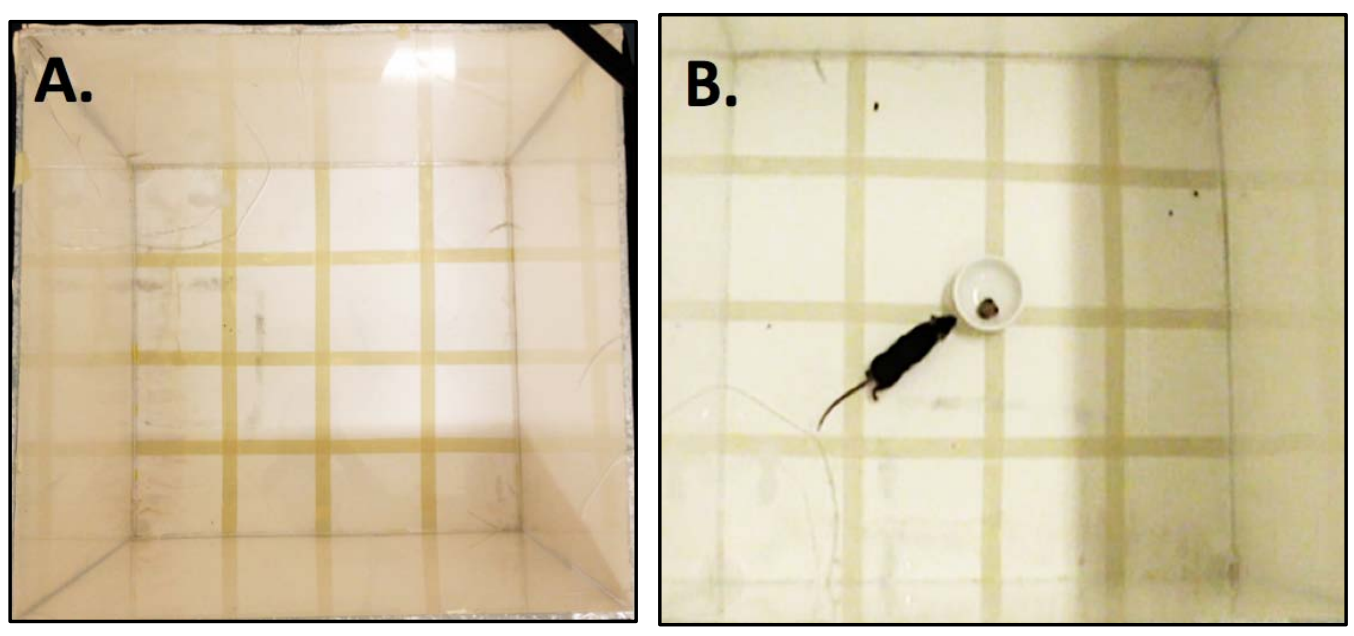

Figure 2.B. A. Open Field Test arena $(50 \times 50 \times 50 \mathrm{~cm})$. B. Novelty suppressed feeding test uses the same chamber as $\mathrm{A}$. with the addition of introducing palatable food such as cookie dough or high fat diet in the center of the chamber. 


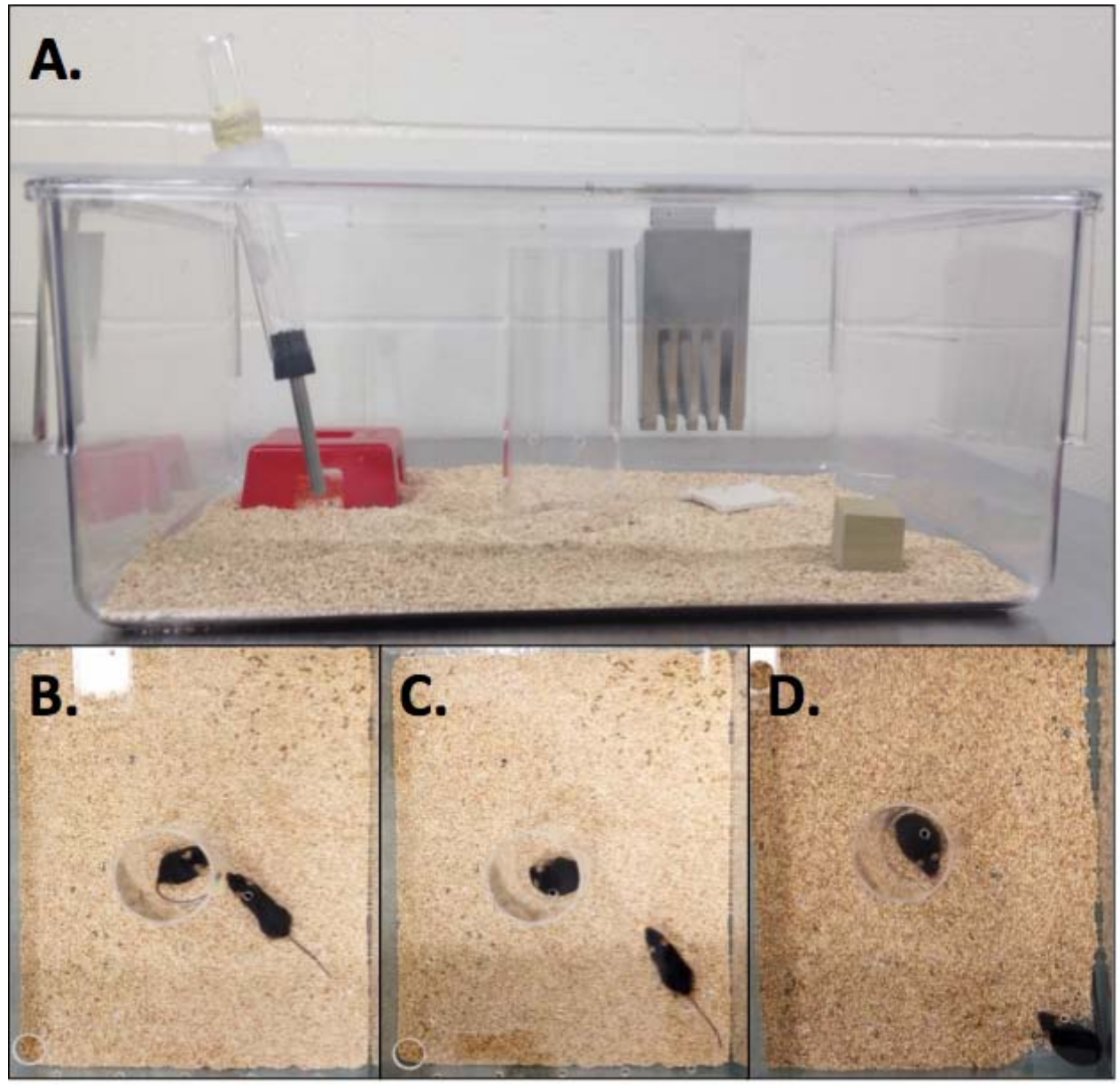

Figure 2.C. The social interaction test design was modified using the method by Tsuda and Ogawa (2012). A. Social interaction chamber with perforated cylinder in the center and enrichment. Mice habituated in this chamber for 48 hours with white board covering all four sides to prevent external cues. B. Sniffing behavior is when the mouse placed its nose in the perforated holes when the stranger mouse was placed in the cylinder. C. Stretching behavior is when the mouse stretches its trunk towards the stranger mouse without getting close to the cylinder. D. Corner observation is when the mouse stayed in the corners of the chamber while fixating its sight on the stranger. 


\section{EXPERIMENTAL DESIGNS}

\section{Experiment 1a: The effect of global GHSR KO on anxiety behavior}

In order to assess the effect of chronic lack of GHSR activity on anxiety behavior, we compared GHSR KO $(n=10)$ and WT mice $(n=10)$ on the anxiety behaviors mentioned above. The time line of Experiment $1 \mathrm{a}$ is shown in Figure.2.D.

\section{Experiment 1b: The effect of acute GHSR antagonism on anxiety behavior}

Following a two-week baseline period, mice were randomly assigned to one of two experimental groups: vehicle $(n=8)$ and JMV2959 $(n=8)$ treated groups. Mice in the vehicle group were injected intraperitoneally (i.p.) with sterile saline $(0.1 \mathrm{ml}$; Stevens Co) and those in the antagonist group with JMV2959 solution ( $3 \mathrm{mg} / \mathrm{kg}$ of body weight dissolved in $0.1 \mathrm{ml}$ saline; Calbiochem® 345888). Injections were administered daily at 10am for 3 days, in which on the third day of injection, behavior test was conducted 2 hours following the third injection. The time line of Experiment $1 \mathrm{~b}$ is shown in Figure.2.E. 


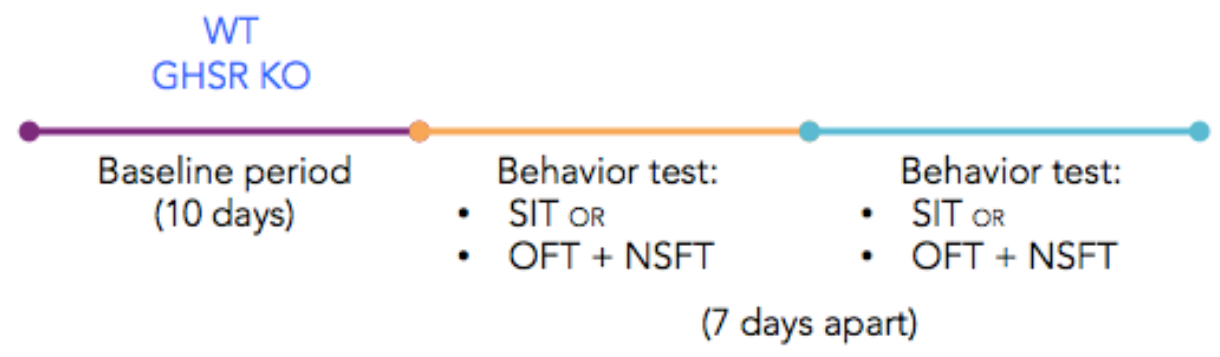

Figure 2.D. Time line of experiment $1 \mathrm{a}$.

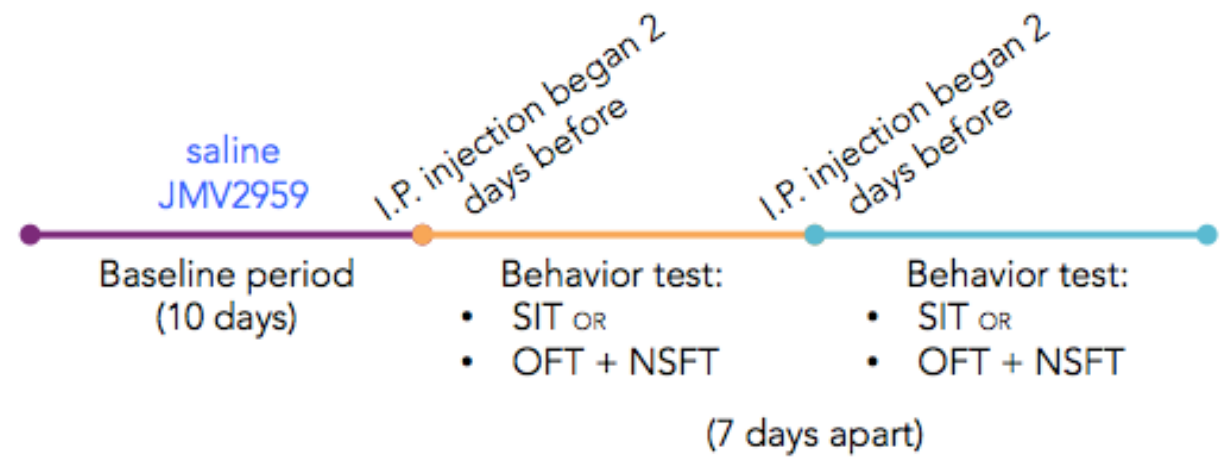

Figure 2.E. Time line of experiment $1 \mathrm{~b}$. 


\section{Experiment 2a: Effect of intra-VTA GHSR antagonism on anxiety behavior}

To explore the role of GHSR in the VTA on anxiety behavior, we implanted an osmotic minipump delivering either saline $(n=8)$ or JMV2959 $(n=6)$ unilaterally via cannula targeting the VTA. Animals with cannula that missed the VTA served as the sham group. Following 25 days of the drug treatment, all animals were tested on the same anxiety behavior tests as experiments $1 \mathrm{a}$ and $1 \mathrm{~b}$. All behavior tests were completed within twenty-eight days since the osmotic minipump is designed to deliver drug for 28 days. The time line of experiment $2 a$ is shown in Figure.2.F.

Experiment 2b: Effect of restoration of GHSR function in the VTA of GHSRnull mice on anxiety behavior

In contrast to experiment $2 \mathrm{a}$, here we investigated the effect of reinstatement of GHSR function in the VTA of GHSR null mice on anxiety behavior. Using WT $(n=16)$ and GHSR null mice $(n=6)$, half of the animals from each genotype group received one time unilateral infusion of either AAV-GFP or AAVCre-recombinase to the VTA. Twenty-five days after the infusion, all animals were tested on the same anxiety behavior as previous experiments. The time line of Experiment $2 \mathrm{~b}$ is shown in Figure.2.G.

28. 


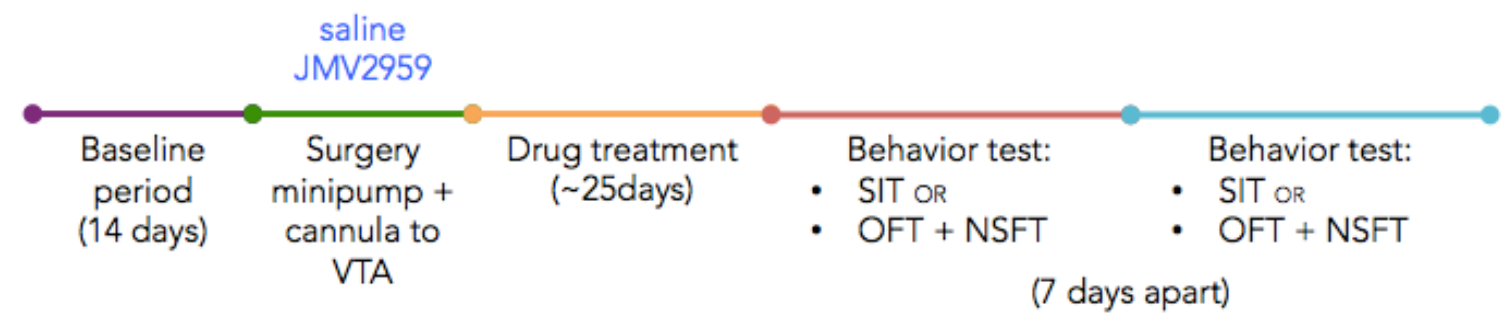

Figure 2.F. Time line of experiment 2a.

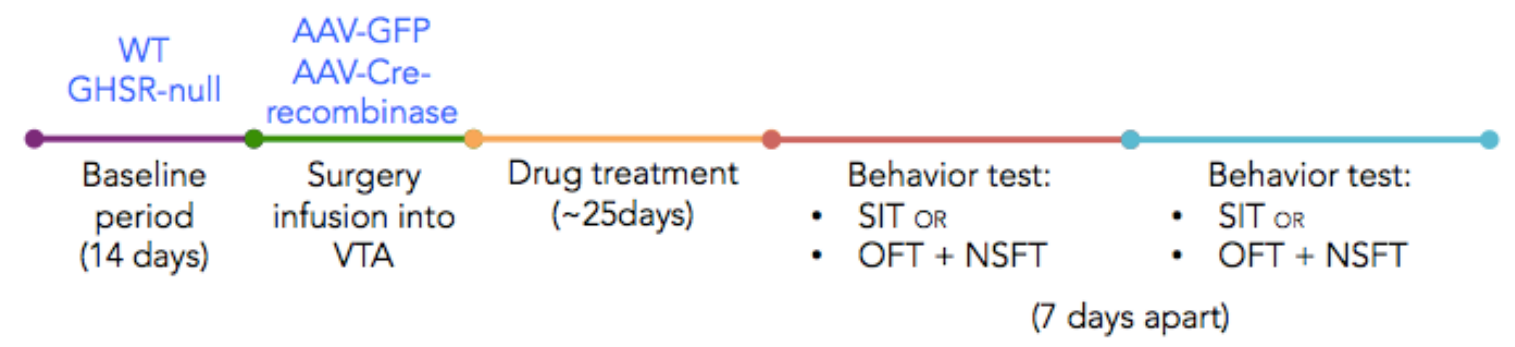

Figure 2.G. Time line of experiment 2b. 


\section{STATISTICS}

Student's t-test was to compare behavior between genotypes (GHSR-WT versus GHSR-KO) or drug treatments (saline versus JMV2959) on behavior.

For the data obtained in experiment 2a, two-way ANOVAs with drug treatment (saline versus JMV2959) and cannula placement (VTA versus missedVTA) as between subject factors were used for analysis. Where appropriate posthoc tests were performed using Tukey's honest significant difference (HSD). A similar method was used for the results of Experiment $2 b$ but in this case genotype (GHSR-WT versus GHSR-null) and drug treatment (GFP versus AAVCre-recombinase) were the between subjects' factors. Post-hoc tests were performed using Tukey's honest significant difference (HSD).

All statistical analyses were performed using SPSS software with the alpha level set at 0.05. Graphs were constructed using GraphPad PRISM and all data are presented as mean \pm SEM.

30. 


\title{
RESULTS
}

\section{EXPERIMENT 1: EFFECTS OF CHRONIC AND ACUTE LOSS OF SYSTEMIC GHSR ON ANXIETY BEHAVIOR}

\author{
CHRONIC AND ACUTE LOSS OF SYSTEMIC GHSR FUNCTION DECREASED \\ SOCIAL INVESTIGATION
}

GHSR KO mice took significantly longer to approach and showed a lower frequency of sniffing a strange mouse than their WT littermates $(t=2.74$, $p=0.0152 ; t=2.34, p=0.0326$ respectively) (see Figure 2.1 panels $\mathbf{a}$ and $\mathbf{b}$ ). The frequency of stretching behavior was significantly higher in the GHSR KO mice than in WT ( $t=3.015, p=0.0078)$ (Figure 2.1.c) whereas the groups did not differ in number of corner observations ( $t=1.458, p=0.1620)$ (Figure 2.1.d).

Consistent with the effects seen in the GHSR KO mice, acute administration of the GHSR antagonist JMV 2959 increased the latency to approach a novel stranger mouse ( $t=2.75, p=0.0157$ ) (Figure 2.2.a). No significant group differences were found in sniffing $(t=0.0197, p=0.9845)$ (Figure 2.2.b), stretching ( $t=0.3065, p=0.7637)$, (Figure 2.2.c), and corner observation $(t=0.4252, p=0.6772)$ (Figure 2.2.d) behaviors. 
(a)

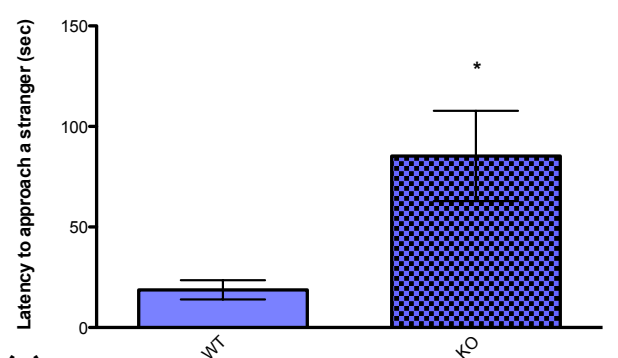

(c)

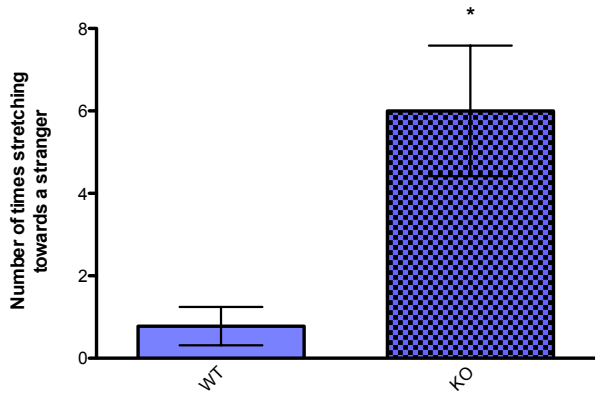

(b)

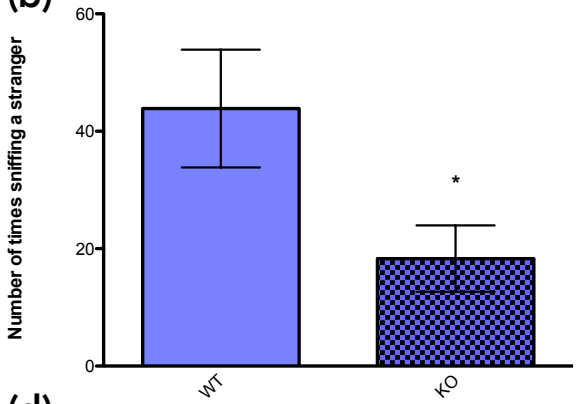

(d)

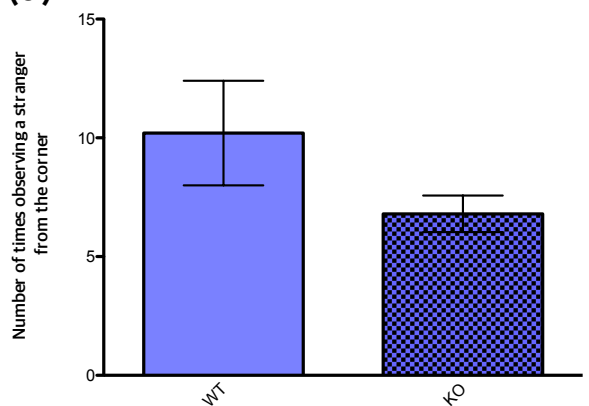

Figure 2.1. Social Behavior Measures of WT and GHSR-KO.

Latency to approach (a), number of times sniffing (b), number of times stretching (c) and observing (d) a novel stranger mouse from a corner between WT and KO. WT - wild type and KO - knock out. The effect of genotype; * $p<0.05$. All values expressed as mean \pm SEM. 
(a)

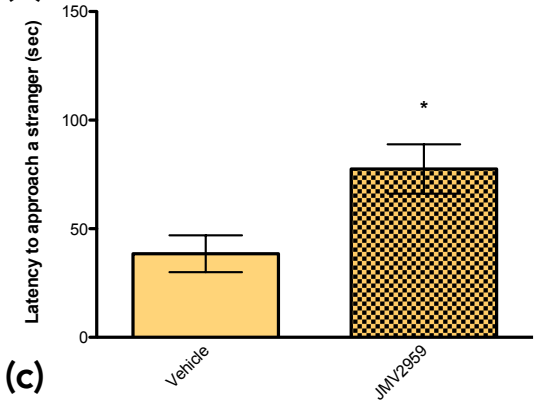

(c)

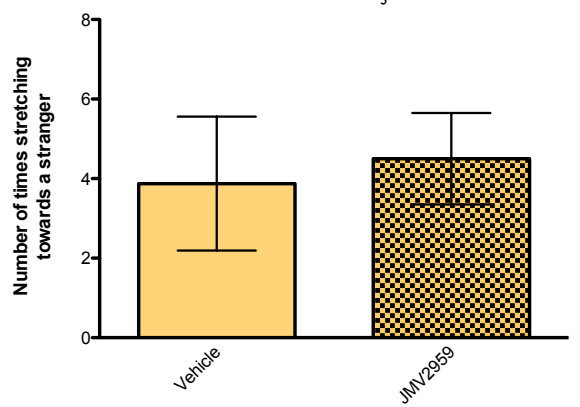

(b)
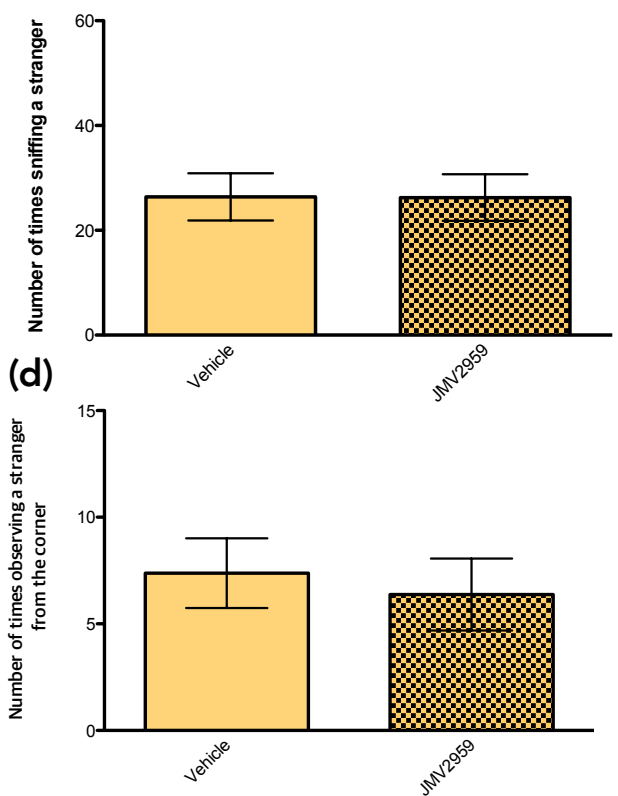

Figure 2.2. Social Behavior Measures of Vehicle and JMV2959.

Latency to approach (a), number of times sniffing (b), number of times stretching (c) and observing (d) a novel stranger mouse from a corner between vehicle and JMV2959 treated mice. Vehicle saline and JMV2959 - ghrelin antagonist. The effect of drug treatment; * $p<0.05$. All values expressed as mean \pm SEM. 


\section{CHRONIC AND ACUTE LOSS OF SYSTEMIC GHSR FUNCTION DECREASED HOME CAGE CONSUMPTION OF PALATABLE FOOD}

To explore food-seeking behaviors, we compared behaviors of GHSR KO and mice treated with JMV2959 to their control counterparts on noveltysuppressed feeding test. These behavioral results for experiments $1 \mathrm{a}$ and $1 \mathrm{~b}$ are shown in Figures 2.3 2.6.

GHSR KO mice consumed significantly less cookie dough than WT mice during the 48-hour ad lib access period ( $t=2.100, p=0.0520$ ) (Figure 2.3.a). When cookie dough was presented in a novel environment, GHSR KO mice took longer to approach the cookie dough (Figure 2.3.b) and showed a lower frequency of approaches to the cookie dough (Figure 2.3.c). However, these effects just failed to reach statistical significance $(t=2.017, p=0.0608 ; t=1.970, p=0.0664$, respectively).

Like the GHSR KO mice, JMV2959 treated mice consumed significantly less cookie dough than saline treated mice when it was available ad libitum $(t=2.447, p=0.0294)$ (Figure 2.4.a). No significant group differences were found in latency to approach and frequency of approaching cookie dough, however $(t=1.092, p=0.2932 ; t=0.1429, p=0.888$ respectively) (Figure $2.4 . b$ and $\mathbf{c}$ ). 


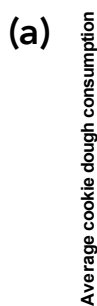

(b)

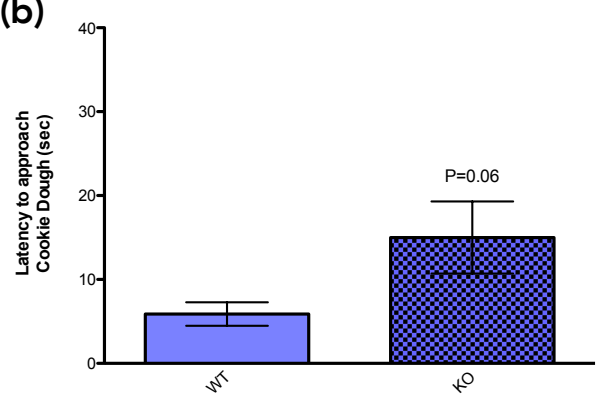

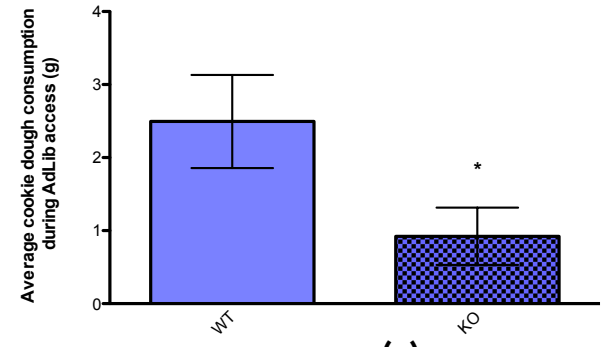

(c)

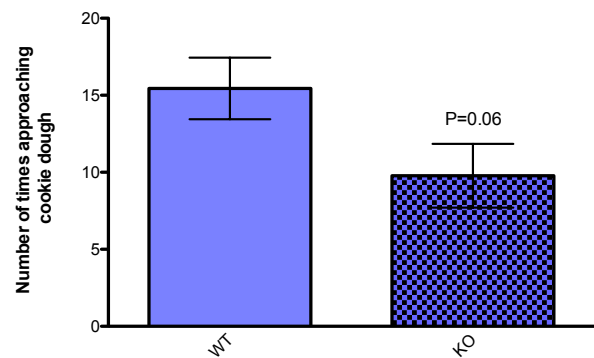

Figure 2.3. Novelty Suppressed Feeding Behaviors of WT and GHSR-KO.

Consumption of cookie dough (g) during the ad lib 48 hour access (a), latency to approach (sec) (b), and number of times approaching cookie dough (c) between WT and KO mice. WT - wild type and $\mathrm{KO}$ - knock out. The effect of genotype; * $p<0.05$. All values expressed as mean $\pm \mathrm{SEM}$. 

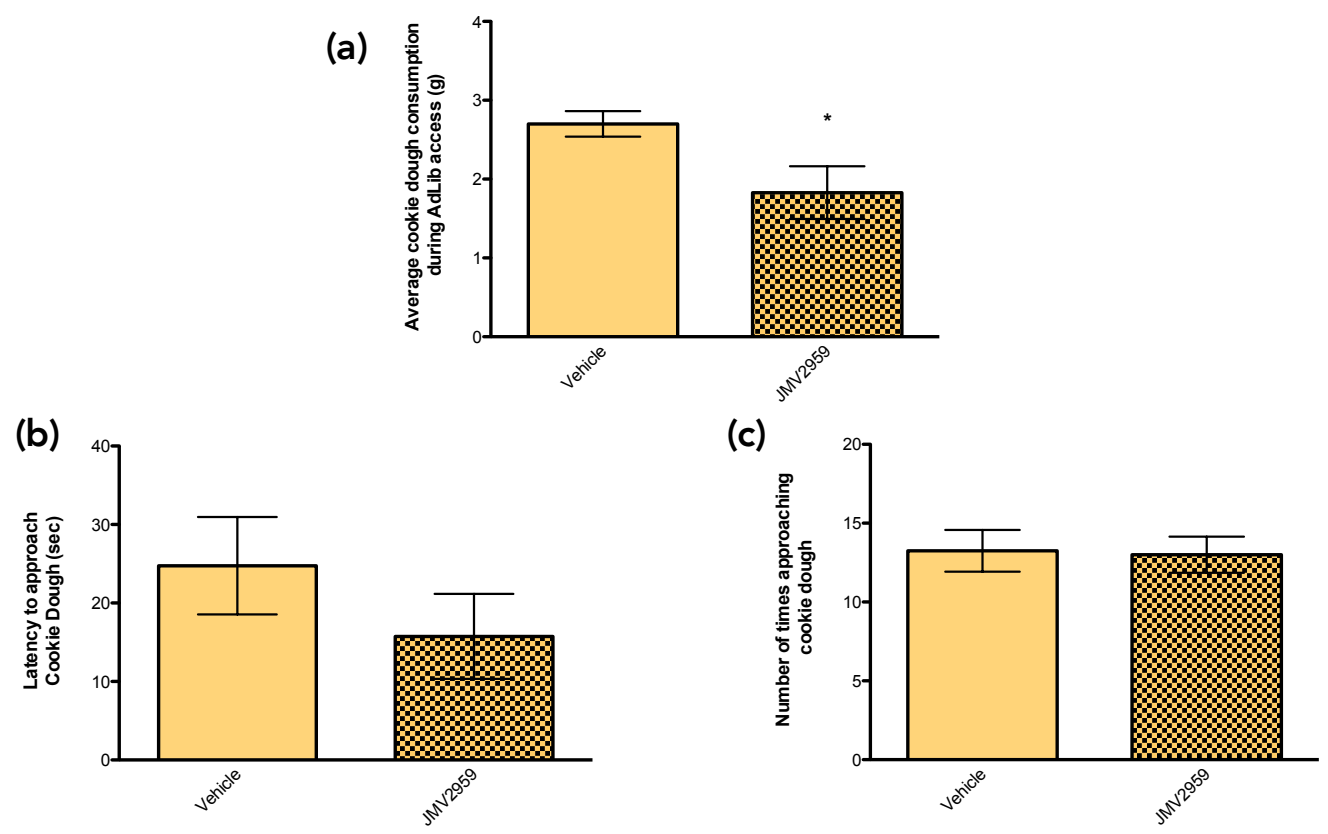

Figure 2.4. Novelty Suppressed Feeding Behaviors of Vehicle and JMV2959.

Consumption of cookie dough (g) during the ad lib 48 hour access (a), latency to approach (sec) (b), and number of times approaching cookie dough (c) between Vehicle and JMV2959 treated mice. Vehicle - saline and JMV2959 - ghrelin antagonist. The effect of genotype; * $p<0.05$. All values expressed as mean \pm SEM 


\section{CHRONIC AND ACUTE LOSS OF GHSR FUNCTION DOES NOT SIGNIFICANTLY INFLEUNCE BEHAVIOR IN THE OPEN FIELD TEST}

No significant group differences were found in the amount of time spent in the center of the arena $(t=0.1705, p=0.8668)$ between WT and GHSR KO mice (Figure 2.5). Similarly, no significant group difference between JMV2959 and saline treated mice was found on this measure $(t=0.5939, p=0.5658)$ (Figure 2.6). 


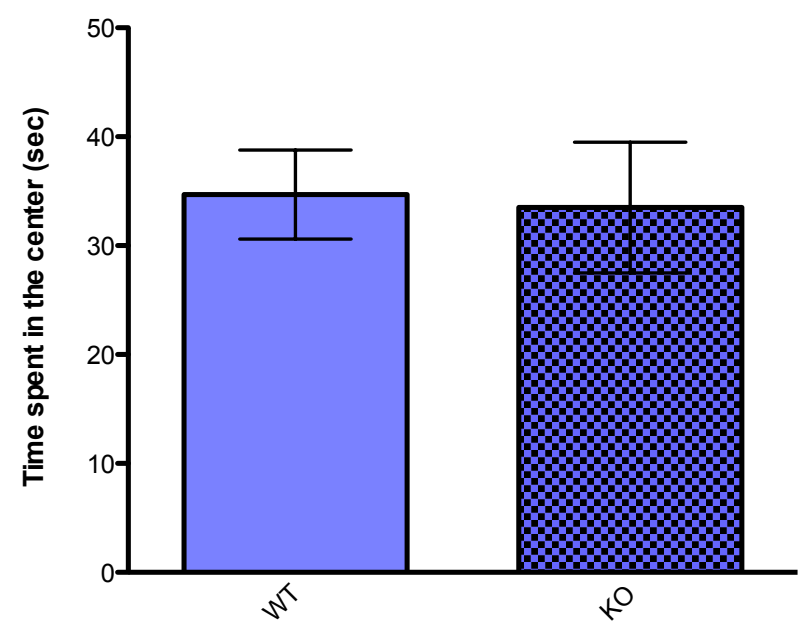

Figure 2.5. Behavior in the Open Field Test of WT and GHSR-KO.

Mean time spent in the center (sec) of the open arena between WT and KO. WT - wild type and KO - knock out. The effect of genotype; * $p<0.05$. All values expressed as mean \pm SEM.

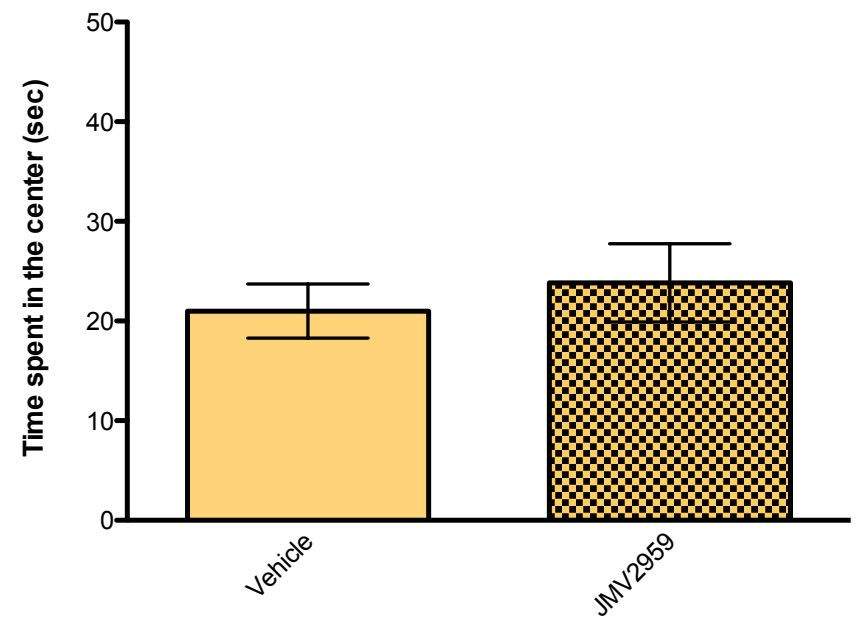

Figure 2.6. Behavior in the Open Field Test of Vehicle and JMV2959.

Mean time spent in the center (sec) of the open arena between Vehicle and JMV2959. Vehicle - saline and JMV2959 - ghrelin antagonist. The effect of genotype; * $p<0.05$. All values expressed as mean \pm SEM. 


\title{
EXPERIMENT 2: EFFECTS OF ALTERING GHSR ACTIVITY IN THE VTA ON ANXIETY BEHAVIORS
}

\author{
CHRONIC INFUSION OF JMV2959 INTO THE VTA DISRUPTS SOCIAL \\ INVESTIGATORY BEHAVIORS and RE-INSTATEMENT OF GHSR FUNCTION IN \\ THE VTA OF GHSR-NULL MICE ENHANCES THEM
}

Chronic administration of the GHSR antagonist JMV2959 in the VTA increased latency to approach a novel mouse (Figure 2.7.a), and increased frequency of stretching behavior (Figure 2.7.c) and corner observations compared to the saline-treated control group (Figure 2.7.d). Antagonist treatment also resulted in a decrease in frequency of sniffing behavior relative to controls (Figure 2.7.b). These effects were only seen in the mice in which the cannula was correctly placed in the VTA and mice that received the antagonist through cannula that were outside the VTA (JMV2959 SHAM group) behaved similarly to mice that were treated with saline. This pattern of results gave rise to significant interaction effects between drug treatment and cannula location on latency to approach $\left(F_{(1,14)}=5.916, p=0.035\right)$; sniffing $\left(F_{(1,14)}=5.477, p=0.041\right)$; and stretching $\left(F_{(1,14)}=5.300, p=0.044\right)$ behaviors. In corner observation, there was a main effect of drug $\left(F_{(1,14)}=6.625, p=0.028\right)$ where JMV2959 treatment significantly increased time spent observing from the corner relative to vehicle and both SHAM groups.

In support of the results of the antagonist study, re-instatement of GHSR function in the VTA of GHSR null mice resulted in a significant interaction between genotype and drug treatment on approach latency $\left(F_{(1,22)}=8.480\right.$, 
$p=0.009$ ), where GHSR null mice administered with Cre-recombinase in the VTA showed a significantly reduced latency to approach a stranger mouse (Figure 2.8.a). Significant interaction between genotype and drug treatment was also seen in corner observation $\left(F_{(1,22)}=5.034, p=0.038\right)$ where GHSR null mice administered with Cre-recombinase in the VTA spent significantly less time observing from the corner (Figure 2.8.d). In GHSR null mice treated with Crerecombinase in the VTA, sniffing (Figure 2.8.b) behavior was enhanced in comparison to all the other groups. However, this effects just failed to reach statistical significance $\left(F_{(1,22)}=3.597, p=0.074\right)$. No significant group differences were found in stretching behavior (Figure 2.8.c). 
(a)

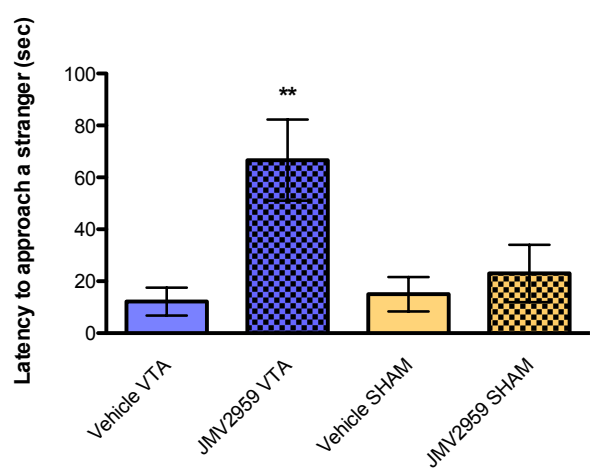

(c)

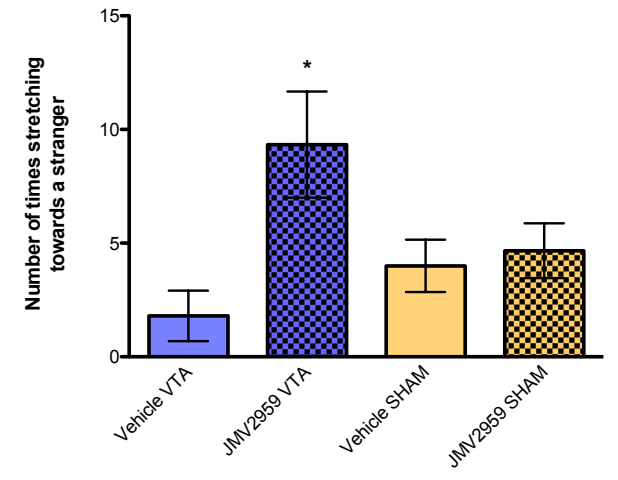

(b)

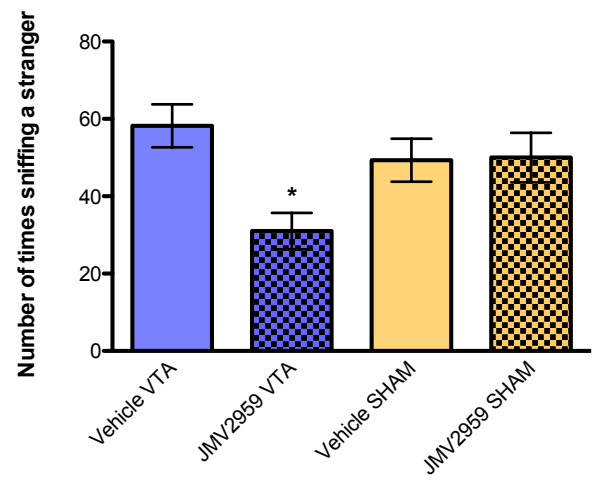

(d)

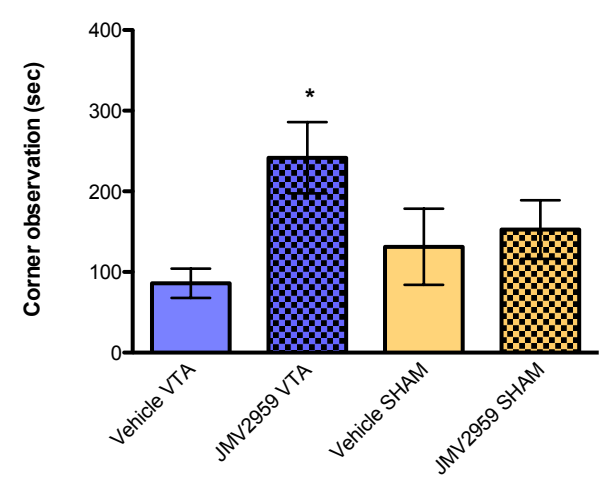

Figure 2.7. Social Behavior Measures.

Latency to approach (a), number of times sniffing (b), number of times stretching (c) and observing (d) a novel stranger mouse from a corner between all treatment groups. Vehicle VTA - saline administered to VTA; JMV2959 VTA - JMV2959 administered to VTA; Vehicle SHAM - saline administered outside of VTA; JMV2959 SHAM - JMV2959 administered outside of VTA. The effect of drug treatment and targeted central region; * $p<0.05$; ${ }^{* *} p<0.001$. All values expressed as mean \pm SEM. 
(a)

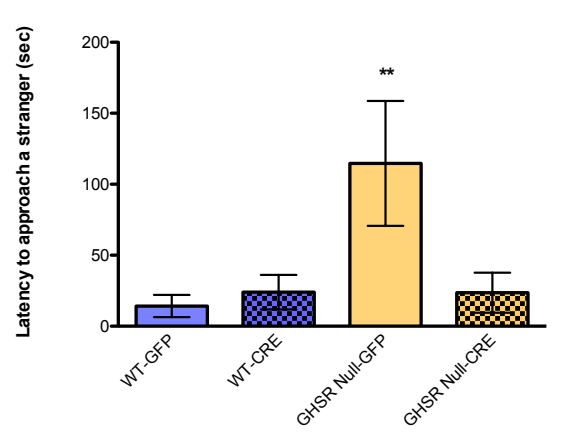

(c)

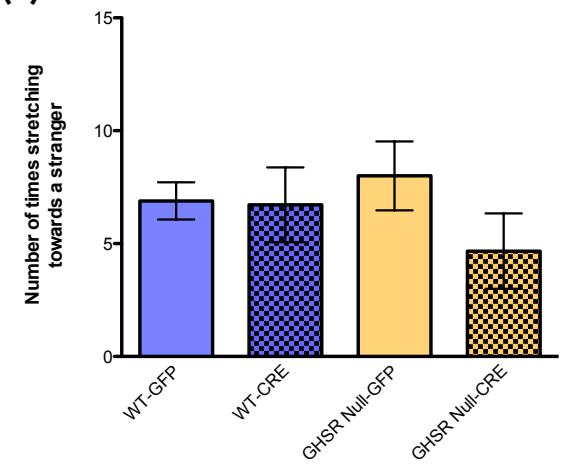

(b)

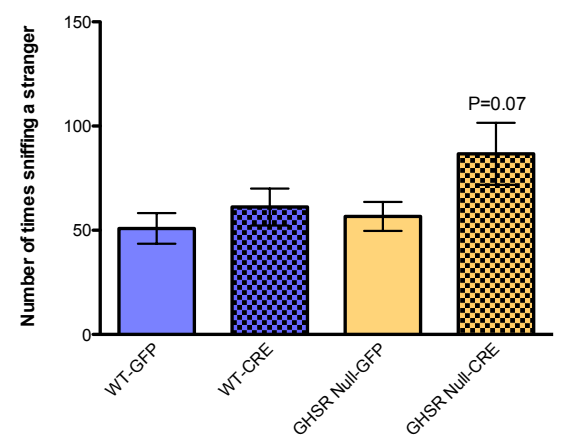

(d)

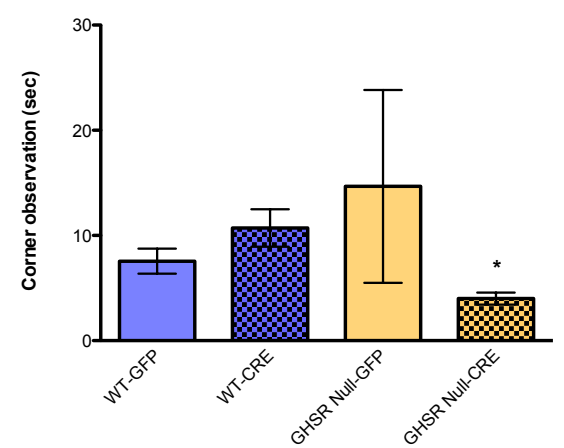

Figure 2.8. Social Behavior Measures.

Latency to approach (a), number of times sniffing (b), number of times stretching (c) and observing (d) a novel stranger mouse from a corner between all treatment groups. WT-GFP - GFP administered WT; WT-CRE - Cre-recombinase administered WT; KO-GFP - GFP administered KO; $\mathrm{KO}-\mathrm{CRE}$ - Cre-recombinase administered KO. The effect of the genotype and drug treatment; ${ }^{*} p<0.05 ;{ }^{* \star} p<0.001$. All values expressed as mean \pm SEM. 


\section{NEITHER CHRONIC INFUSION OF JMV2959 INTO THE VTA NOR RE- INSTATEMENT OF THE GHSR IN THE VTA OF GHSR-NULL MICE SIGNIFICANTLY INFLUENCE BEHAVIOR IN THE NOVELTY-SUPPRESSED FEEDING TEST AND THE OPEN FIELD TEST}

No significant differences were observed in latency to approach (Figure 2.9.a) and in frequency of approaching high fat chow (Figure 2.9.b) in mice chronically infused with JMV2959 into the VTA relative to the control and SHAM groups. In addition, time spent in the center of the open arena did not differ significantly between these groups (Figure 2.10).

Similarly, no significant difference was observed in latency to approach the high fat diet (Figure 2.11.a). However, there was a trend towards a genotype and drug treatment interaction on frequency of approaching cookie dough $\left(F_{(1,22)}=3.527, p=0.077\right)$ (Figure 2.11.b) where GHSR null mice administered with Cre-recombinase in the VTA increased the number of times they approached the high fat chow. As seen in previous studies, time spent in the center of the open arena did not differ significantly between these groups (Figure 2.12).

43. 
(a)

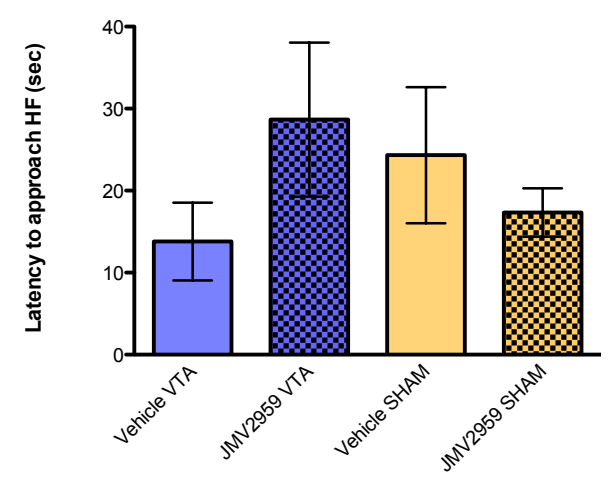

(b)

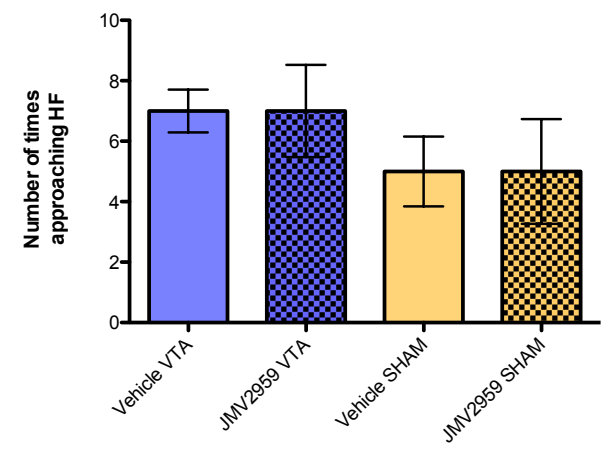

Figure 2.9. Novelty Suppressed Feeding Behaviors.

Latency to approach (sec) (a), and number of times approaching high fat (b) between all treatment groups. Vehicle VTA - saline administered to VTA; JMV2959 VTA - JMV2959 administered to VTA; Vehicle SHAM - saline administered outside of VTA; JMV2959 SHAM - JMV2959 administered outside of VTA. The effect of drug treatment and targeted central region; ${ }^{*} p<0.05 ;{ }^{\star \star} p<0.001$. All values expressed as mean \pm SEM.

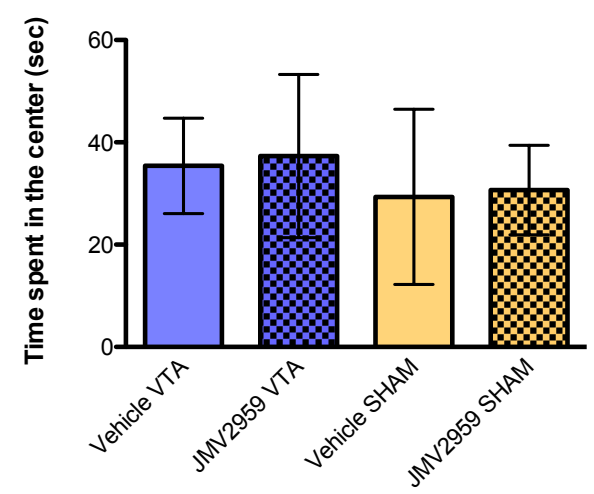

Figure 2.10. Behavior in the Open Field Test.

Time spent in the center (sec) of the open arena between all treatment groups. Vehicle VTA saline administered to VTA; JMV2959 VTA - JMV2959 administered to VTA; Vehicle SHAM saline administered outside of VTA; JMV2959 SHAM - JMV2959 administered outside of VTA. The effect of drug treatment and targeted central region; * $p<0.05$; ${ }^{* \star} p<0.001$.

All values expressed as mean \pm SEM. 
(a)

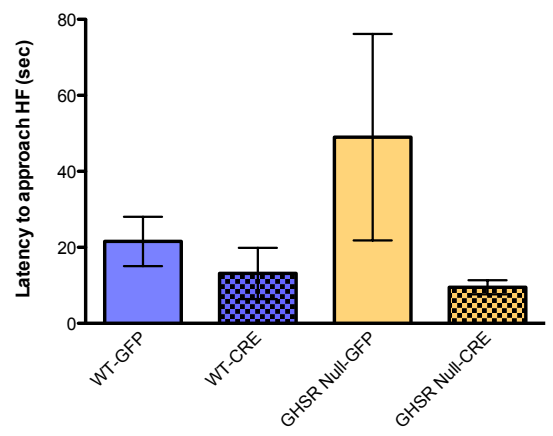

(b)

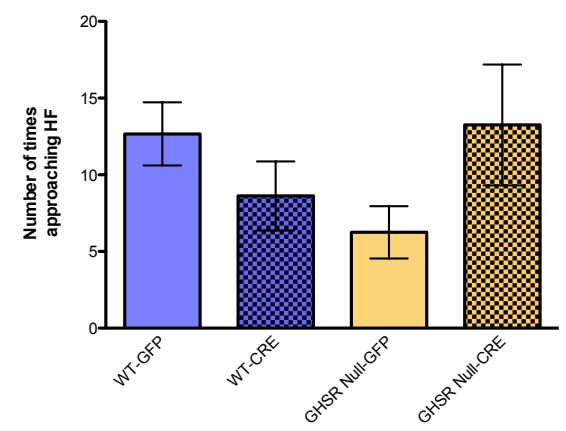

Figure 2.11. Novelty Suppressed Feeding Behaviors.

Latency to approach (sec) (a), and number of times approaching high fat (b) between all treatment groups. WT-GFP - GFP administered WT; WT-CRE - Cre-recombinase administered WT; KO-GFP GFP administered KO; KO-CRE - Cre-recombinase administered KO. The effect of the genotype and drug treatment; * $p<0.05 ;{ }^{* \star} p<0.001$. All values expressed as mean \pm SEM.

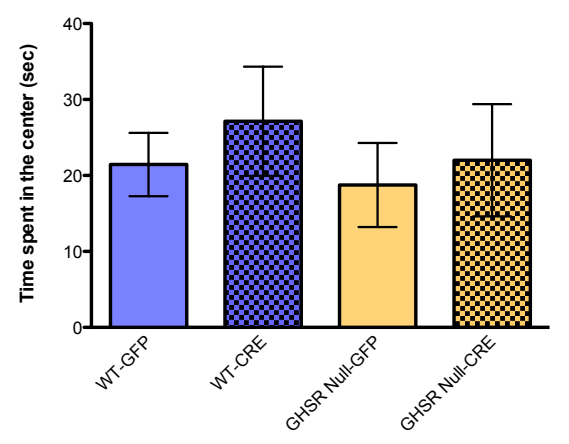

Figure 2.12. Behavior in the Open Field Test.

Time spent in the center (sec) of the open arena between all treatment groups. WT-GFP - GFP administered WT; WT-CRE - Cre-recombinase administered WT; KO-GFP - GFP administered $\mathrm{KO}$; KO-CRE - Cre-recombinase administered KO. The effect of the genotype and drug treatment; * $p<0.05 ;{ }^{\star \star} p<0.001$. All values expressed as mean \pm SEM. 


\section{DISCUSSION}

Previous studies on the role of ghrelin in anxiety have been inconclusive with some authors reporting anxiogenic and others reporting anxiolytic effects of increasing ghrelin receptor activity. In these studies, we used a variety of tests of anxiety to elucidate the conditions in which ghrelin receptor activation modulates anxiety behavior and investigated where in the brain ghrelin acts to produce its effects. Ghrelin receptor activation increases novelty seeking and exploratory behaviors towards both food and non-food associated cues (Hansson et al., 2012). Thus, our hypothesis was that loss of function of ghrelin receptors would increase anxiety in tests of social approach and eating in a novel environment while having little effect in the open field, an open arena that lacks a specific stimulus to trigger exploratory behavior. Given the central role of the mesocorticolimbic DA system in exploration and responses to novelty, we also hypothesized that any effects of changes in GHSR activity on anxiety behaviors that we observed would be mediated, at least in part, by GHSR activation within the VTA.

Approach and investigation of a novel mouse were used as measures of social anxiety. In support of our hypothesis, both GHSR KO mice and mice treated with the ghrelin antagonist JMV2959 took longer to approach the strange mouse (Figure 2.1.a and Figure 2.2.a). GHSR KO mice also displayed less sniffing behavior (Figure 2.1b) while stretching behavior (Figure 2.1.c), which is a form of social investigation with caution, allowing the mouse to flee immediately in the face of danger (Tsuda and Ogawa, 2012), was increased in this group relative to their wildtype controls. These effects were not seen in JMV2959 
treated mice (Figure 2.2.b and Figure 2.2.c) potentially due to the impact of intraperitoneal injections on behavior. According to Lapin (1995), intraperitoneal injections of saline in mice caused anxiogenic responses on the elevated plus maze, suggesting that handling mice and injection generated a stress response. Overall, our findings agree with those of Lutter and colleagues (2008), who found that GHSR KO mice exhibited greater social deficits than WT mice when both were exposed to chronic social stress (Lutter et al., 2008).

Consistent with the well-established ability of ghrelin to increase food intake, GHSR KO and mice treated with JMV2959 consumed less cookie dough than their respective controls when it was available in their home cage, (Figure 2.3.a and Figure 2.4.a). GHSR KO mice also showed a longer latency to approach the cookie dough and a lower number of approaches than their WT controls, although this difference, just failed to reach statistical significance. Contrary to our expectation, however, neither of these measures was affected by administration of JMV2959. These results, partially, support those of a recent study by Lockie and colleagues (2017), who found that elevating circulating ghrelin either by fasting or by exogenous administration enhances food-seeking behavior in a risky environment. The lack of an effect of GHSR antagonist administration may simply reflect the fact that the dose of JMV2959 used in the current study, which was chosen on the basis of its ability to decrease food intake, may not be sufficient to modulate anxiety behavior. A study comparing the effectiveness of various doses of JMV2959 would be useful to resolve this issue. 
Loss of function of the ghrelin receptor had little effect in the open field (Figure 2.4.a and Figure 2.5.a). These results, combined with our findings in social investigation and novelty suppressed feeding test, suggest that ghrelin receptor activation exerts its anxiolytic effect, under conditions where the animal has to assess risk in order to reach an incentive.

In the first two studies, we manipulated GHSR activity systemically but we assume that the effects on anxiety that we observed were mediated centrally. Given the role attributed to the mesolimbic dopamine system in novelty- and reward- seeking behaviors, we hypothesized that ghrelin receptor activation made an important contribution to these effects. We, therefore, manipulated ghrelin receptor activity in the VTA by chronically administering JMV2959 and reinstating GHSR expression in the VTA of a GHSR null mice by delivering AAVCre-recombinase. As with systemic down regulation of GHSR activity, intra-VTA JMV2959 administration increased approach latency (Figure 2.7.a), reduced sniffing (Figure 2.7.b) and increased stretching behaviors (Figure 2.7.c) towards a stranger mouse. Interestingly, these animals spent significantly more time observing from a corner (Figure 2.7.d), a social withdrawal behavior seen in chronically stressed animals and one that was not observed following our systemic manipulations (Krishnan and Nestler, 2008; Lutter et al., 2008). As hypothesized, we did not see any of these behaviors in mice in which the cannula delivering JMV2959 missed the VTA, supporting the idea that decreasing GHSR activity in the VTA is sufficient to modulate anxiety behavior in these situations.

Given that our data suggest that ghrelin receptor activity in the VTA is important for the modulation of social behavior, we asked whether social anxiety 
seen in mice lacking GHSR activity could be attenuated if GHSR expression were restored in the VTA. As expected, re-instatement of the GHSR in the VTA lowered latency to approach a stranger mouse, whereas GFP treated GHSR null mice took significantly longer time to approach (Figure 2.8.a) than both WT mice as well as GHSR null mice treated with Cre-recombinase. Time spent observing from the corner was also significantly reduced in GHSR null mice with reinstatement of GHSR in the VTA (Figure 2.8.d). Although differences in sniffing (Figure 2.8.b) and stretching (Figure 2.8.c) behaviors were not statistically significant, there was a trend toward higher levels of sniffing behavior in GHSR null mice with re-instatement of GHSR in the VTA than in any other treatment group. Together, the results of these studies support our hypothesis that ghrelin receptor activity in the VTA is important for the modulation of social behavior.

While we expected to find that intra-VTA JMV2959 and restoration of GHSR expression in the VTA would affect behavior in the novelty-suppressed feeding test, no statistical significance was found, perhaps due to the low sample size $(n=4-6)$. However, the differences were in the expected direction such that VTA-JMV2959 treated mice and GFP treated GHSR-null mice took a longer time to approach high fat (Figure2.9.a and Figure 2.11.a). Our findings are consistent with work by Skov and colleagues (2017) demonstrating that bilateral reinstatement of the GHSR in the VTA of mice resulted in increased food intake during the novel environment stress test.

Consistent with our previous findings, manipulating GHSR activity within the VTA had no significant effects on behavior in the open field test (Figure 2.10 and Figure 2.12) supporting our overall hypothesis that ghrelin receptor activity 
exerts anxiolytic effects in anxiety tests when anxiety is pitted against reinforcers such as palatable food, or interaction with a novel conspecific mouse, and that GHSR activation within the VTA plays an important role in this process.

In summary, the results of the studies presented here have extended our understanding of ghrelin's role in anxiety, and in particular of its role in social behavior. Moreover, we showed that modulating ghrelin receptor signalling within the VTA is sufficient to affect social interaction. Since disrupted social behavior is a common feature of many psychiatric conditions, and that social behavior was most affected by the manipulation of the ghrelin receptor, we suspect that targeting ghrelin receptors or ghrelin would be a good treatment to improve social deficits seen in many psychiatric conditions such as depression, anxiety disorders, and eating disorders. This particular hypothesis was tested in the next chapter. 


\section{CHAPTER 3}

\section{EFFECTS OF GHRELIN AGONIST GHRP6}

\section{ALONE AND IN COMBINATION WITH \\ CITALOPRAM ON DEPRESSIVE SYMPTOMS EVOKED BY CHRONIC SOCIAL STRESS}

Data from the experiments described in chapter 2, and from studies in other labs support the idea that ghrelin could be used alone or in combination with commonly used antidepressants and /or anti-anxiety drugs to improve the outcome of mood disorders (Spencer et al., 2012; Park et al., 2015; Wallace et al., 2015; Landrigan et al., 2016; Jensen et al., 2016). Given that depression is a leading public health concern affecting all genders, ages, and social backgrounds, resulting in a large personal and socioeconomic burden increasing treatment efficacy would be of wide ranging benefit.

The etiology of depression remains poorly understood, but one of the widely accepted environmental risk factors for depressive disorders is stress, and both severe stressful events as well as a series of relatively minor stressors (i.e. daily hassles) have been shown to induce depression (Anisman and Matheson, 
2005). In addition, the negative perceptions associated with depression, and their effects on behavior such as social withdrawal, provoke further interpersonal stress that serves to exacerbate depressive symptoms (Hammen et al., 1995; Anisman and Matheson, 2005).

Stressors activate the sympathetic nervous system and the hypothalamicpituitary-adrenal (HPA) axis, which causes a rise in plasma glucocorticoids (GC) (Nemerof et al., 1984; Mizoguchi et al., 2001). In healthy subjects, the physiological response to stress can self-terminate via negative feedback loops, acting either directly at the hypothalamus and pituitary, or indirectly on brain regions enriched in glucocorticoid receptors such as the prefrontal cortex and the hippocampus (Sapolsky et al., 1984; Mizoguchi et al., 2001; Mizoguchi et al., 2003). The ability to terminate the neuroendocrine response to stressors is affected in depression, resulting in increased basal levels of glucocorticoids. Dysfunction of the HPA axis is also linked to impaired neuronal survival, excitability, proliferation and metabolism (Sapolsky et al., 1985). As a consequence of this dysfunctional HPA axis, post-mortem brains of depressed individuals often display reduced volume of the prefrontal cortex and the hippocampus in comparison to individuals who died with no record of depression (Sheline et al., 1996; Sheline et al., 2003; Swaab et al., 2005).

Another neurochemical correlate of depression is the depletion of monoamines in the brain, serotonin (5-hydroxytryptamine, 5-HT) being the most notable example (Lanfumey et al., 2008; Schultz, 2007). Indeed, drugs, that are designed to enhance the release of, or inhibit the reuptake of, the monoamines, are currently the first-line of pharmacological treatment for depression (Bambico 
et al., 2009; McGrath et al., 2008). Chronic administration of typical antidepressants that block the reuptake and breakdown of monoamines, for example, the selective serotonin reuptake inhibitor (SSRI) citalopram have been shown to increase synaptic plasticity and induce hippocampal neurogenesis (Czeh et al., 2001; Santarelli et al., 2003; Hill et al., 2015). In fact, emerging data suggest that hippocampal neurogenesis is required for the behavioral effects of antidepressants in both rodent and non-human primate models (Czeh et al., 2001; Santarelli et al., 2003; Lagace et al., 2010; Van Bokhoven et al., 2011; Perera et al., 2011; Hill et al., 2015). Unfortunately, antidepressants such as SSRIs have limited treatment efficacy and $20-40 \%$ of depressed individuals do not respond to these treatments indicative of the complex mechanisms that underlie the etiology of depression (Crown et al., 2002; Belzeaux et al., 2016). This has led researchers to investigate a role for neurochemical signals other than glucocorticoids and serotonin in the etiology and/or treatment of depression.

One hormone that has been investigated for its potential antidepressive effects is the orexigenic peptide ghrelin. Ghrelin is a 28 amino acid peptide hormone, primarily secreted by the enteroendocrine X/A like cells lining the wall of the stomach (Kojima et al., 1999). Human subjects exposed acutely to psychosocial stress display higher plasma ghrelin concentrations than nonstressed individuals (Rouach et al., 2007). Further, reduced levels of plasma acyland desacyl-ghrelin have been reported in depressed individuals, and treatment with the SSRI's citalopram and fluoxetine is not sufficient to restore these levels to those of non-depressed subjects (Brunetti et al., 2002; Carlini et al., 2007; Barim et al., 2009). In addition, Leu72Met polymorphism in the ghrelin gene has also been linked to depression where genotype frequency differed in 
comparison to healthy controls (Nakashima et al., 2008). Given the association between ghrelin and stress/depression, it remains in question whether this low plasma ghrelin contributes to prolonged symptoms of depression that may not be treatable by antidepressants alone.

Some of the strongest evidence in support of the antidepressive effects of ghrelin comes from animal studies showing that manipulation of ghrelin receptor activity could modulate the effects of paradigms designed to induce depressive symptom in mice. For example, Lutter et al (2008) found that mice bearing a genetic mutation of the ghrelin receptor (GHSR) spend less time in the open arm of the elevated plus maze and these animals exhibited more social avoidance behaviors than control animals when exposed to the chronic social defeat paradigm (CSDP). Similarly, peripheral and central administration of ghrelin or the ghrelin agonist (GHRP6) alleviated the anxiety and depression-like behaviors induced by chronic unpredictable mild stress in both mice and rats (Huang et al., 2017). Further, in mice, depressive behaviors such as increased immobility in the tail suspension test and reduced locomotion in the open field that are induced by olfactory bulbectomy can be alleviated by acute central administration of ghrelin (Harkin et al., 2003; Carlini et al., 2012).

The route(s) through which ghrelin might influence depressive symptomatology are unclear. There is considerable evidence that ghrelin, like the typical antidepressants, stimulates cellular proliferation and differentiation of adult rat hippocampal progenitor cells (Diano et al., 2006; Johansson et al., 2008; Moon et al., 2009). Ghrelin also reduces anxiety behaviors in rodents. For instance, acute and chronic ghrelin administration lowered the time spent 
immobile during the forced swim test and had anxiolytic effects in standard tests of anxiety such as the open field test, light/dark chambers and elevated plus maze (Spencer et al., 2012; Landrigan et al., 2016; Jensen et al., 2016). In addition, work by Tong and colleagues (2011) showed that ghrelin potentiates exploratory sniffing in rodents and olfactory sensitivity in both rodents and humans, which could influence social behavior. The results of the studies described in chapter 2 suggest that, in mice, ghrelin receptor activation in the VTA may play a particularly important role in social anxiety and in the willingness to approach a novel mouse. A potential role for ghrelin receptor activation in modulating social behavior is particularly intriguing in the context of psychiatric illnesses in general, and depression in particular. Social withdrawal is one of the most common symptoms of depression and often persists, even after chronic antidepressant treatment (Berton et al., 2006; Der-Avakian et al., 2014; Burghardt et al., 2013).

Together, these findings led us to hypothesize that 1) exogenous ghrelin agonist treatment might protect against the development of some depressive symptoms and 2) that co-treatment with ghrelin might increase the antidepressive effects of the SSRI citalopram. This is an important issue given that SSRIs only work on a subset of patients suffering from depression, their beneficial effects are not immediate, and are associated with undesirable side effects that include weight gain and flat affect. While ghrelin or its analogs may also have metabolic side effects, it is possible that at combined low doses of these of ghrelin analogs and SSRIs we might prevent these side effects. Moreover, and given the data from the previous chapter, we expected that any effects of ghrelin treatment we observed would be greatest on measures of 
social withdrawal. We used an animal model of chronic social stress, the chronic social defeat paradigm (CSDP), in which exposing subject mice to an aggressive resident produces depressive symptoms. This paradigm is considered one of the most ethologically valid animal models of the development of psychosocial depression in humans (Krishnan et al., 2007). The symptoms precipitated by exposure to CSDP include social withdrawal, helplessness, and attenuation of hippocampal neurogenesis among others. In the first study (experiment 3a), we investigated whether chronic administration of the ghrelin agonist GHRP6 would prevent, or at least delay, the development of depressive symptoms during exposure to CSDP. In the second experiment (experiment 3b), we used a treatment rather than prevention model and compared the effectiveness of treatment with either GHRP6 alone or GHRP6 with citalopram and citalopram treatment alone in alleviating the depressive symptoms induced by exposure to CSDP. 


\section{GENERAL METHODS}

\section{Animals}

Male C57/BL6 mice weighing 23-25g at the start of the experiment and male retired breeder CD1 mice were purchased from the Charles Rivers Farms (St.Constant, QC, Canada) and used as subjects in these studies. All animals were single-housed in standard plastic mouse cages $(27 \times 21 \times 14 \mathrm{~cm})$ in a temperature-controlled $\left(22 \pm 1^{\circ} \mathrm{C}\right)$ and humidity-controlled $(50 \pm 5 \%)$ environment on a $12 \mathrm{~h}$ light dark cycle (lights on at 08:00h) with ad libitum access to chow $(2.9 \mathrm{kcal} / \mathrm{g}$, with $70 \%$ of calories derived from carbohydrates) and water. Stressed animals were housed in a different room from the non-stressed animals. All procedures were approved by the Carleton University Animal Care Committee and followed the guidelines of the Canadian Council on Animal Care.

\section{Osmotic Minipump implantation}

Mice were anesthetized with a $4 \%$ isoflurane/oxygen mixture and injected s.c. with analgesic meloxicam (1 mg/kg, Metacam). Surgiprep and Priviodine were applied to the back of the neck to provide sterilization. An incision was made on the skin and blunt surgical tools were used to separate the back muscle from skin to create a pocket to insert an osmotic minipump (Alzet pump model 1004; 4weeks, flow rate $0.11 \mathrm{ul} / \mathrm{hr}$ ) near the hind back area. Each minipump contained

either saline or GHRP6 dissolved in saline to deliver a dose of 13.5ug/day/animal. This pattern of GHRP6 administration induces weight gain when administered continuously using an infusion pump (McDowell et al., 1995). Silk surgical sutures 
were used to close all incisions, and polysporin $₫(\subset$ Johnson \& Johnson, New

Jersey, USA) and 2\% lidocaine hydrochloride topical anaesthetic jelly (Xylocaine, AstraZeneca, CDMV, Saint-Hyacinthe, OC, Canada) were administered on the surgical sites to prevent bacterial infection and as site-analgesic respectively. Mice were allowed to recover from surgery in a clean homecage with a heating pad and metacam $(1 \mathrm{mg} / \mathrm{kg})$ injected s.c.. The recovery of the animals was closely monitored through daily weight, chow and water intake as well as behavioral checks.

\section{Citalopram administration}

Following the surgery, animals were provided with either $0.5 \%$ sucrose water or citalopram $(0.06 \mathrm{mg} / \mathrm{ml})$ dissolved in $0.5 \%$ sucrose water to mask the aversive taste of citalopram. Nicolas and colleagues (2006) reported that citalopram exerts anxiolytic effects between $0.01-0.3 \mathrm{mg} / \mathrm{ml}$ dosages. Delivery of citalopram in drinking water was previously shown to better mimic citalopram intake in humans than injections.

\section{Chronic social defeat paradigm}

Mice assigned to the stress condition were exposed to the chronic social defeat paradigm. These mice were transferred to the stress room where resident sexually experienced CD1 mice were individually housed. During each stress episode, the intruder mouse was transferred to the cage of the resident CD1 mouse and allowed to interact until the first physical encounter occurred (usually less than 5 minutes) or until subordinate postures were observed from the 
intruder mouse. Further physical encounters were prevented by placing a transparent acryl frame with wire mesh between the two animals that allows exchange of auditory, visual and olfactory cues. These mice were then housed together until the next stress episode in which the defeated mouse was introduced to a different dominant resident mouse. This stress procedure was repeated daily for 10 days.

\section{BEHAVIOR TESTS}

\section{Open field test (OFT) and Social Interaction Test (SIT)}

The open field test and social interaction test were conducted as described in Chapter 2.

\section{Sucrose preference test}

Anhedonic-like behavior was evaluated by assessing sucrose preference in a two choice test in which mice were presented with water and 3.5\% sucrose for 24h (Willner et al., 1987). Fluids were presented in 50ml test tubes fitted with rubber stoppers and a ball-point sipper tube. Sucrose preference was calculated as a percentage of total fluid intake (3.5\% sucrose water consumption/total volume fluid consumed $\times 100$ ). 


\section{Forced swim test}

The forced swim test was conducted using the method of Porsolt and colleagues (1977). Mice were individually placed in a glass cylinder $(29(h) \times 14(w)$ $\mathrm{cm})$ that was filled $19 \mathrm{~cm}$ high with water at ambient temperature $\left(\sim 22-25^{\circ} \mathrm{C}\right)$.

Mice were allowed to swim for 5 minutes and their activity was video recorded. The duration of immobility defined as the absence of escape-oriented behavior such as swimming and jumping against the wall was scored. These immobility behaviors are interpreted as behavioral despair and can be quantified to measure the level of motivation to escape (Castagne et al., 2011).

To avoid confounds due to the order of behavioral tests, in all experiments order of test presentation was counterbalanced across subjects within groups.

\section{Immunohistochemistry}

\section{5-bromo-2'-deoxyuridine ( $\mathrm{BrDU})$ injections}

At approximately 10:00, on the day after the last behavior test, mice were injected intraperitoneally 4 times at $2 \mathrm{~h}$ intervals with BrDU (Sigma Aldrich B5002) dissolved in $0.9 \%$ saline with $0.007 \mathrm{~N} \mathrm{NaOH}$ at a concentration of $75 \mathrm{mg} / \mathrm{kg}$ of body weight (Malberg et al., 2000). This pattern of BrDU administration has been shown to capture proliferation of hippocampal neurons in the dentate gyrus (Malberg et al., 2000).

60. 


\section{Perfusion}

One day after the BrDU injections, all mice were deeply anesthetized with sodium pentobarbital and transcardially perfused with $0.9 \%$ saline, followed by $4 \%$ paraformaldehyde (PFA) in $0.1 \mathrm{M}$ phosphate buffer. Brains were collected and post-fixated in $4 \%$ PFA at $4^{\circ} \mathrm{C}$ for at least 48 hours and transferred into a $30 \%$ sucrose solution containing sodium azide for dehydration and storage. Brains were coronally sliced at 40 $\mu \mathrm{m}$ in a 1-in-5 series, on a cryostat (Fischer Scientific).

\section{Immunofluorescence for BrDU Staining}

One series of sections was stained for BrDU to identify newly divided cells at the time of euthanization as a measure of cellular proliferation. Free floating brain tissues were rinsed in phosphate buffered (PB) solution and treated with quenching solution (30\% $\mathrm{H} 2 \mathrm{O} 2$ in methanol and $\mathrm{PB})$ for 15 minutes at room temperature. To denature DNA, sections were placed in a solution of $1 \mathrm{~N}$ hydrochloric acid for 30 minutes at $45^{\circ} \mathrm{C}$, followed by 10 minute incubation with 0.3\% glycine in PB. Sections were blocked with a blocking solution (3ul Triton-X, $0.01 \mathrm{~g}$ bovine serum albumen, and 40ul normal goat serum dissolved in $1 \mathrm{ml} P B$ ) for 30 minutes. Immediately after the removal of the blocking solution, tissues were incubated with the primary antibody, rat anti-BrDU (1:1000; Abcam AB6326) mixed in a fresh blocking solution, at $4^{\circ} \mathrm{C}$ overnight under gentle agitation. After washing tissues with PB (5 times), tissues were incubated in a secondary antibody containing donkey anti-rat Alexa Fluor 594 lgG (1:200, Life Technologies A11007). Finally sections were mounted on glass slides and coverslipped with Fluoroshield $^{\mathrm{TM}}$ mounting medium containing DAPI (Sigma F6057). 


\section{Doublecortin (DCX)-DAB Staining}

Another series of sections was stained for DCX to identify immature neurons in the granule cellular layer of the dentate gyrus. Free floating brain tissues were rinsed in phosphate buffered (PB) solution and treated with quenching solution (30\% $\mathrm{H} 2 \mathrm{O} 2$ in $\mathrm{PB}$ ) for 30 minutes at room temperature. Sections were blocked with a blocking solution (3ul Triton-X, $0.01 \mathrm{~g}$ bovine serum albumen, and 40ul normal goat serum dissolved in $1 \mathrm{ml}$ PB) for 30 minutes at room temperature. Immediately after the removal of the blocking solution, tissues were incubated with the primary antibody rat anti-DCX (1:1000; Santa Cruz Biotechnology SC-8066) mixed in fresh blocking solution at $4^{\circ} \mathrm{C}$ overnight under gentle agitation. After washing tissues with PB (5 times), tissues were incubated in biotinylated donkey anti-Goat secondary antibody (1:200; Santa Cruz Biotechnology SC2020) mixed in fresh blocking solution for 2 hours at room temperature under gentle agitation. Sections were then treated with the $A B C$ system (Vectastain PK6100) and stained using 3'3-diaminobenzidine (Sigma Aldrich D8001) chromogen followed by Pyronin Y counter stain (Sigma Aldrich P9172).

\section{Quantification of the $D C X$ and BrDU immunoreactive cells}

DCX stained (roughly 4-6 sections per animal) tissues were digitally imaged using a Zeiss Axioplan universal microscope (Carl Zeiss Light Microscope, Gottingen, Germany) attached with OptixCam Summit K2 camera. Pyronin $Y$ counterstain was used to contrast DCX-DAB immunolabeled cells.

62. 
ImageJ (National Institutes of Health) was used to quantify BrDU immunoreactive cells within the boundaries of the dentate gyrus.

BrDU Stained (roughly 4-6 sections per animal) tissues were imaged on Olympus BX61 microscope equipped with an Olympus DSU disk-staining confocal unit. DAPI counterstaining was used to locate the dentate gyrus. ImageJ (National Institutes of Health) was used to quantify BrDU immunoreactive cells within the boundaries of the dentate gyrus established by the nuclear counterstain DAPI. 


\section{EXPERIMENTAL DESIGNS}

Experiment 3a: Does continuous administration of a ghrelin agonist or a ghrelin agonist in combination with citalopram prevent or delay the development of depressive-like behaviors during chronic stress exposure?

To explore whether ghrelin agonist (GHRP6) or the combination of GHRP6 and citalopram can prevent, or at least delay, the development of depressive like behaviors during chronic stress exposure half of the mice were assigned to the stress condition and the remainder to the non-stressed condition. Within each of these conditions mice were assigned to one of 4 drug treatments: saline (Control), citalopram, GHRP6 and GHRP6+CIT. This design resulted in eight groups ( $n=8$ mice per group): Non stressed (NS) control, NS Citalopram, NS GHRP6 and NS GHRP6+Citalopram, Stressed (S) control, S Citalopram, S GHRP6, S GHRP6+Citalopram.

Following 15 days of baseline monitoring of body weight, food intake and water intake, all mice underwent surgery for minipump implantation after which there was a 3-day recovery period. Mice in the stressed condition were then exposed to the CSDP procedure for 10 days whereas those in the non-stressed condition remained in their home cages. At the end of the CSDP procedure all mice were again housed in the same room and underwent behavioral testing. All tests were presented in counterbalanced order. The day after the last behavioral test mice were injected intraperitoneally with BRDU and then euthanized (See Figure 3.A). 
Experiment 3b: Does continuous administration of ghrelin agonist or ghrelin agonist in combination with citalopram alleviate depressive-like behaviors following exposure to chronic social defeat?

To explore whether ghrelin agonist (GHRP6) or combination of GHRP6 and citalopram can alleviate depressive-like behaviors precipitated by chronic stress exposure, we used the same design as described in Experiment 3a but in this case the drugs were administered at the end of the 10-day CSDP exposure. Each mouse was included in each experimental group. Daily measurements of food intake, water intake and body weight were made throughout the experiment. The time line of Experiment 3b is shown in Figure.3.B. 
Treatment Conditions:

Saline or GHRP6 (13.5ug/day) via osmotic minipump

$0.5 \%$ sucrose or $0.5 \%$ sucrose with citalopram $(0.06 \mathrm{mg} / \mathrm{ml})$

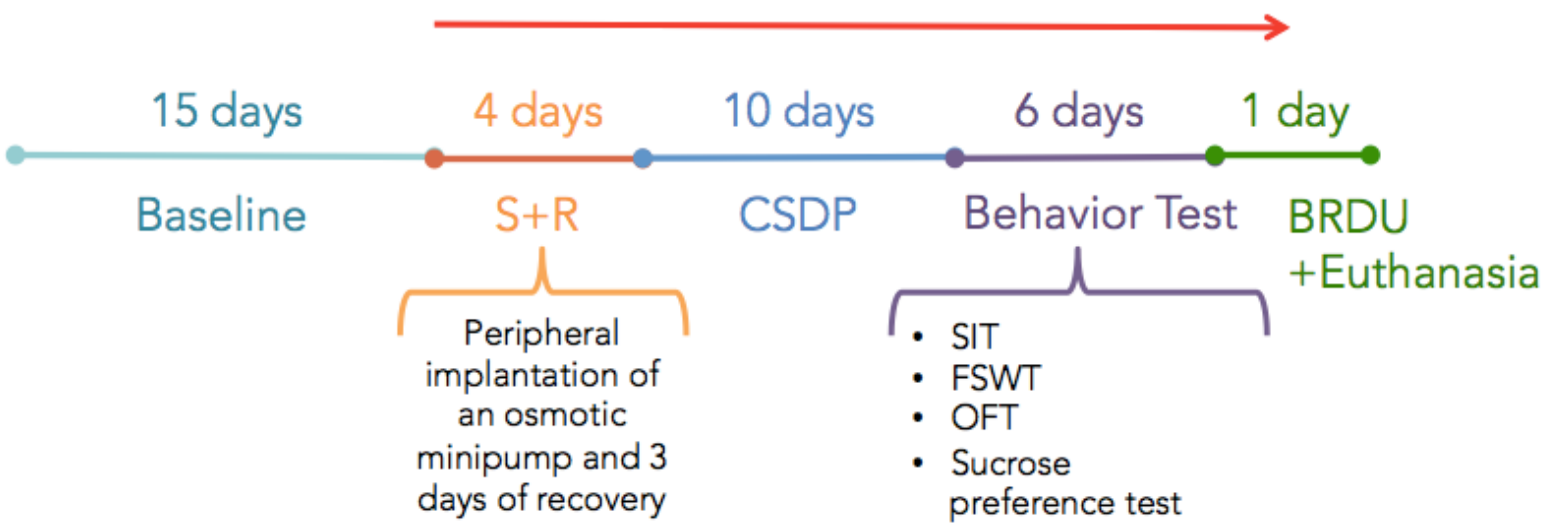

Figure 3.A. Time line of experiment 3a.

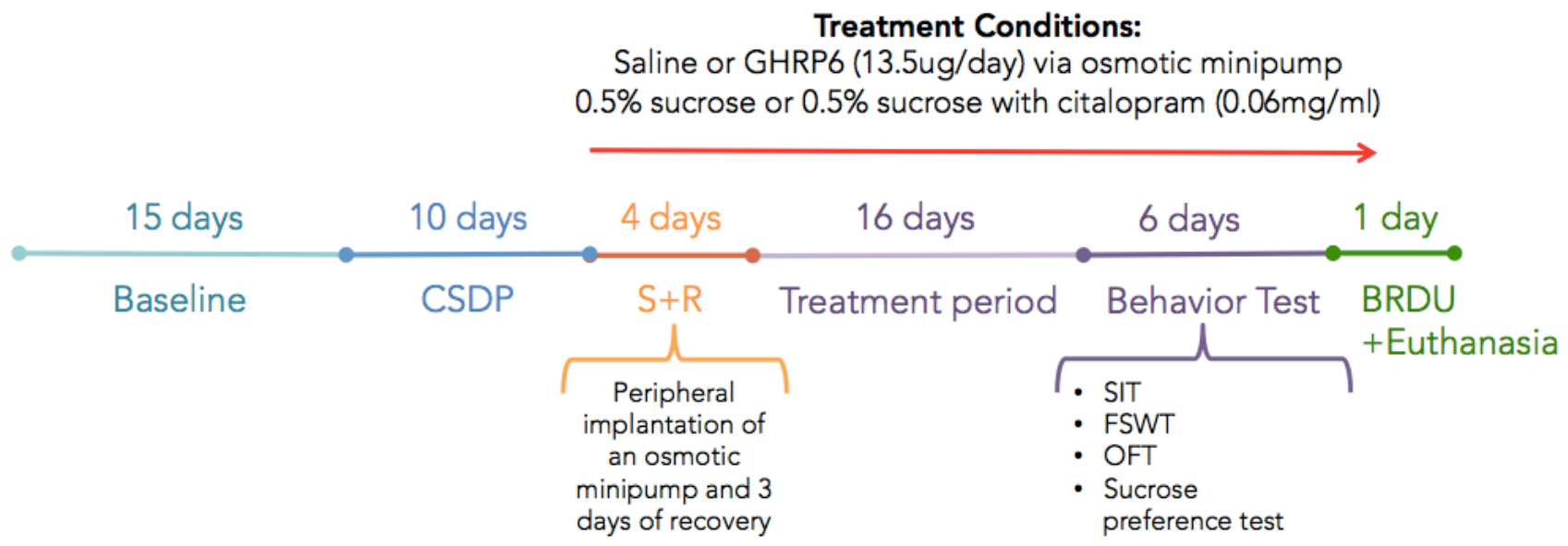

Figure 3.B. Time line of experiment 3b.

66. 


\section{STATISTICS}

Data obtained for the behavioral tests were analyzed using two-way ANOVAs with drug treatment and stress exposure as between subjects' factors. Food intake and water intake, during the CSDP period (10 days) and treatment period ( 16 days) for experiment $3 a$ and $3 b$ respectively, were normalized to the body weight of the corresponding day, and were analyzed using a 3-way ANOVA with stress exposure and drug treatment as between subjects factors and time as the within subject factor. For the analysis of citalopram consumption, two-way ANOVAs with stress (stress vs no stress) and drug treatment (citalopram vs no citalopram) as between subject factors were used for analysis. Significant interactions were explored using simple main effects and where appropriate, post-hoc tests were performed using Tukey's honest significant difference (HSD). All statistical analysis was done using the SPSS software with the significance criterion set at $p<0.05$.

All graphs were constructed using GraphPad PRISM and data are shown as Mean + SEM. 


\section{RESULTS}

Experiment 3a: Does continuous administration of a ghrelin agonist or a ghrelin agonist in combination with citalopram prevent or delay the development of depressive-like behaviors during chronic stress exposure?

As expected, exposure to CSDP increased the latency to approach the stranger mouse and corner observations (significant main effect of stress; $F_{(1,}$ $\left.{ }_{62}\right)=5.351, p=0.025 ; F_{(1,62)}=32.782, p<0.001$ respectively) (Figure 3.1.a and $d$ ). The effect of stress on latency to approach appeared to be present only in groups treated with citalopram, GHRP6, and GHRP6+citalopram but the drug x stress interaction effect was not significant. There was a trend towards increased stretching behavior in the stressed groups (main effect of stress $\left(F_{(1,62)}=3.557\right.$, $p=0.065$ ) (Figure 3.1.c), which, similar to latency to approach, was not seen in the control groups. No significant effects of drug or drug $x$ stress interaction were found on any measure of social behavior (Figure 3.1).

As expected, stress-exposed mice spent less time in the center of the open arena (significant main effect of stress $\left.F_{(1,62)}=22.091, p<0.001\right)$ (Figure 3.2) but there was no significant effect of drug nor a drug $x$ stress interaction on this parameter. There was a significant stress $x$ drug interaction effect on immobility $\left(F_{(3,62)}=2.715, p=0.05\right)$ during the forced swim test (Figure 3.3). Pairwise comparisons revealed that stressed controls were less immobile than nonstressed Controls $(p<0.05)$ whereas stressed animals treated with citalopram+GHRP6 showed greater levels of immobility compared to non- 
stressed citalopram+GHRP6 ( $p<0.05)$. No significant effects of drug, stress exposure or their interaction were found in the sucrose preference test (Figure 3.4).

Significant stress $X$ drug interactions were seen in change in body weight, chow intake, and water consumption $\left(F_{(3,62)}=3.066, p=0.035 ; F_{(3,80)}=4.325\right.$, $p=0.007 ; F_{(3,80)}=3.562, p=0.018$ respectively) (see Figure 3.5 panels $a, b$ and $c$ ). Stressed animals gained more body weight than non-stressed animals, with the exception of non-stressed animals treated with GHRP6 or the combination of GHRP6 + citalopram, which gained as much body weight as stressed animals (Figure 3.5.a). All stressed animals significantly increased consumption of chow relative to non-stressed groups (Figure 3.5.b). Among all treatment groups, pairwise comparisons revealed that stressed animals treated with both GHRP6 + citalopram consumed significantly more chow than other treatment groups $(p<0.05)$ (Figure 3.5.b). Water consumption was significantly higher in stressed control and GHRP6 treated groups than citalopram and GHRP6+citalopram groups (Figure 3.5.c). Animals treated with GHRP6 + citalopram consumed significantly less water than other groups $(p<0.05)$ (Figure 3.5.c). As citalopram was administered in the water, this pattern of water intake resulted in differences in citalopram intake between the groups that received citalopram alone and those that were treated with $\mathrm{GHRP6}+$ citalopram $\left(F_{(1,32)}=5.841, p=0.022\right)$ (Figure 3.5.d). Stress exposure did not influence citalopram consumption. 
(a)
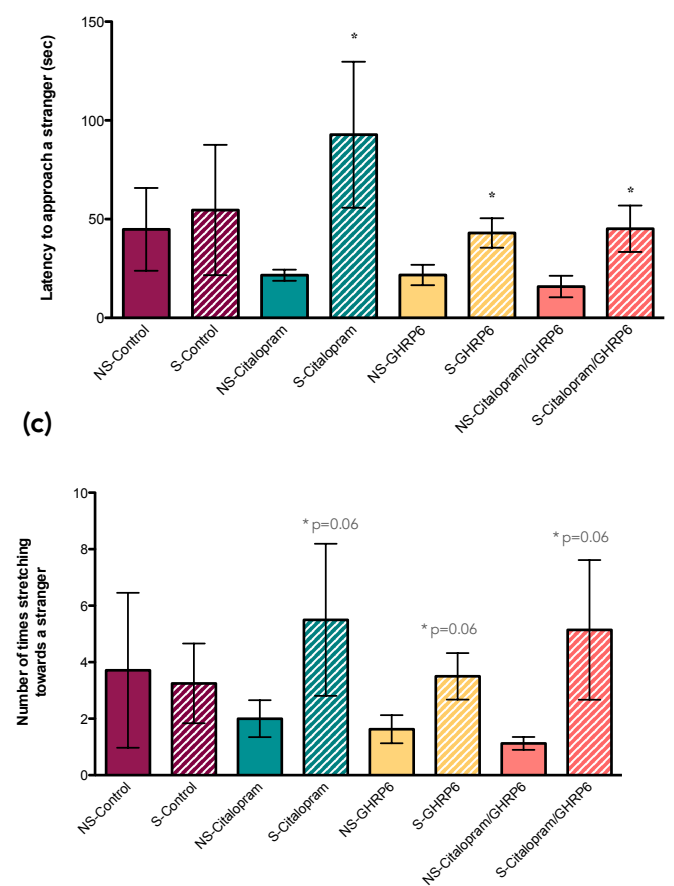

(b)

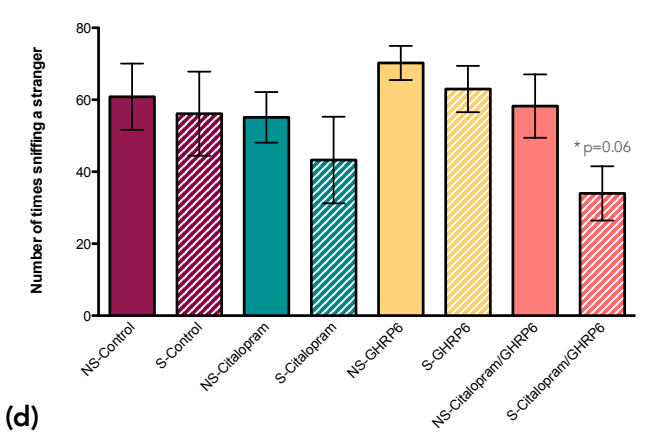

(d)

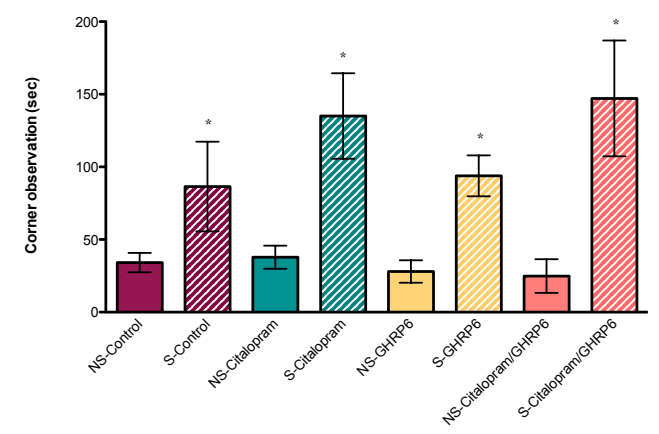

Figure 3.1. Social Behavior Measures.

Mean latency to approach a novel stranger mouse(a) shown for each treatment groups. NS - Non-stressed and S - stressed. The effect of stress; * $p<0.05$. The effect of trends are shown in grey color with the $p$ value. All values expressed as mean $\pm S E M$. 


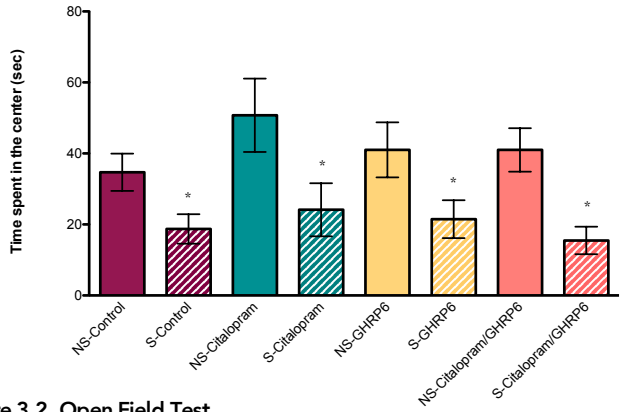

Figure 3.2. Open Field Test.

Mean time spent in the center of the arena for each treatment groups. NS - Non-stressed and S - stressed. The effect of stress; ${ }^{*} \mathrm{p}<0.05$. All values expressed as mean $\pm \mathrm{SEM}$.

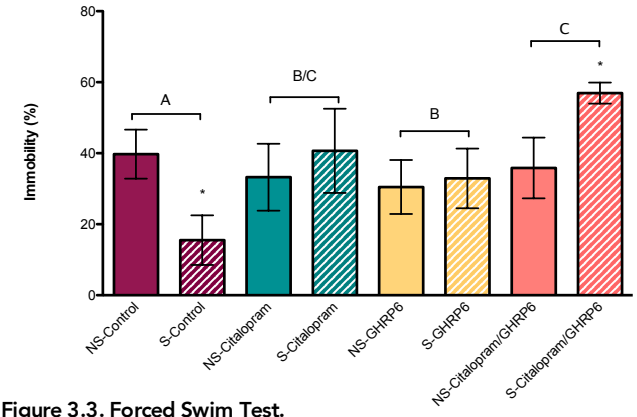

Figure 3.3. Forced Swim Test.

Mean time spent immobile (\%) in the water for each treatment groups. NS - Non-stressed and S - stressed. The effect of stress; ${ }^{*} p<0.05$. The effect of drugs; $A$ is different from $B, p<0.05$. All values expressed as mean $\pm \mathrm{SEM}$.

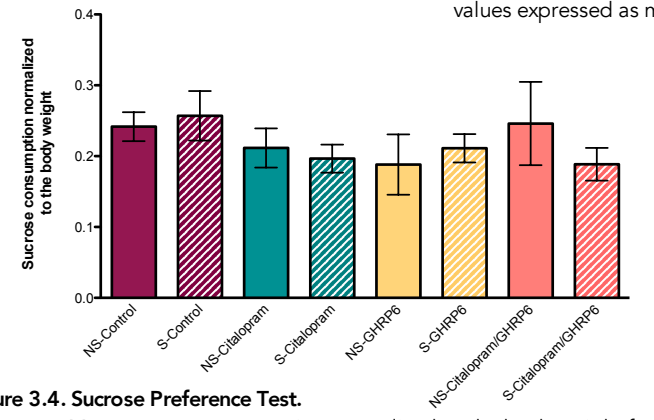

Figure 3.4. Sucrose Preference Test.

Mean sucrose consumption normalized to the body weight for

each treatment groups. NS - Non-stressed and S - stressed.

All values expressed as mean \pm SEM 
(a)

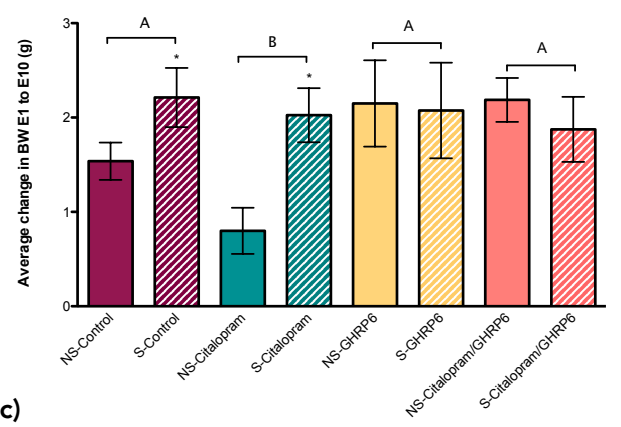

(c)

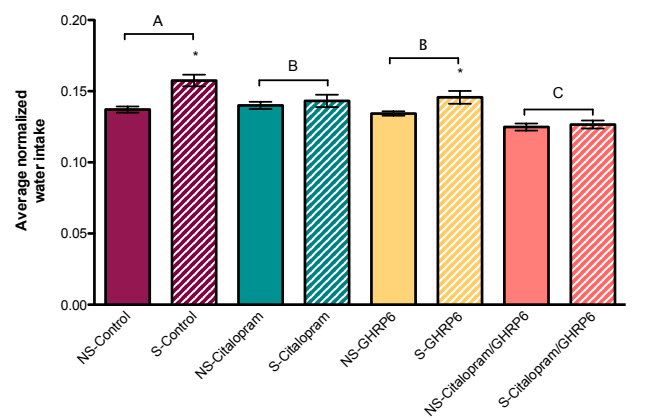

(b)

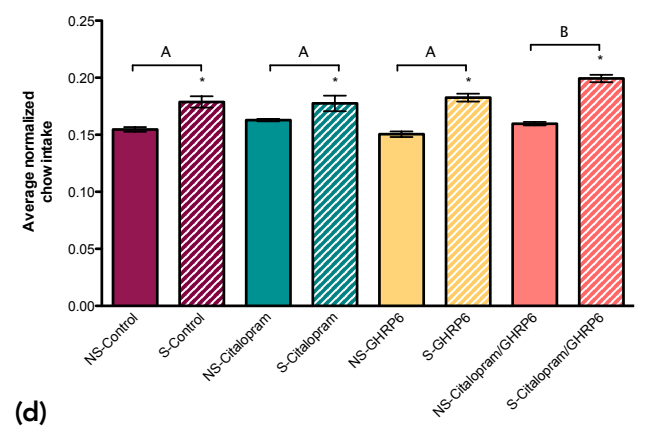

(d)

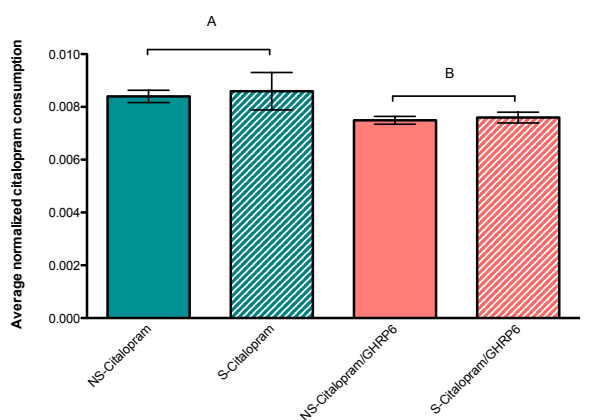

Figure 3.5. Body weight and Chow, Water and Citalopram Intake.

Average change in body weight during E1 to E10 (a) shown for each treatment groups. Average intake of chow (b) and water (c) normalized to the body weight. Average intake of citalopram in citalopram treated animals are shown in (d). NS - Non-stressed and S - stressed. The effect of stress; * $p<0.05$. The effect of the drug; $A$ is different from $B, p<0.05$. All values expressed as mean $\pm S E M$. 


\section{Experiment 3b: Does continuous administration of a ghrelin agonist or a ghrelin agonist in combination with citalopram alleviate depressive-like behaviors following exposure to chronic social defeat?}

No significant effects of either stress exposure or drug or their interaction were found on latency to approach the stranger mouse or on frequency of stretching behavior (see Figure 3.6 panels a and c). A main effect of stress was seen in frequency of sniffing and corner observation, in which stressed animals showed a reduced frequency of sniffing and increased frequency of corner observation ( $F_{(1,54)}=11.795, p=0.001 ; F_{(1,54)}=34.271, p<0.001$ respectively) (see Figure 3.2 panels $b$ and d). In corner observation, there was a trend towards a main effect of drug $\left(F_{(1,54)}=2.454, p=0.07\right)$ where animals treated with GHRP6 and combined treatment of GHRP6 + citalopram showed fewer corner observations than control and citalopram alone treated animals.

No significant effects of either drug treatment or stress were found on behaviors in the open field, forced swim or sucrose preference tests (see Figure

\section{7, Figure 3.8 and Figure 3.9 respectively).}

There was a significant main effect of stress $\left(F_{(1,54)}=5.720, p=0.021\right)$ as well as a significant interaction between stress and drug treatment on the number of doublecortin (DCX) immunoreactive cells $\left(F_{(3,54)}=6.992, p=0.001\right)$ (Figure 3.10). Post-hoc investigation of the interaction showed that stress decreased DCX immunoreactivity in control and citalopram treated mice, but had no effect in the GHRP6 treated group, whereas GHRP6+citalopram treated mice showed increased DCX immunoreactivity relative to their nonstressed counterparts 
$(p<0.05)$. As expected, overall, stress exposure significantly reduced BrDU immunoreactivity $\left(F_{(1,54)}=14.679, p<0.001\right)$ (Figure 3.11). A significant main effect of drug $\left(F_{(3,54)}=3.679, p=0.018\right)$ was also observed where control groups showed higher BrDU immunoreactivity than GHRP6 treated groups. These main effects seem to be driving a trend towards stress $X$ drug interaction $\left(F_{(3,54)}=2.318\right.$, $p=0.088$ ) but it failed to reach a statistical significance.

Stressed animals gained significantly more body weight $(t=4.722, p=0.034)$ than non-stressed animals during the period of stress exposure (Stress: Mean $1.570 \mathrm{~g} \pm 0.22 \mathrm{~g}$, Non-stressed: Mean $1.069 \mathrm{~g} \pm 0.08 \mathrm{~g})$. Stress experience, however, did not significantly influence body weight change during post-stress treatment, instead there was a main effect of drug $\left(F_{(3,61)}=4.572, p=0.006\right)$ (Figure 3.12a) and post hoc analysis showed that animals treated with GHRP6 alone gained less weight than any other group, whereas citalopram treatment resulted in increased body weight (pairwise comparisons $p<0.05$ ). It appears from Figure 3.12a, that the ability of GHRP6 to suppress weight gain was also seen in stressed mice treated with GHRP6 + citalopram but this did not result in a significant stress $\mathrm{x}$ drug interaction. Significant stress $X$ drug interactions were seen in chow and water consumption $\left(F_{(3,128)}=2.982, p=0.034 ; F_{(3,128)}=2.784\right.$, $p=0.044$ respectively) together with significant main effects for stress (see Figure 3.12 panels $b$ and $c$ ). Pairwise comparisons revealed that consumption of chow and water intake was significantly higher in stressed animals regardless of the drug treatment $(p<0.05)$ but stressed animals treated with GHRP6 consumed more chow $(p<0.05)$, than the other groups. In non-stressed animals, chow consumption did not differ significantly with drug treatment. Among the stressed groups, water intake was highest in saline-treated mice $(p<0.05)$ while those 
treated with GHRP6+citalopram consumed the least $(p<0.05)$. In non-stressed groups, water intake was also highest in the saline treated groups and the GHRP6 treated group drank least $(p<0.05)$. Consistent with patterns of water consumption, there was a trend towards a main effect of drug $(F(1,31)=3.818$, $p=0.06$ ) that appears to reflect the increased citalopram intake in animals treated with citalopram alone. 
(a)
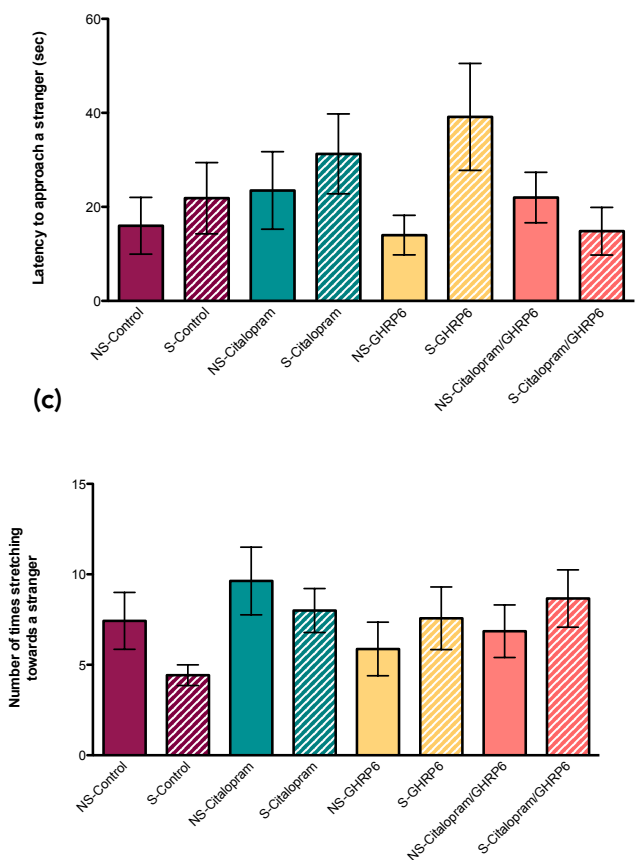

(b)

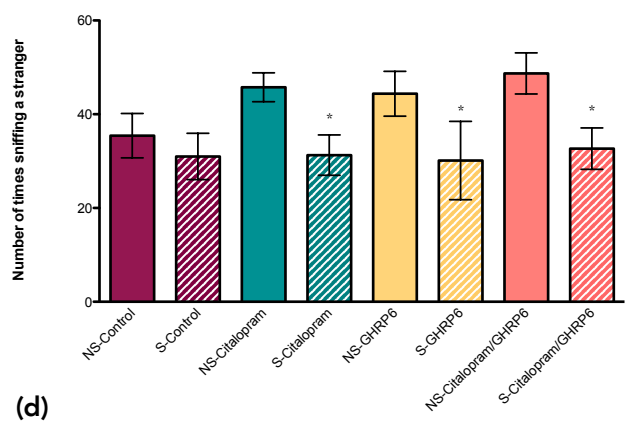

(d)

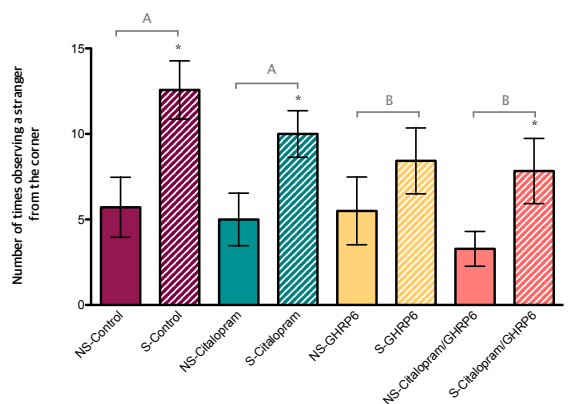

Figure 3.6. Social Behavior Measures.

Latency to approach (a), number of times sniffing (b), number of times stretching (c) and observing (d) a novel stranger mouse from a corner shown for each treatment groups. NS - Non-stressed and S - stressed. The effect of stress; * $p<0.05$. Trend towards main effect of drugs are shown in grey; $A$ is different from $B p=0.07$. All values expressed as mean $\pm S E M$. 


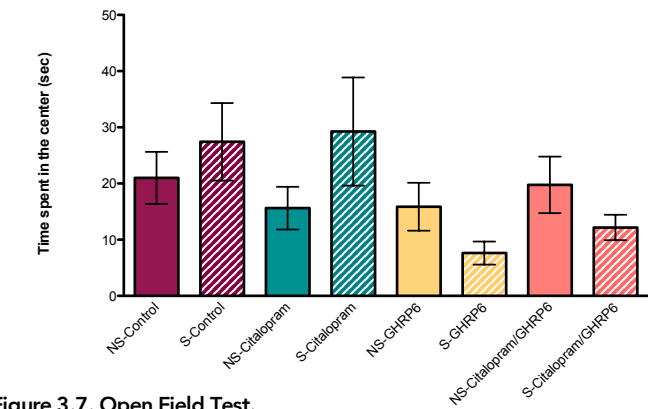

Figure 3.7. Open Field Test

Mean time spent in the center of the arena for each treatment groups. NS - Non-stressed and S - stressed.

All values expressed as mean \pm SEM.

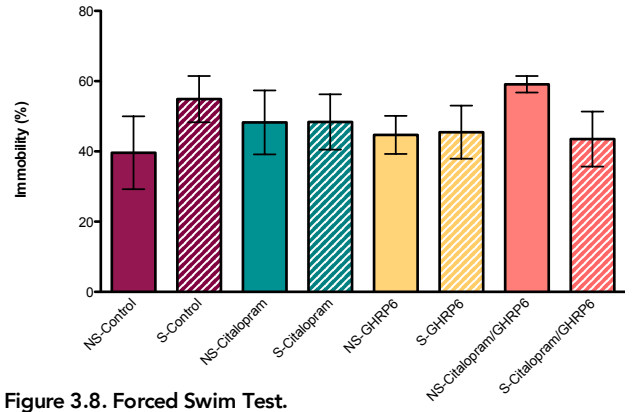

Figure 3.8. Forced Swim Test.

Mean time spent immobile (\%) in the water for each treatment groups. NS - Non-stressed and S - stressed.

All values expressed as mean \pm SEM.

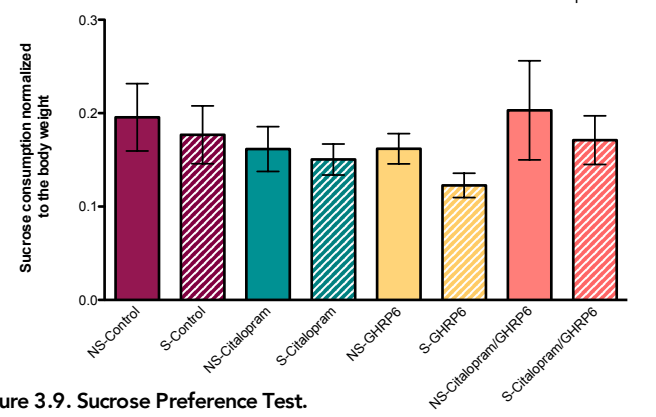

Figure 3.9. Sucrose Preference Test.

Mean sucrose consumption normalized to the body weight for each

treatment groups. NS - Non-stressed and S - stressed. All values

expressed as mean $\pm \mathrm{SEM}$. 


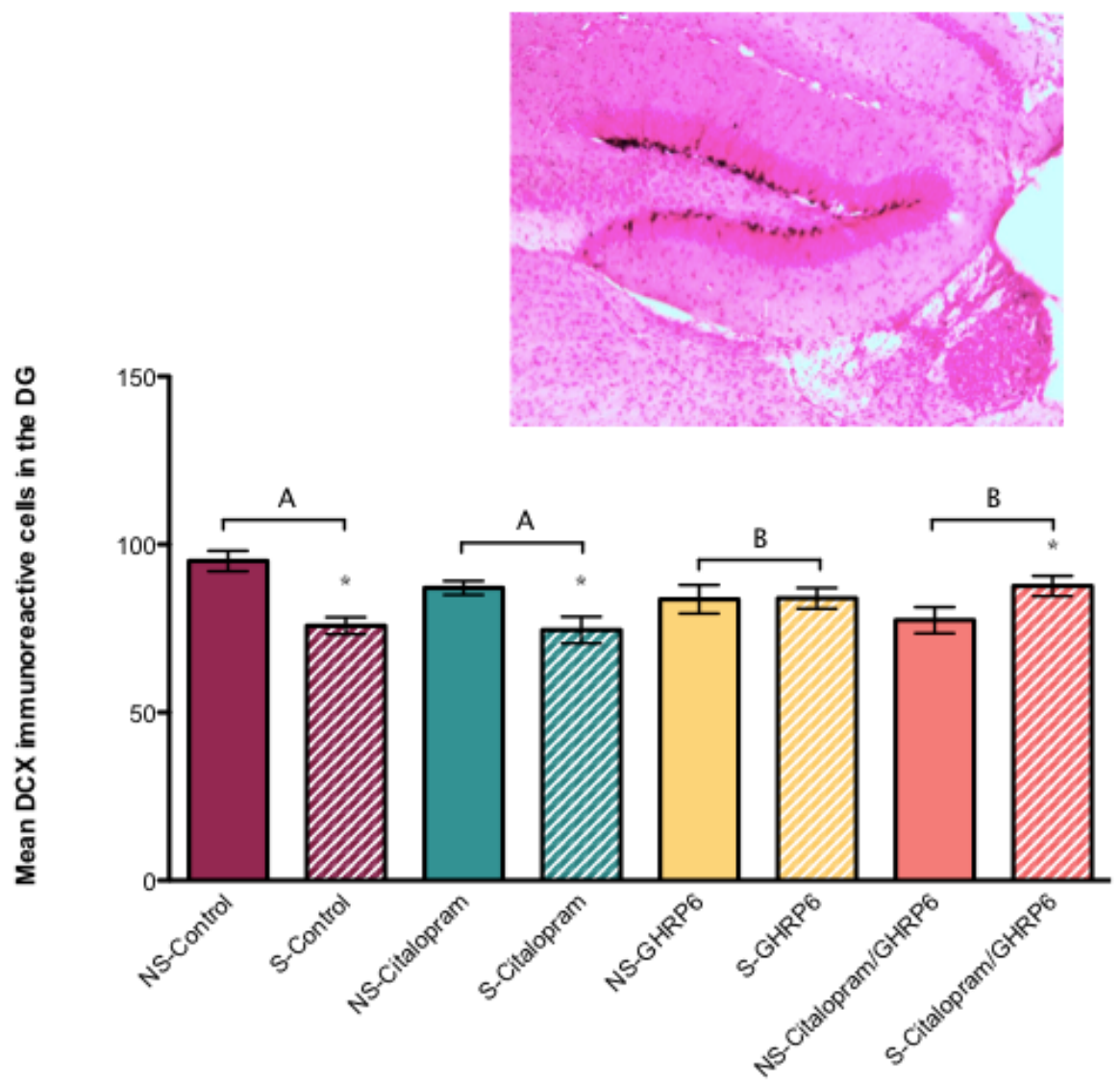

Figure 3.10. Mean Doublecortin (DCX) immunorectivity in the dentate gyrus (DG).

Average number of DCX shown for each treatment groups. NS - Non-stressed and S - stressed. The effect of stress; " $p<0.05$. The effect of the treatment for stressed animals; The effect of drug; A is different from $\mathrm{BP}<0.05$. All values expressed as mean $\pm \mathrm{SEM}$. 


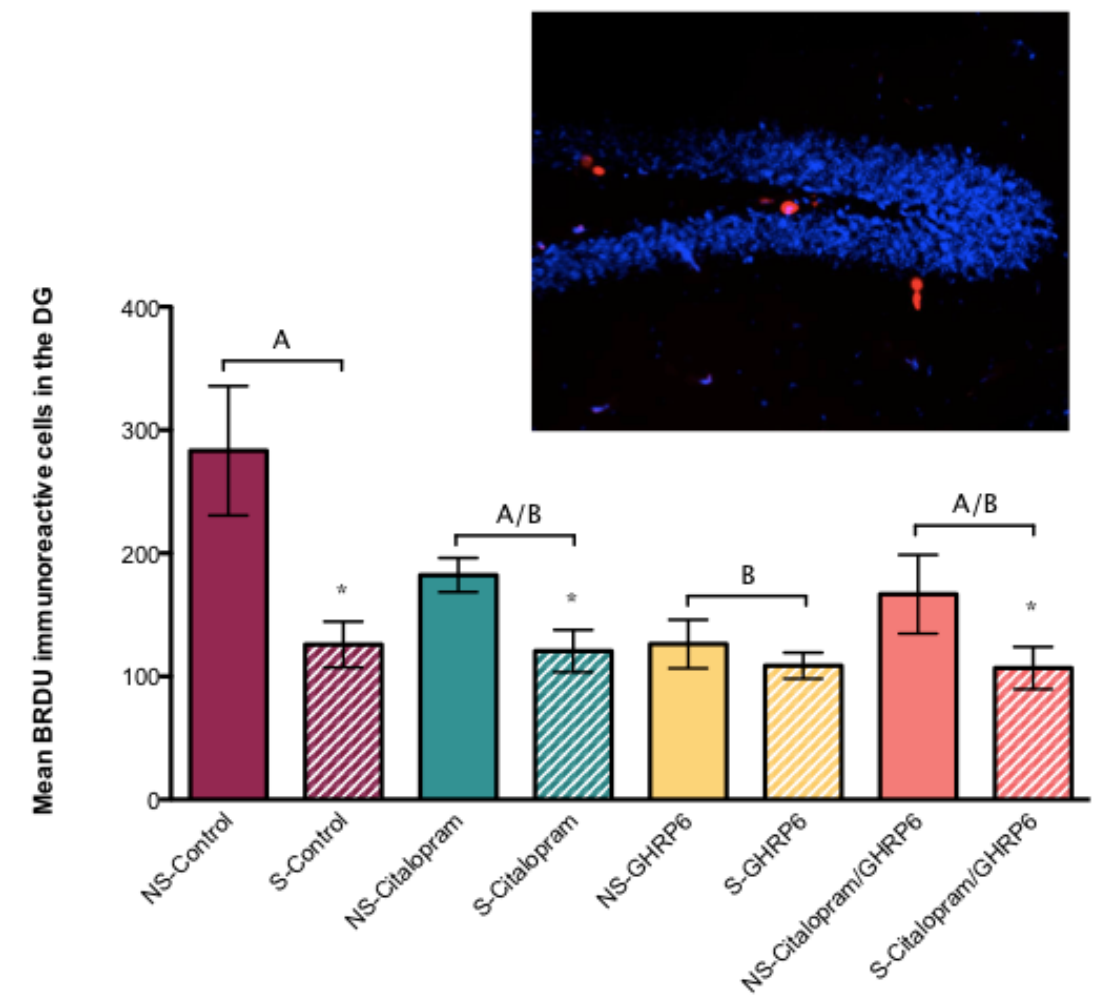

Figure 3.11. Mean bromodeoxyuridine (BRDU) immunoreactivity in the dentate gyrus (DG).

Average number of BRDU shown for each treatment groups. NS - Non-stressed and S - stressed. The effect of stress; * $p<0.05$. All values expressed as mean \pm SEM. 
(a)
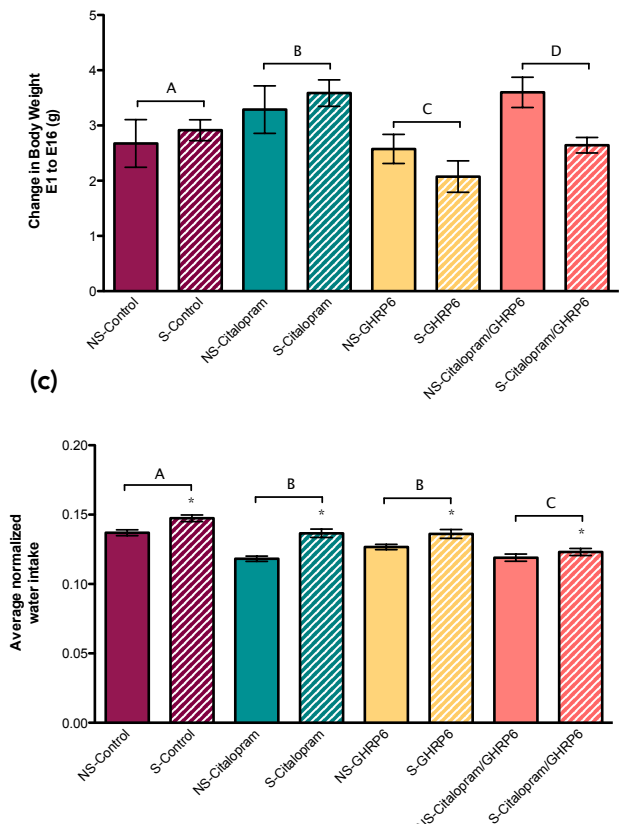

(b)
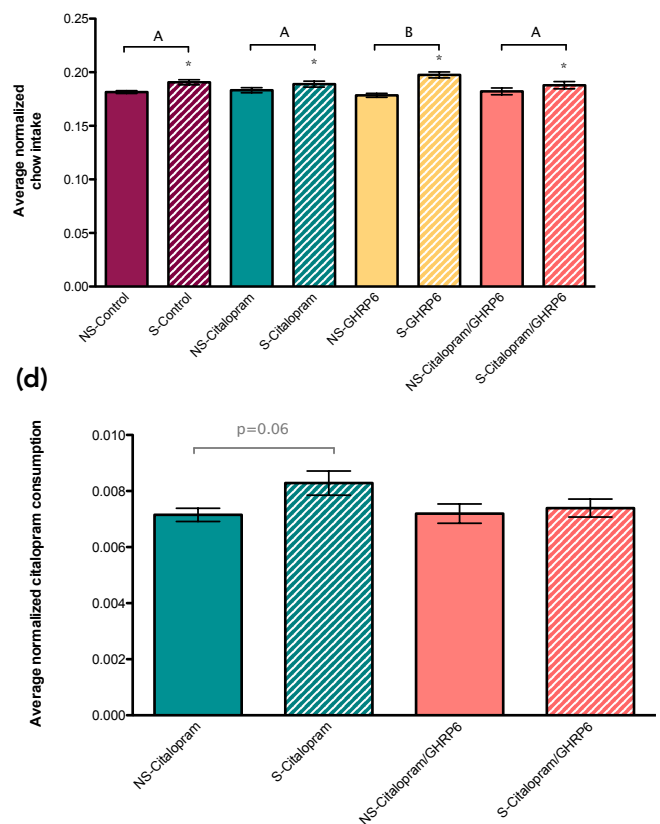

Figure 3.12. Body weight and Chow, Water and Citalopram Intake.

Average change in body weight during E1 to E16 (a) shown for each treatment groups. Average intake of chow (b) and water (c) normalized to the body weight. Average intake of citalopram in citalopram treated animals are shown in (d). NS - Non-stressed and S - stressed. The effect of stress; * $p<0.05$. Trends are shown in grey, with the $p$ value. Th effect of the drugs; each letter differs from others, $p<0.05$. All values expressed as mean $\pm \mathrm{SEM}$. 


\section{DISCUSSION}

The current experiments were designed to test the hypothesis that exogenous administration of the ghrelin agonist GHRP6 either alone or in combination with citalopram would prevent the development of, and/or alleviate depressive symptoms, particularly those related to social behavior. Like antidepressants, GHRP6 administration has been shown to stimulate the proliferation and differentiation of hippocampal neurons, thus we expected that chronic treatment with GHRP6 or a citalopram GHRP6 combination would enhance neurogenesis in stressed animals. Finally, given that both chronic stress exposure and antidepressant treatment have been shown to affect food intake and body weight and that ghrelin is a powerful modulator of energy balance, we also investigated how stress and drug treatments combined to influence bodyweight and food intake.

As expected, stress exposure induced some deficits in the tests of social interaction. In Experiment 3a, exposure to CSDP increased latency to approach a stranger mouse, as well as frequency of stretching and time spent observing from the corner (Figure 3.1). Fewer effects of CSDP exposure were observed in Experiment $3 b$, although decreases in sniffing frequency and increased corner observations were observed in stressed mice (Figure 3.6). The relatively mild effects of stress seen in Experiment $3 \mathrm{~b}$ are perhaps not surprising given that in this experiment, these measures were obtained 3 weeks after the cessation of CSDP rather than immediately after as in Experiment 3a. Contrary to our hypothesis, few effects of drug administration on social behaviors were observed in either experiment. 
Consistent with the literature, in Experiment 3a, stress exposure decreased the time that mice spent in the center of the open field (Figure 3.2) but this effect was not observed in animals tested 3 weeks after the last stress episode in Experiment 3b (Figure 3.7). The effect of stress on immobility in the forced swim test was inconsistent, and in Experiment 3a, stress was associated with decreased immobility in saline treated mice and increased immobility in mice treated with citalopram + GHRP6. No effects of stress on behavior in the forced swim test were seen in Experiment 3b (Figure 3.8). In neither experiment was there an effect of stress in the sucrose preference test. It is possible that the use of a sucrose solution as a vehicle for delivering citalopram rendered the $3.5 \%$ sucrose solution used to assess sucrose preference less rewarding.

Considerable evidence supports the idea that hippocampal neurogenesis is required for the behavioral effects of antidepressants in both rodents and nonhuman primate models (Czeh et al., 2001; Santarelli et al., 2003; Hill et al., 2015). In Experiment 3b, we tested this hypothesis by examining the effect of stress and drug treatment on neurogenesis by immuno-labeling of doublecortin (DCX) for immature granule cells and 5-bromo-2'-deoxyuridine (BrDU) for cellular proliferation in the dentate gyrus. In spite of the relatively mild effects stress exposure had on behaviors measured at this time point, it did decrease the number of both $\mathrm{DCX}$ and $\mathrm{BrDU}$ immunoreactive cells within the dentate gyrus (Figure 3.10 and Figure 3.11 respectively). Treatment with both GHRP6 alone and in combination with citalopram increased the number of DCX immunoreactive cells but had no effect on the number of BrDU immunoreactive cells. DCX is a marker of immature neurons and down-regulation of DCX begins 2 weeks after the cell is born when cells begin to express NeuN, a marker for 
mature neurons (Brown et al., 2003; Spampanato et al., 2012). In this study, BrDU and DCX were assessed approximately 4 weeks after the end of stress exposure and one week after the end of treatment. It is possible then that at this point, any effects of treatment on cellular genesis, itself, had dissipated but the presence of a greater number of immature neurons in GHRP6 treated mice suggests that this dose had been sufficient to induce cellular genesis.

In addition to our behavioral and immunohistochemistical data, we also investigated the effects of stress and drug treatments on body weight and food intake. Consistent with the literature, in both Experiments 3a and 3b, all stressed animals gained significantly more body weight than non-stressed animals during the CSDP exposure. In Experiment 3a, GHRP6 treatment increased body weight gain in non-stressed mice (Figure 3.5.a). Interestingly, however, when the drug treatment was initiated after CSDP (Experiment 3b), treatment with GHRP6 and GHRP6 + citalopram decreased body weight gain and this effect appeared greater in stressed mice (Figure 3.12.a). This change in weight gain appears to be independent of food intake, as all stressed animals consumed more than nonstressed controls in both experiments (Figure 3.5.b. and Figure 3.12.b). Intriguingly, GHRP6 treated animals showing least body weight gain consumed most chow in Experiment 3b (Figure 3.12.b).

Water consumption is typically driven by food intake but was also the route of citalopram delivery in our experiments. In Experiment 3a, animals given citalopram alone consumed more water, hence more citalopram, than animals given combined GHRP6 + citalopram treatment regardless of the stress exposure (Figure 3.5.c and Figure 3.5.d). This pattern of water and citalopram 
consumption was found in Experiment 3b (Figure 3.12.c and Figure 3.12.d). Despite these similarities, in Experiments $3 a$ and 3b, timing of the start of treatment resulted in differences in citalopram-induced weight gain. Citalopram treatment during the stress exposure led to the least body weight gain whereas citalopram treatment after stress resulted in most body weight gain in comparison to other treatment groups. This finding is consistent with the literature, both human and animal studies show that chronic treatment of citalopram leads to body weight gain (Strekalova et al., 2013; Uguz et al., 2015). In contrast to citalopram effect on body weight, our data suggests that treatment with GHRP6 after stress reduces this citalopram induced body weight gain.

Given the widely known role of ghrelin as an orexigenic peptide, one would expect GHRP6 to increase body weight as a result of increased feeding behavior. In this thesis, our data suggests that this simple assumption does not fit, especially in the context of recovery from stress. On the basis that GHRP6 and citalopram have antidepressive effects, we expected to see drug treatment alone or in combination prevent the development of, and/or alleviate depressive symptoms. Similar to stress, drug treatments showed few behavioral effects but we find that animals with GHRP6 in the system show higher DCX immunoreactive cells than controls and other treatment groups. Rather surprising drug effects on the body weight and food intake were found such that chronic GHRP6 and citalopram differentially influenced body weight gain. Initially, GHRP6 treatment during the stress period induced body weight gain but after stress, GHRP6 treatment leads to reduced body weight gain. The opposite pattern was seen in the citalopram treated group which gained more body weight post stress. It is not surprising that chronic citalopram treatment leads to greater body weight, as

\section{4.}


it is widely reported in literature. Our data shows that, in stressed animals, combined treatment of GHRP6 and citalopram can resist the citalopram induced body weight gain.

In summary, we have provided evidence that chronic administration of GHRP6 at a dose sufficient to induce feeding was relatively ineffective in preventing and treating behavioral symptoms of depression induced by CSDP. It was, however, effective in ameliorating some of the effects of stress on neurogenesis as reflected in increased immunoreactivity for DCX suggesting that the timing of testing for the behavioral effects might have been inappropriate. Perhaps surprisingly, we did find that GHRP6 reduces citalopram induced body weight gain particularly in the stress group. This could have therapeutic implications because weight gain and its associated health risk is a major side effect of antidepressant treatment. 


\section{CHAPTER 4}

\section{GENERAL DISCUSSION}

The goal of the experiments described in this thesis were first to investigate the role of GHSR signaling on anxiety behavior and second, to explore the idea that a GHSR agonist can prevent and/or treat the behavioral and physiological deficits that occur as a consequence of chronic stress. The previous literature on the role of ghrelin in anxiety behavior has been confusing with some authors reporting anxiogenic and some others reporting anxiolytic effects of ghrelin (Carlini et al., 2002; Kanehisa et al., 2006; Lutter et al., 2008; Spencer et al., 2012; Landrigan et al., 2016; Jensen et al., 2016). One explanation for these discrepancies is that they result from differences in drug dose, route of administration, timing of administration and timing of behavioral test after administration (Chuang and Zigman, 2010). To avoid some of these issues, we used various methods of manipulating ghrelin receptor signaling and tested mice on an array of tests of anxiety behavior in the most consistent manner possible.

To do this, we compared the behavior of GHSR KO mice with that of WT controls in a number of paradigms designed to measure anxiety-like behaviors. Lack of GHSR activity resulted in a more anxious phenotype than WTs, in behavior tests that involved approaching a goal object such as palatable food or 
a novel stranger mouse. This anxiolytic response of GHSR activity was not seen in the open field test. This finding is consistent with reports by Lutter and colleagues (2008) who showed that exposure to the chronic social defeat paradigm resulted in a greater magnitude of anxiety-like symptoms in GHSR KO mice relative to WT controls. Here, they also reported that this effect was most pronounced in tests of social investigation (Lutter et al., 2008).

To confirm the findings we obtained using the GHSR KO mice, we then pharmacologically down regulated GHSR activity by peripheral administration of the GHSR antagonist JMV2959 and found a similar pattern of effects. Thus both the life long elimination of GHSR activity that occurs with genetic mutation or acute down regulation of GHSR activity by administering a GHSR antagonist increased anxiety in tests involving approach to either a novel goal object or a familiar goal object in a novel situation.

In both GHSR KO mice and mice treated peripherally with a GHSR antagonist, the GHSR activity is reduced both peripherally and centrally. However, our assumption was that the effects on anxiety behavior that we observed were mediated centrally, thus we went on to investigate areas within the brain that might mediate the effect of GHSR activation on anxiety behavior. The area we targeted, was the ventral tegmental area (VTA), which has abundant GHSRs and is an important region for reward-seeking behaviors. Ghrelin has been shown to act in the VTA to stimulate increased dopamine (DA) turnover in the nucleus accumbens (Abizaid et al., 2006). It is also known that social behavior is mediated by the type 1 dopamine receptor cells from the VTA signaling downstream in the NAc (Gunaydin et al., 2014). Consistent with our hypothesis, 
reducing GHSR activity in the VTA by administration of JMV2959 resulted in behavioral deficits, particularly in social behavior. These findings were confirmed using a gain of function approach, in which GHSR expression was restored in the VTA by administration of AAV-cre recombinase that removed the transcriptional blocking cassette embedded between two loxP sites allowing transcription and translation of the GHSR gene to resume (Zigman et al., 2005). As expected, restoring GHSR in the VTA had anxiogenic effects in the social investigation tests.

Together, this body of work suggests that ghrelin receptor activity is important for those aspects of anxiety behavior that are elicited when the animal has to approach a goal object in a potentially "risky" situation such as approaching a novel conspecific. The mechanism through which ghrelin receptor activation within the VTA modulates this behavior is not known but presumably involves the ability of ghrelin to stimulate DA neurons in the VTA and the ensuing release of DA into NAcc.

Social withdrawal and willingness to socialize are persistent features of depression, thus, in the subsequent experiments we investigated whether the ghrelin agonist GHRP6 could prevent and/or treat the social withdrawal induced by exposure to chronic social defeat. As expected, stress exposure induced some deficits in social interaction, as well as in behavior in the open field. Neither administration of GHRP6 alone nor in combination with the common SSRI citalopram during the stress exposure phase of the experiment prevented the appearance of these behaviors, thus in the final experiment described in this thesis, we adopted a treatment model and administered GHSR agonist and

\section{8.}


citalopram after the stress exposure period and behavior testing took place at the end of treatment about 3 weeks after the termination of the stress exposure. Not surprisingly, we observed few effects of stress exposure on anxiety behavior at this time and an alleviating effect of GHSR agonist administration was only seen on one aspect of social anxiety.

In general, the effects of CSDP on depressive-like behavior that we observed were mild compared with those reported in the literature (Blanchard et al., 2001; Krishnan et al., 2007; Czeh et al., 2007). This probably reflects the fact that in the version of the paradigm used for this study, we prevented animals from aggressive physical interaction that could result in physical injuries. This 'mild' psychosocial stressor may also best represents stressors experienced by humans. In current society, individuals are more likely to be exposed to minor stressors (i.e. daily stressors) rather than physically abusive stressors. According to Anisman and Matheson (2005), both severe stressful events as well as a series of relatively mild stressors induce depression.

In spite of the relatively mild stress effects on behavior, we did find a reduction in cellular proliferation as measured by BrDU immunocytochemistry and fewer immature neurons in the dentate gyrus of stressed mice 4 weeks after the cessation of the stress paradigm. Decreased hippocampal neurogenesis is a well-established correlate of depressive behavior, and the efficacy of antidepressant drugs has been linked to their ability to increase hippocampal neurogenesis (Czeh et al., 2001; Santarelli et al., 2003; Van Bokhoven et al., 2011; Perera et al., 2011; Hill et al., 2015). Consistent with an antidepressant effect of ghrelin, we found that stress-induced decreases in doublecortin (DCX), a marker 
of immature neurons, were prevented by treatment with GHRP6 and combined treatment with GHRP6 and citalopram actually resulted in an increase in DCX staining. Thus, while we found no behavioral evidence of an antidepressant effect of ghrelin receptor agonist, it did have the expected effects at the cellular level.

One of the most intriguing findings from this work is that chronic GHRP6 treatment reduced body weight when administered either alone or with citalopram after the stress exposure. These effects on body weight gain were independent of any alterations in food intake. The mechanism through which GHRP6 exerts this effect is unclear and this finding seems counterintuitive given that ghrelin exerts orexigenic effects, and hence one would expect to see GHRP6 treatment increase body weight gain as a result of increased feeding. One possibility is that GHRP6 interacts with other body weight regulating signals such as leptin, insulin and NPY. Among these signals, NPY is widely known for its role in anxiety. Both administration and overexpression of NPY resulted in anxiolytic effects, and it is also known that ghrelin directly acts on NPY neurons in the arcuate nucleus to induce food intake (Heilig et al., 1989; Broqua et al., 1995; McEwen, 1998; Kohno et al., 2003). Perhaps, the systems controlling food intake shift in times of stress exposure to combat against the stressor and this process may involve ghrelin signaling. This finding is potentially of clinical significance. There is a large body of literature describing how chronic antidepressant treatment raises secondary health concerns such as obesity, cardiovascular diseases, and diabetes due to increased body weight gain and weight gain is a frequent reason for individuals to give up taking their antidepressant medication (Berken et al., 1984; Vanina et al., 2002; Seretti et al., 2010; Grundy et al., 2014; Schwartz et al,. 2016; Correll et al., 2017). Thus, our finding that combination of 
GHRP6 + citalopram can reduce citalopram induced body weight gain has therapeutic potential.

In this thesis, we provide evidence that ghrelin receptor activity, influences social behavior, and that ghrelin receptor activity in the VTA is sufficient for this effect. This effect on social behavior may be driven by ghrelin receptor activity increasing dopaminergic activation in the mesocorticolimbic pathway. Our assumption that ghrelin agonist GHRP6 treatment would improve social behavior in chronically stressed animals was not met although it did have effects on neurogenesis. We did find that post-stress treatment of chronic GHRP6 and combined treatment of GHRP6 + citalopram reduced body weight gain, that was independent from chow intake. Therapeutic avenues exploring potential treatments for stress-induced as well as antidepressant treatment induced metabolic dysfunctions should consider targeting the ghrelin signaling system. 


\section{REFERENCES}

Abizaid, A., \& Horvath, T. L. (2008). Brain circuits regulating energy homeostasis. Regulatory Peptides, 149(1), 3-10.

Abizaid, A., Mineur, Y., Roth, R., Elsworth, J., Sleeman, M., Picciotto, M., \& Horvath, T. (2011). Reduced locomotor responses to cocaine in ghrelindeficient mice. Neuroscience, 192, 500-506.

Abizaid, A., Liu, Z. W., Andrews, Z. B., Shanabrough, M., Borok, E., Elsworth, J. D.,... Horvath, T. L. (2006). Ghrelin modulates the activity and synaptic input organization of midbrain dopamine neurons while promoting appetite. The Journal of Clinical Investigation, 116(12), 3229-3239. doi:10.1172/JCI29867

Alvarez-Crespo, M., Skibicka, K. P., Farkas, I., Molnár, C. S., Egecioglu, E., Hrabovszky, E., .. Dickson, S. L. (2012). The amygdala as a neurobiological target for ghrelin in rats: Neuroanatomical, electrophysiological and behavioral evidence. PLoS One, 7(10), e46321.

Anderberg, R. H., Hansson, C., Fenander, M., Richard, J. E., Dickson, S. L., Nissbrandt, H., . . Skibicka, K. P. (2016). The stomach-derived hormone ghrelin increases impulsive behavior. Neuropsychopharmacology, 41(5), 1199-1209.

Anisman, H., \& Matheson, K. (2005). Stress, depression, and anhedonia: Caveats concerning animal models. Neuroscience \& Biobehavioral Reviews, 29(4), $525-546$. 
Anisman, H., \& Zacharko, R. M. (1990). Multiple neurochemical and behavioral consequences of stressors: Implications for depression. Pharmacology \& Therapeutics, 46(1), 119-136.

Asakawa, A., Inui, A., Kaga, T., Yuzuriha, H., Nagata, T., Fujimiya, M., ... Kasuga, M. (2001). A role of ghrelin in neuroendocrine and behavioral responses to stress in mice. Neuroendocrinology, 74(3), 143-147. doi:54680 [pii]

Atasoy, D., Betley, J. N., Su, H. H., \& Sternson, S. M. (2012). Deconstruction of a neural circuit for hunger. Nature, 488(7410), 172-177. doi:10.1038/nature11270 [doi]

Bagnol, D., Lu, X. Y., Kaelin, C. B., Day, H. E., Ollmann, M., Gantz, I., ... Watson, S. J. (1999). Anatomy of an endogenous antagonist: Relationship between agouti-related protein and proopiomelanocortin in brain. The Journal of Neuroscience : The Official Journal of the Society for Neuroscience, 19(18), RC26.

Bambico, F. R., Nguyen, N., \& Gobbi, G. (2009). Decline in serotonergic firing activity and desensitization of 5-HT1A autoreceptors after chronic unpredictable stress. European Neuropsychopharmacology, 19(3), 215-228.

Barim, A. O., Aydin, S., Colak, R., Dag, E., Deniz, O., \& Sahin, İ. (2009). Ghrelin, paraoxonase and arylesterase levels in depressive patients before and after citalopram treatment. Clinical Biochemistry, 42(10), 1076-1081.

Beery, A. K., \& Kaufer, D. (2015). Stress, social behavior, and resilience: Insights from rodents. Neurobiology of Stress, 1, 116-127. 
Beheshti, S., \& Shahrokhi, S. (2015). Blocking the ghrelin receptor type 1a in the rat brain impairs memory encoding. Neuropeptides, 52, 97-102.

Belzeaux, R., Lin, C., Ding, Y., Bergon, A., Turecki, G., Tseng, G., \& Sibille, E. (2016). Predisposition to treatment response in major depressive episode: A peripheral blood gene coexpression network analysis. Journal of Psychiatric Research, 81, 119-126.

Berken, G. H., Weinstein, D. O., \& Stern, W. C. (1984). Weight gain: A side-effect of tricyclic antidepressants. Journal of Affective Disorders, 7(2), 133-138.

Berton, O., McClung, C. A., Dileone, R. J., Krishnan, V., Renthal, W., Russo, S. J., . .. Nestler, E. J. (2006). Essential role of BDNF in the mesolimbic dopamine pathway in social defeat stress. Science (New York, N.Y.), 311(5762), 864-868. doi:311/5762/864 [pii]

Blanchard, R. J., McKittrick, C. R., \& Blanchard, D. C. (2001). Animal models of social stress: Effects on behavior and brain neurochemical systems. Physiology \& Behavior, 73(3), 261-271.

Bodnoff, S. R., Suranyi-Cadotte, B., Aitken, D. H., Quirion, R., \& Meaney, M. J. (1988). The effects of chronic antidepressant treatment in an animal model of anxiety. Psychopharmacology, 95(3), 298-302.

Brody, A. L., Saxena, S., Stoessel, P., Gillies, L. A., Fairbanks, L. A., Alborzian, S., . .. Ho, M. L. (2001). Regional brain metabolic changes in patients with major depression treated with either paroxetine or interpersonal therapy: Preliminary findings. Archives of General Psychiatry, 58(7), 631-640. 
Broqua, P., Wettstein, J., Rocher, M., Gauthier-Martin, B., \& Junien, J. (1995).

Behavioral effects of neuropeptide $Y$ receptor agonists in the elevated plusmaze and fear-potentiated startle procedures. Behavioural Pharmacology, 6(3), 215-222.

Brown, J. P., Couillard-Després, S., Cooper-Kuhn, C. M., Winkler, J., Aigner, L., \& Kuhn, H. G. (2003). Transient expression of doublecortin during adult neurogenesis. Journal of Comparative Neurology, 467(1), 1-10.

Brunetti, L., Recinella, L., Orlando, G., Michelotto, B., Di Nisio, C., \& Vacca, M. (2002). Effects of ghrelin and amylin on dopamine, norepinephrine and serotonin release in the hypothalamus. European Journal of Pharmacology, 454(2), 189-192.

Burghardt, N. S., Sigurdsson, T., Gorman, J. M., McEwen, B. S., \& LeDoux, J. E. (2013). Chronic antidepressant treatment impairs the acquisition of fear extinction. Biological Psychiatry, 73(11), 1078-1086.

Buwalda, B., Kole, M. H., Veenema, A. H., Huininga, M., de Boer, S. F., Korte, S. M., \& Koolhaas, J. M. (2005). Long-term effects of social stress on brain and behavior: A focus on hippocampal functioning. Neuroscience \& Biobehavioral Reviews, 29(1), 83-97.

Cabib, S., \& Puglisi-Allegra, S. (1996). Stress, depression and the mesolimbic dopamine system. Psychopharmacology, 128(4), 331-342.

Carlini, V. P., Gaydou, R. C., Schiöth, H. B., \& de Barioglio, S. R. (2007). Selective serotonin reuptake inhibitor (fluoxetine) decreases the effects of ghrelin on memory retention and food intake. Regulatory Peptides, 140(1), 65-73. 
Carlini, V. P., Ghersi, M., Schiöth, H. B., \& de Barioglio, S. R. (2010). Ghrelin and memory: Differential effects on acquisition and retrieval. Peptides, 31(6), 1190-1193.

Carlini, V. P., Monzón, M. E., Varas, M. M., Cragnolini, A. B., Schiöth, H. B., Scimonelli, T. N., \& de Barioglio, S. R. (2002). Ghrelin increases anxiety-like behavior and memory retention in rats. Biochemical and Biophysical Research Communications, 299(5), 739-743.

Carlini, V. P., Machado, D. G., Buteler, F., Ghersi, M., Ponzio, M. F., Martini, A. C., ... de Barioglio, S. R. (2012). Acute ghrelin administration reverses depressive-like behavior induced by bilateral olfactory bulbectomy in mice. Peptides, 35(2), 160-165.

Castagné, V., Moser, P., Roux, S., \& Porsolt, R. D. (2010). Rodent models of depression: Forced swim and tail suspension behavioral despair tests in rats and mice. Current Protocols in Pharmacology, , 5.8. 1-5.8. 14.

Chaudhury, D., Walsh, J. J., Friedman, A. K., Juarez, B., Ku, S. M., Koo, J. W., . . . Han, M. H. (2013). Rapid regulation of depression-related behaviours by control of midbrain dopamine neurons. Nature, 493(7433), 532-536. doi:10.1038/nature11713 [doi]

Chuang, J. C., \& Zigman, J. M. (2010). Ghrelin's roles in stress, mood, and anxiety regulation. International Journal of Peptides, 2010, 10.1155/2010/460549. Epub 2010 Feb 14. doi:10.1155/2010/460549 [doi]

Clifford, P. S., Rodriguez, J., Schul, D., Hughes, S., Kniffin, T., Hart, N., ... Martinez, J. (2012). Attenuation of cocaine-induced locomotor sensitization 
in rats sustaining genetic or pharmacologic antagonism of ghrelin receptors. Addiction Biology, 17(6), 956-963.

Correll, C. U., \& Galling, B. (2017). Polypharmacy in Youth Treated with Antipsychotics: Do Antidepressants Or Stimulants Add to the Risk for Type 2 Diabetes?,

Cowley, M. A., Smith, R. G., Diano, S., Tschöp, M., Pronchuk, N., Grove, K. L., . . . Heiman, M. L. (2003). The distribution and mechanism of action of ghrelin in the CNS demonstrates a novel hypothalamic circuit regulating energy homeostasis. Neuron, 37(4), 649-661.

Crown, W. H., Finkelstein, S., Berndt, E. R., Ling, D., Poret, A. W., Rush, A. J., \& Russell, J. M. (2002). The impact of treatment-resistant depression on health care utilization and costs. The Journal of Clinical Psychiatry, 63(11), 963-971.

Cummings, D. E., Purnell, J. Q., Frayo, R. S., Schmidova, K., Wisse, B. E., \& Weigle, D. S. (2001). A preprandial rise in plasma ghrelin levels suggests a role in meal initiation in humans. Diabetes, 50(8), 1714-1719.

Currie, P. J., Khelemsky, R., Rigsbee, E. M., Dono, L. M., Coiro, C. D., Chapman, C. D., \& Hinchcliff, K. (2012). Ghrelin is an orexigenic peptide and elicits anxiety-like behaviors following administration into discrete regions of the hypothalamus. Behavioural Brain Research, 226(1), 96-105.

Czéh, B., Müller-Keuker, J. I., Rygula, R., Abumaria, N., Hiemke, C., Domenici, E., \& Fuchs, E. (2007). Chronic social stress inhibits cell proliferation in the adult medial prefrontal cortex: Hemispheric asymmetry and reversal by fluoxetine treatment. Neuropsychopharmacology, 32(7), 1490. 
Czeh, B., Michaelis, T., Watanabe, T., Frahm, J., de Biurrun, G., van Kampen, M., . .. Fuchs, E. (2001). Stress-induced changes in cerebral metabolites, hippocampal volume, and cell proliferation are prevented by antidepressant treatment with tianeptine. Proceedings of the National Academy of Sciences of the United States of America, 98(22), 12796-12801. doi:10.1073/pnas.211427898 [doi]

Date, Y., Murakami, N., Toshinai, K., Matsukura, S., Niijima, A., Matsuo, H., . . . Nakazato, M. (2002). The role of the gastric afferent vagal nerve in ghrelininduced feeding and growth hormone secretion in rats. Gastroenterology, 123(4), 1120-1128.

Date, Y., Shimbara, T., Koda, S., Toshinai, K., Ida, T., Murakami, N., ... Ishida, Y. (2006). Peripheral ghrelin transmits orexigenic signals through the noradrenergic pathway from the hindbrain to the hypothalamus. Cell Metabolism, 4(4), 323-331.

Davis, K. W., Wellman, P. J., \& Clifford, P. S. (2007). Augmented cocaine conditioned place preference in rats pretreated with systemic ghrelin. Regulatory Peptides, 140(3), 148-152.

De La Cour, C Dornonville, Björkqvist, M., Sandvik, A., Bakke, I., Zhao, C., Chen, D., \& Håkanson, R. (2001). A-like cells in the rat stomach contain ghrelin and do not operate under gastrin control. Regulatory Peptides, 99(2), 141-150.

Deng, W., Aimone, J. B., \& Gage, F. H. (2010). New neurons and new memories: How does adult hippocampal neurogenesis affect learning and memory? Nature Reviews.Neuroscience, 11(5), 339-350. doi:10.1038/nrn2822 [doi] 
Der-Avakian, A., Mazei-Robison, M. S., Kesby, J. P., Nestler, E. J., \& Markou, A. (2014). Enduring deficits in brain reward function after chronic social defeat in rats: Susceptibility, resilience, and antidepressant response. Biological Psychiatry, 76(7), 542-549.

Diano, S., Farr, S. A., Benoit, S. C., McNay, E. C., da Silva, I., Horvath, B., . . Banks, W. A. (2006). Ghrelin controls hippocampal spine synapse density and memory performance. Nature Neuroscience, 9(3), 381.

Dickson, S. L., Egecioglu, E., Landgren, S., Skibicka, K. P., Engel, J. A., \& Jerlhag, E. (2011). The role of the central ghrelin system in reward from food and chemical drugs. Molecular and Cellular Endocrinology, 340(1), 80-87.

Disse, E., Bussier, A., Veyrat-Durebex, C., Deblon, N., Pfluger, P. T., Tschöp, M. H., ... Rohner-Jeanrenaud, F. (2010). Peripheral ghrelin enhances sweet taste food consumption and preference, regardless of its caloric content. Physiology \& Behavior, 101(2), 277-281.

Drevets, W. C. (2001). Neuroimaging and neuropathological studies of depression: Implications for the cognitive-emotional features of mood disorders. Current Opinion in Neurobiology, 11(2), 240-249.

Egecioglu, E., Jerlhag, E., Salomé, N., Skibicka, K. P., Haage, D., Bohlooly-Y, M., . . Engel, J. A. (2010). PRECLINICAL STUDY: FULL ARTICLE: Ghrelin increases intake of rewarding food in rodents. Addiction Biology, 15(3), 304-311.

Egecioglu, E., Prieto-Garcia, L., Studer, E., Westberg, L., \& Jerlhag, E. (2016). The role of ghrelin signalling for sexual behaviour in male mice. Addiction Biology, 21(2), 348-359. 
Elias, C. F., Lee, C., Kelly, J., Aschkenasi, C., Ahima, R. S., Couceyro, P. R., . . Elmquist, J. K. (1998). Leptin activates hypothalamic CART neurons projecting to the spinal cord. Neuron, 21(6), 1375-1385.

Elmquist, J. K., Elias, C. F., \& Saper, C. B. (1999). From lesions to leptin: Hypothalamic control of food intake and body weight. Neuron, 22(2), 221232.

Faulconbridge, L. F., Cummings, D. E., Kaplan, J. M., \& Grill, H. J. (2003). Hyperphagic effects of brainstem ghrelin administration. Diabetes, 52(9), 2260-2265.

Friedman, A. K., Walsh, J. J., Juarez, B., Ku, S. M., Chaudhury, D., Wang, J., . . . Han, M. H. (2014). Enhancing depression mechanisms in midbrain dopamine neurons achieves homeostatic resilience. Science (New York, N.Y.), 344(6181), 313-319. doi:10.1126/science.1249240 [doi]

Fry, M., \& Ferguson, A. V. (2009). Ghrelin modulates electrical activity of area postrema neurons. American Journal of Physiology. Regulatory, Integrative and Comparative Physiology, 296(3), R485-92. doi:10.1152/ajpregu.90555.2008 [doi]

Gould, E., Tanapat, P., Rydel, T., \& Hastings, N. (2000). Regulation of hippocampal neurogenesis in adulthood. Biological Psychiatry, 48(8), 715720.

Grill, H. J. (2006). Distributed neural control of energy balance: Contributions from hindbrain and hypothalamus. Obesity, 14(S8) 
Grundy, A., Cotterchio, M., Kirsh, V. A., \& Kreiger, N. (2014). Associations between anxiety, depression, antidepressant medication, obesity and weight gain among canadian women. PloS One, 9(6), e99780.

Gualillo, O., Caminos, J. E., Nogueiras, R., Seoane, L. M., Arvat, E., Ghigo, E., . . . Diéguez, C. (2002). Effect of food restriction on ghrelin in normal-cycling female rats and in pregnancy. Obesity Research, 10(7), 682-687.

Guan, X., Yu, H., Palyha, O. C., McKee, K. K., Feighner, S. D., Sirinathsinghji, D. J., ... Howard, A. D. (1997). Distribution of mRNA encoding the growth hormone secretagogue receptor in brain and peripheral tissues. Molecular Brain Research, 48(1), 23-29.

Gunaydin, L. A., Grosenick, L., Finkelstein, J. C., Kauvar, I. V., Fenno, L. E., Adhikari, A., ... Zalocusky, K. A. (2014). Natural neural projection dynamics underlying social behavior. Cell, 157(7), 1535-1551.

Gutierrez, J. A., Solenberg, P. J., Perkins, D. R., Willency, J. A., Knierman, M. D., Jin, Z., ... Hale, J. E. (2008). Ghrelin octanoylation mediated by an orphan lipid transferase. Proceedings of the National Academy of Sciences of the United States of America, 105(17), 6320-6325. doi:10.1073/pnas.0800708105 [doi]

Hagan, M. M., Rushing, P. A., Pritchard, L. M., Schwartz, M. W., Strack, A. M., Van Der Ploeg, L. H., . . Seeley, R. J. (2000). Long-term orexigenic effects of AgRP-(83---132) involve mechanisms other than melanocortin receptor blockade. American Journal of Physiology.Regulatory, Integrative and Comparative Physiology, 279(1), R47-52. 
Hansson, C., Shirazi, R. H., Näslund, J., Vogel, H., Neuber, C., Holm, G., . . . Skibicka, K. P. (2012). Ghrelin influences novelty seeking behavior in rodents and men. PLoS One, 7(12), e50409.

Harkin, A., Kelly, J. P., \& Leonard, B. E. (2003). A review of the relevance and validity of olfactory bulbectomy as a model of depression. Clinical Neuroscience Research, 3(4), 253-262.

Harmatz, E. S., Stone, L., Lim, S. H., Lee, G., McGrath, A., Gisabella, B., . . Liu, E. (2017). Central ghrelin resistance permits the overconsolidation of fear memory. Biological Psychiatry, 81(12), 1003-1013.

Harmmen, C., Burge, D., Shannon, E., Davila, J., Paley, B., \& Rudolph, K. (1995). Interpersonal attachment cognitions and prediction of symptomatic responses to interpersonal stress. Journal of Abnormal Psychology, 104(3), 436-443.

Heilig, M., Söderpalm, B., Engel, J. A., \& Widerlöv, E. (1989). Centrally administered neuropeptide Y (NPY) produces anxiolytic-like effects in animal anxiety models. Psychopharmacology, 98(4), 524-529.

Hill, A. S., Sahay, A., \& Hen, R. (2015). Increasing adult hippocampal neurogenesis is sufficient to reduce anxiety and depression-like behaviors. Neuropsychopharmacology: Official Publication of the American College of Neuropsychopharmacology, 40(10), 2368-2378. doi:10.1038/npp.2015.85 [doi]

Holst, B., \& Schwartz, T. W. (2004). Constitutive ghrelin receptor activity as a signaling set-point in appetite regulation. Trends in Pharmacological Sciences, 25(3), 113-117. 
Huang, H., Zhu, X., Han, Q., Wang, Y., Yue, N., Wang, J., . . Liu, Q. (2017).

Ghrelin alleviates anxiety-and depression-like behaviors induced by chronic unpredictable mild stress in rodents. Behavioural Brain Research, 326, 33-43.

Hyland, L., Park, S., Edwards, A., Klein, M., Rosenbaum, S., and Abizaid, A. (2015).

Does ghrelin play a role in male rat sexual behavior? P17 poster presentation. $7^{\text {th }}$ annual IMHR Young Researchers Conference, Ottawa, ON Canada

Jensen, M., Ratner, C., Rudenko, O., Christiansen, S. H., Skov, L. J., Hundahl, C., . .. Holst, B. (2016). Anxiolytic-like effects of increased ghrelin receptor signaling in the amygdala. International Journal of Neuropsychopharmacology, 19(5)

Jerlhag, E., Egecioglu, E., Dickson, S. L., \& Engel, J. A. (2010). Ghrelin receptor antagonism attenuates cocaine-and amphetamine-induced locomotor stimulation, accumbal dopamine release, and conditioned place preference. Psychopharmacology, 211(4), 415-422.

Jerlhag, E., Landgren, S., Egecioglu, E., Dickson, S. L., \& Engel, J. A. (2011). The alcohol-induced locomotor stimulation and accumbal dopamine release is suppressed in ghrelin knockout mice. Alcohol, 45(4), 341-347.

Johansson, I., Destefanis, S., Aberg, N. D., Aberg, M. A., Blomgren, K., Zhu, C., . . . Muccioli, G. (2008). Proliferative and protective effects of growth hormone secretagogues on adult rat hippocampal progenitor cells. Endocrinology, 149(5), 2191-2199. 
Jokela, M., Hamer, M., Singh-Manoux, A., Batty, G., \& Kivimäki, M. (2014). Association of metabolically healthy obesity with depressive symptoms: Pooled analysis of eight studies. Molecular Psychiatry, 19(8), 910-914.

Kanehisa, M., Akiyoshi, J., Kitaichi, T., Matsushita, H., Tanaka, E., Kodama, K., . . . Isogawa, K. (2006). Administration of antisense DNA for ghrelin causes an antidepressant and anxiolytic response in rats. Progress in NeuroPsychopharmacology and Biological Psychiatry, 30(8), 1403-1407.

Karolewicz, B., Szebeni, K., Stockmeier, C., Konick, L., Overholser, J., Jurjus, G., . . . Ordway, G. (2004). Low nNOS protein in the locus coeruleus in major depression. Journal of Neurochemistry, 91(5), 1057-1066.

Kent, B. A., Beynon, A. L., Hornsby, A. K., Bekinschtein, P., Bussey, T. J., Davies, J. S., \& Saksida, L. M. (2015). The orexigenic hormone acyl-ghrelin increases adult hippocampal neurogenesis and enhances pattern separation. Psychoneuroendocrinology, 51, 431-439.

Kim, M. S., Yoon, C. Y., Park, K. H., Shin, C. S., Park, K. S., Kim, S. Y., ... Lee, H. K. (2003). Changes in ghrelin and ghrelin receptor expression according to feeding status. Neuroreport, 14(10), 1317-1320. doi:10.1097/01.wnr.0000078703.79393.d2 [doi]

King, S., Isaacs, A., O'farrell, E., \& Abizaid, A. (2011). Motivation to obtain preferred foods is enhanced by ghrelin in the ventral tegmental area. Hormones and Behavior, 60(5), 572-580. 
Kirschbaum, C., Pirke, K. M., \& Hellhammer, D. H. (1993). The 'trier social stress test'--a tool for investigating psychobiological stress responses in a laboratory setting. Neuropsychobiology, 28(1-2), 76-81. doi:119004 [pii]

Klimek, V., Schenck, J. E., Han, H., Stockmeier, C. A., \& Ordway, G. A. (2002). Dopaminergic abnormalities in amygdaloid nuclei in major depression: A postmortem study. Biological Psychiatry, 52(7), 740-748.

Kohno, D., Gao, H. Z., Muroya, S., Kikuyama, S., \& Yada, T. (2003). Ghrelin directly interacts with neuropeptide-Y-containing neurons in the rat arcuate nucleus: $\mathrm{Ca} 2+$ signaling via protein kinase $\mathrm{A}$ and $\mathrm{N}$-type channel-dependent mechanisms and cross-talk with leptin and orexin. Diabetes, 52(4), 948-956.

Kojima, M., Hosoda, H., Date, Y., Nakazato, M., Matsuo, H., \& Kangawa, K. (1999). Ghrelin is a growth-hormone-releasing acylated peptide from stomach. Nature, 402(6762), 656-660.

Krishnan, V., Han, M., Graham, D. L., Berton, O., Renthal, W., Russo, S. J., . . . Lagace, D. C. (2007). Molecular adaptations underlying susceptibility and resistance to social defeat in brain reward regions. Cell, 131(2), 391-404.

Krishnan, V., \& Nestler, E. J. (2008). The molecular neurobiology of depression. Nature, 455(7215), 894-902. doi:10.1038/nature07455 [doi]

Kristensen, P., Judge, M. E., Thim, L., \& Ribel, U. (1998). Hypothalamic CART is a new anorectic peptide regulated by leptin. Nature, 393(6680), 72. 
Kumar, J., Chuang, J., Na, E. S., Kuperman, A., Gillman, A. G., Mukherjee, S., . . Lutter, M. (2013). Differential effects of chronic social stress and fluoxetine on meal patterns in mice. Appetite, 64, 81-88.

Lagace, D. C., Donovan, M. H., DeCarolis, N. A., Farnbauch, L. A., Malhotra, S., Berton, O., ... Eisch, A. J. (2010). Adult hippocampal neurogenesis is functionally important for stress-induced social avoidance. Proceedings of the National Academy of Sciences of the United States of America, 107(9), 4436-4441. doi:10.1073/pnas.0910072107 [doi]

Landgren, S., Simms, J. A., Hyytiä, P., Engel, J. A., Bartlett, S. E., \& Jerlhag, E. (2012). Ghrelin receptor (GHS-R1A) antagonism suppresses both operant alcohol self-administration and high alcohol consumption in rats. Addiction Biology, 17(1), 86-94.

Landrigan, J., Shawaf, F., Dwyer, Z., Abizaid, A., \& Hayley, S. (2016). Interactive effects of ghrelin and ketamine on forced swim performance: Implications for novel antidepressant strategies. Neuroscience Letters,

Lanfumey, L., Mongeau, R., Cohen-Salmon, C., \& Hamon, M. (2008).

Corticosteroid-serotonin interactions in the neurobiological mechanisms of stress-related disorders. Neuroscience \& Biobehavioral Reviews, 32(6), $1174-$ 1184.

Lapin, I. (1995). Only controls: Effect of handling, sham injection, and intraperitoneal injection of saline on behavior of mice in an elevated plusmaze. Journal of Pharmacological and Toxicological Methods, 34(2), 73-77. 
Leonard, B., \& Tuite, M. (1981). Anatomical, physiological, and behavioral aspects of olfactory bulbectomy in the rat. International Review of Neurobiology, 22, 251-286.

Li, E., Chung, H., Kim, Y., Kim, D. H., Ryu, J. H., Sato, T., . . Park, S. (2013). Ghrelin directly stimulates adult hippocampal neurogenesis: Implications for learning and memory. Endocrine Journal, 60(6), 781-789.

Lledo, P., Alonso, M., \& Grubb, M. S. (2006). Adult neurogenesis and functional plasticity in neuronal circuits. Nature Reviews.Neuroscience, 7(3), 179.

Lockie, S. H., McAuley, C. V., Rawlinson, S., Guiney, N., \& Andrews, Z. B. (2017). Food seeking in a risky environment: A method for evaluating risk and reward value in food seeking and consumption in mice. Frontiers in Neuroscience, 11

Luppino, F. S., de Wit, L. M., Bouvy, P. F., Stijnen, T., Cuijpers, P., Penninx, B. W., \& Zitman, F. G. (2010). Overweight, obesity, and depression: A systematic review and meta-analysis of longitudinal studies. Archives of General Psychiatry, 67(3), 220-229.

Lutter, M., Sakata, I., Osborne-Lawrence, S., Rovinsky, S. A., Anderson, J. G., Jung, S., . . Nestler, E. J. (2008). The orexigenic hormone ghrelin defends against depressive symptoms of chronic stress. Nature Neuroscience, 11(7), 752-753.

MacKay, H., Charbonneau, V. R., St-Onge, V., Murray, E., Watts, A., Wellman, M. K., \& Abizaid, A. (2016). Rats with a truncated ghrelin receptor (GHSR) do not 
respond to ghrelin, and show reduced intake of palatable, high-calorie food. Physiology \& Behavior, 163, 88-96.

Magarinos, A. M., McEwen, B. S., Flugge, G., \& Fuchs, E. (1996). Chronic psychosocial stress causes apical dendritic atrophy of hippocampal CA3 pyramidal neurons in subordinate tree shrews. The Journal of Neuroscience: The Official Journal of the Society for Neuroscience, 16(10), 3534-3540.

Malberg, J. E., Eisch, A. J., Nestler, E. J., \& Duman, R. S. (2000). Chronic antidepressant treatment increases neurogenesis in adult rat hippocampus. The Journal of Neuroscience: The Official Journal of the Society for Neuroscience, 20(24), 9104-9110. doi:20/24/9104 [pii]

Malik, S., McGlone, F., Bedrossian, D., \& Dagher, A. (2008). Ghrelin modulates brain activity in areas that control appetitive behavior. Cell Metabolism, 7(5), 400-409.

Marsh, D. J., Hollopeter, G., Huszar, D., Laufer, R., Yagaloff, K. A., Fisher, S. L., . . . Palmiter, R. D. (1999). Response of melanocortin-4 receptor-deficient mice to anorectic and orexigenic peptides. Nature Genetics, 21(1), 119-122.

McDowell, R. S., Elias, K. A., Stanley, M. S., Burdick, D. J., Burnier, J. P., Chan, K. S., ... Somers, T. C. (1995). Growth hormone secretagogues: Characterization, efficacy, and minimal bioactive conformation. Proceedings of the National Academy of Sciences of the United States of America, 92(24), $11165-11169$.

McEwen, B. S. (1998). Stress, adaptation, and disease: Allostasis and allostatic load. Annals of the New York Academy of Sciences, 840(1), 33-44. 
McEwen, B. S., \& Magarinos, A. M. (2001). Stress and hippocampal plasticity: Implications for the pathophysiology of affective disorders. Human Psychopharmacology: Clinical and Experimental, 16(S1)

McGrath, P. J., Khan, A. Y., Trivedi, M. H., Stewart, J. W., Morris, D. W., Wisniewski, S. R., . . Rush, A. J. (2008). Response to a selective serotonin reuptake inhibitor (citalopram) in major depressive disorder with melancholic features: A STAR D report. The Journal of Clinical Psychiatry, 69(12), 18471855. doi:ej07m03711 [pii]

Mizoguchi, K., Ishige, A., Aburada, M., \& Tabira, T. (2003). Chronic stress attenuates glucocorticoid negative feedback: Involvement of the prefrontal cortex and hippocampus. Neuroscience, 119(3), 887-897.

Mizoguchi, K., Yuzurihara, M., Ishige, A., Sasaki, H., Chui, D., \& Tabira, T. (2001). Chronic stress differentially regulates glucocorticoid negative feedback response in rats. Psychoneuroendocrinology, 26(5), 443-459.

Mondal, M. S., Date, Y., Yamaguchi, H., Toshinai, K., Tsuruta, T., Kangawa, K., \& Nakazato, M. (2005). Identification of ghrelin and its receptor in neurons of the rat arcuate nucleus. Regulatory Peptides, 126(1), 55-59.

Moon, M., Kim, S., Hwang, L., \& Park, S. (2009). Ghrelin regulates hippocampal neurogenesis in adult mice. Endocrine Journal, 56(3), 525-531.

Müller, T. D., Nogueiras, R., Andermann, M. L., Andrews, Z. B., Anker, S., Argente, J., ... Broglio, F. (2015). Ghrelin. Molecular Metabolism, 4(6), 437460. 
Nakashima, K., Akiyoshi, J., Hatano, K., Hanada, H., Tanaka, Y., Tsuru, J., . . . Isogawa, K. (2008). Ghrelin gene polymorphism is associated with depression, but not panic disorder. Psychiatric Genetics, 18(5), 257. doi:10.1097/YPG.0b013e328306c979 [doi]

Naleid, A. M., Grace, M. K., Cummings, D. E., \& Levine, A. S. (2005). Ghrelin induces feeding in the mesolimbic reward pathway between the ventral tegmental area and the nucleus accumbens. Peptides, 26(11), 2274-2279.

Nemeroff, C. B., Widerlov, E., Bissette, G., Walleus, H., Karlsson, I., Eklund, K., . . . Vale, W. (1984). Elevated concentrations of CSF corticotropin-releasingfactor-like immunoreactivity in depressed patients. Science, 226, 1342-1345.

Nestler, E. J., \& Carlezon, W. A. (2006). The mesolimbic dopamine reward circuit in depression. Biological Psychiatry, 59(12), 1151-1159.

Nicolas, L. B., Kolb, Y., \& Prinssen, E. P. (2006). A combined marble buryinglocomotor activity test in mice: A practical screening test with sensitivity to different classes of anxiolytics and antidepressants. European Journal of Pharmacology, 547(1), 106-115.

Ortiz, J., Fitzgerald, L. W., Lane, S., Terwilliger, R., \& Nestler, E. J. (1996). Biochemical adaptations in the mesolimbic dopamine system in response to repeated stress. Neuropsychopharmacology, 14(6), 443-452.

Park, S., Rodrigues, T., Wallace, C., Mezher, K., Hyland, L., Klein, M., Edwards, A., Patterson, Z., MacKay, H., and Abizaid, A. (2015). Ghrelin receptors in the VTA mediate stress induced changes in caloric intake during chronic social defeat. AA44, Society for Neuroscience Conference, Chicago IL, USA 
Patterson, Z., Ducharme, R., Anisman, H., \& Abizaid, A. (2010). Altered metabolic and neurochemical responses to chronic unpredictable stressors in ghrelin receptor-deficient mice. European Journal of Neuroscience, 32(4), 632-639.

Patterson, Z., Khazall, R., Mackay, H., Anisman, H., \& Abizaid, A. (2013). Central ghrelin signaling mediates the metabolic response of C57BL/6 male mice to chronic social defeat stress. Endocrinology, 154(3), 1080-1091.

Peña, C. J., Kronman, H. G., Walker, D. M., Cates, H. M., Bagot, R. C., Purushothaman, I., ... Kiraly, D. D. (2017). Early life stress confers lifelong stress susceptibility in mice via ventral tegmental area OTX2. Science, 356(6343), 1185-1188.

Perello, M., Sakata, I., Birnbaum, S., Chuang, J., Osborne-Lawrence, S., Rovinsky, S. A., ... Zigman, J. M. (2010). Ghrelin increases the rewarding value of highfat diet in an orexin-dependent manner. Biological Psychiatry, 67(9), 880-886.

Perera, T. D., Dwork, A. J., Keegan, K. A., Thirumangalakudi, L., Lipira, C. M., Joyce, N., ... Hen, R. (2011). Necessity of hippocampal neurogenesis for the therapeutic action of antidepressants in adult nonhuman primates. PloS One, 6(4), e17600.

Porsolt, R. D., Bertin, A., \& Jalfre, M. (1977). Behavioral despair in mice: A primary screening test for antidepressants. Archives Internationales De Pharmacodynamie Et De Therapie, 229(2), 327-336.

Pratt, L. A., \& Brody, D. J. (2014). Depression and obesity in the US adult household population, 2005-2010. Women, 20, 39. 
Prut, L., \& Belzung, C. (2003). The open field as a paradigm to measure the effects of drugs on anxiety-like behaviors: A review. European Journal of Pharmacology, 463(1), 3-33.

Richardson, L. P., Davis, R., Poulton, R., McCauley, E., Moffitt, T. E., Caspi, A., \& Connell, F. (2003). A longitudinal evaluation of adolescent depression and adult obesity. Archives of Pediatrics \& Adolescent Medicine, 157(8), 739-745.

Rouach, V., Bloch, M., Rosenberg, N., Gilad, S., Limor, R., Stern, N., \& Greenman, Y. (2007). The acute ghrelin response to a psychological stress challenge does not predict the post-stress urge to eat. Psychoneuroendocrinology, 32(6), 693-702.

Santarelli, L., Saxe, M., Gross, C., Surget, A., Battaglia, F., Dulawa, S., ... Hen, R. (2003). Requirement of hippocampal neurogenesis for the behavioral effects of antidepressants. Science (New York, N.Y.), 301(5634), 805-809. doi:10.1126/science.1083328 [doi]

Sapolsky, R. M., Krey, L. C., \& McEwen, B. S. (1984). Glucocorticoid-sensitive hippocampal neurons are involved in terminating the adrenocortical stress response. Proceedings of the National Academy of Sciences of the United States of America, 81(19), 6174-6177.

Sapolsky, R. M., Krey, L. C., \& McEwen, B. S. (1985). Prolonged glucocorticoid exposure reduces hippocampal neuron number: Implications for aging. The Journal of Neuroscience: The Official Journal of the Society for Neuroscience, 5(5), 1222-1227. 
Schultz, S. K. (2007). Depression in the Older Adult: The Challenge of Medical Comorbidity,

Schwartz, B. S., Glass, T. A., Pollak, J., Hirsch, A. G., Bailey-Davis, L., Moran, T. H., \& Bandeen-Roche, K. (2016). Depression, its comorbidities and treatment, and childhood body mass index trajectories. Obesity, 24(12), 2585-2592.

Scott, K. M., Bruffaerts, R., Simon, G. E., Alonso, J., Angermeyer, M., de Girolamo, G., ... Karam, E. (2008). Obesity and mental disorders in the general population: Results from the world mental health surveys. International Journal of Obesity, 32(1), 192-200.

Serretti, A., \& Mandelli, L. (2010). Antidepressants and body weight: A comprehensive review and meta-analysis. The Journal of Clinical Psychiatry, 71(10), 1259-1272. doi:10.4088/JCP.09r05346blu [doi]

Shanks, N., Zalcman, S., Zacharko, R. M., \& Anisman, H. (1991). Alterations of central norepinephrine, dopamine and serotonin in several strains of mice following acute stressor exposure. Pharmacology Biochemistry and Behavior, 38(1), 69-75.

Sheline, Y. I., Gado, M. H., \& Kraemer, H. C. (2003). Untreated depression and hippocampal volume loss. American Journal of Psychiatry, 160(8), 1516-1518.

Sheline, Y. I., Wang, P. W., Gado, M. H., Csernansky, J. G., \& Vannier, M. W. (1996). Hippocampal atrophy in recurrent major depression. Proceedings of the National Academy of Sciences of the United States of America, 93(9), 3908-3913. 
Simon, G. E., Von Korff, M., Saunders, K., Miglioretti, D. L., Crane, P. K., Van Belle, G., \& Kessler, R. C. (2006). Association between obesity and psychiatric disorders in the US adult population. Archives of General Psychiatry, 63(7), 824-830.

Skibicka, K. P., Hansson, C., Alvarez-Crespo, M., Friberg, P. A., \& Dickson, S. L. (2011). Ghrelin directly targets the ventral tegmental area to increase food motivation. Neuroscience, 180, 129-137.

Skibicka, K. P., Hansson, C., Egecioglu, E., \& Dickson, S. L. (2012). Role of ghrelin in food reward: Impact of ghrelin on sucrose self-administration and mesolimbic dopamine and acetylcholine receptor gene expression. Addiction Biology, 17(1), 95-107.

Skibicka, K. P., Shirazi, R. H., Rabasa-Papio, C., Alvarez-Crespo, M., Neuber, C., Vogel, H., \& Dickson, S. L. (2013). Divergent circuitry underlying food reward and intake effects of ghrelin: Dopaminergic VTA-accumbens projection mediates ghrelin's effect on food reward but not food intake. Neuropharmacology, 73, 274-283.

Skov, L. J., Jensen, M., Christiansen, S. H., Ratner, C., Woldbye, D. P., \& Holst, B. (2017). Exploring the behavioral and metabolic phenotype generated by reintroduction of the ghrelin receptor in the ventral tegmental area. International Journal of Molecular Sciences, 18(5), 914.

Solomon, A., De Fanti, B., \& Martinez, J. (2006). The nucleus tractus solitari (NTS) participates in peripheral ghrelin glucostatic hunger signalling mediated by insulin. Neuropeptides, 40(3), 169-175. 
Spampanato, J., Sullivan, R. K., Turpin, F. R., Bartlett, P. F., \& Sah, P. (2012).

Properties of doublecortin expressing neurons in the adult mouse dentate gyrus. PLoS One, 7(9), e41029.

Spencer, S. J., Xu, L., Clarke, M. A., Lemus, M., Reichenbach, A., Geenen, B., . . . Andrews, Z. B. (2012). Ghrelin regulates the hypothalamic-pituitary-adrenal axis and restricts anxiety after acute stress. Biological Psychiatry, 72(6), 457465.

Stanley, B. G., Kyrkouli, S. E., Lampert, S., \& Leibowitz, S. F. (1986). Neuropeptide $Y$ chronically injected into the hypothalamus: A powerful neurochemical inducer of hyperphagia and obesity. Peptides, 7(6), 1189-1192.

St-Onge, V., Watts, A., \& Abizaid, A. (2016). Ghrelin enhances cue-induced bar pressing for high fat food. Hormones and Behavior, 78, 141-149.

Strekalova, T., Anthony, D. C., Dolgov, O., Anokhin, K., Kubatiev, A., Steinbusch, H. M., \& Schroeter, C. (2013). The differential effects of chronic imipramine or citalopram administration on physiological and behavioral outcomes in naïve mice. Behavioural Brain Research, 245, 101-106.

Sun, Y., Asnicar, M., Saha, P. K., Chan, L., \& Smith, R. G. (2006). Ablation of ghrelin improves the diabetic but not obese phenotype of ob/ob mice. Cell Metabolism, 3(5), 379-386.

Swaab, D. F., Bao, A., \& Lucassen, P. J. (2005). The stress system in the human brain in depression and neurodegeneration. Ageing Research Reviews, 4(2), 141-194. 
Swendsen, J. D., Merikangas, K. R., Canino, G. J., Kessler, R. C., Rubio-Stipec, M., \& Angst, J. (1998). The comorbidity of alcoholism with anxiety and depressive disorders in four geographic communities. Comprehensive Psychiatry, 39(4), 176-184.

Szentirmai, E., Kapas, L., Sun, Y., Smith, R. G., \& Krueger, J. M. (2009). The preproghrelin gene is required for the normal integration of thermoregulation and sleep in mice. Proceedings of the National Academy of Sciences of the United States of America, 106(33), 14069-14074. doi:10.1073/pnas.0903090106 [doi]

Tong, J., Mannea, E., Aime, P., Pfluger, P. T., Yi, C. X., Castaneda, T. R., .. . Tschop, M. H. (2011). Ghrelin enhances olfactory sensitivity and exploratory sniffing in rodents and humans. The Journal of Neuroscience : The Official Journal of the Society for Neuroscience, 31(15), 5841-5846. doi:10.1523/JNEUROSCI.5680-10.2011 [doi]

Toshinai, K., Mondal, M. S., Nakazato, M., Date, Y., Murakami, N., Kojima, M., . . . Matsukura, S. (2001). Upregulation of ghrelin expression in the stomach upon fasting, insulin-induced hypoglycemia, and leptin administration. Biochemical and Biophysical Research Communications, 281(5), 1220-1225.

Tremblay, L. K., Naranjo, C. A., Graham, S. J., Herrmann, N., Mayberg, H. S., Hevenor, S., \& Busto, U. E. (2005). Functional neuroanatomical substrates of altered reward processing in major depressive disorder revealed by a dopaminergic probe. Archives of General Psychiatry, 62(11), 1228-1236. 
Tschop, M., Smiley, D. L., \& Heiman, M. L. (2000). Ghrelin induces adiposity in rodents. Nature, 407(6806), 908.

Tsuda, M. C., \& Ogawa, S. (2012). Long-lasting consequences of neonatal maternal separation on social behaviors in ovariectomized female mice. PloS One, 7(3), e33028.

Uguz, F., Sahingoz, M., Gungor, B., Aksoy, F., \& Askin, R. (2015). Weight gain and associated factors in patients using newer antidepressant drugs. General Hospital Psychiatry, 37(1), 46-48.

Van Bokhoven, P., Oomen, C., Hoogendijk, W., Smit, A., Lucassen, P., \& Spijker, S. (2011). Reduction in hippocampal neurogenesis after social defeat is longlasting and responsive to late antidepressant treatment. European Journal of Neuroscience, 33(10), 1833-1840.

Vanina, Y., Podolskaya, A., Sedky, K., Shahab, H., Siddiqui, A., Munshi, F., \& Lippmann, S. (2002). Body weight changes associated with psychopharmacology. Psychiatric Services, 53(7), 842-847.

Veenema, A. H., Meijer, O. C., de Kloet, E. R., Koolhaas, J. M., \& Bohus, B. G. (2003). Differences in basal and stress-induced HPA regulation of wild house mice selected for high and low aggression. Hormones and Behavior, 43(1), 197-204.

Wallace, C., Mehzer, K., Rodrigues, T., Klein, M., Hyland, L., Edwards, A., MacKay, H., and Abizaid, A. (2015). GHSRs in the VTA and their contributions to stress-induced anxiety and depression. P4 poster presentation. $7^{\text {th }}$ annual IMHR Young Researchers Conference, Ottawa, ON Canada 
Wellman, P. J., Davis, K. W., \& Nation, J. R. (2005). Augmentation of cocaine hyperactivity in rats by systemic ghrelin. Regulatory Peptides, 125(1), 151-154.

Wellman, P. J., Hollas, C. N., \& Elliott, A. E. (2008). Systemic ghrelin sensitizes cocaine-induced hyperlocomotion in rats. Regulatory Peptides, 146(1), 33-37.

Williams, D. L., Grill, H. J., Cummings, D. E., \& Kaplan, J. M. (2003). Vagotomy dissociates short-and long-term controls of circulating ghrelin. Endocrinology, 144(12), 5184-5187.

Williams, K. W., \& Elmquist, J. K. (2012). From neuroanatomy to behavior: Central integration of peripheral signals regulating feeding behavior. Nature Neuroscience, 15(10), 1350-1355.

Willner, P., Towell, A., Sampson, D., Sophokleous, S., \& Muscat, R. (1987). Reduction of sucrose preference by chronic unpredictable mild stress, and its restoration by a tricyclic antidepressant. Psychopharmacology, 93(3), 358364.

Wren, A., Seal, L., Cohen, M., Brynes, A., Frost, G., Murphy, K., ... Bloom, S. (2001). Ghrelin enhances appetite and increases food intake in humans. J Clin Endocrinol Metab, 86(12), 5992.

Wren, A., Small, C., Ward, H., Murphy, K., Dakin, C., Taheri, S., ... Ghatei, M. (2000). The novel hypothalamic peptide ghrelin stimulates food intake and growth hormone secretion. Endocrinology, 141(11), 4325-4328. 
Yang, J., Brown, M. S., Liang, G., Grishin, N. V., \& Goldstein, J. L. (2008).

Identification of the acyltransferase that octanoylates ghrelin, an appetitestimulating peptide hormone. Cell, 132(3), 387-396.

Zhang, W., Hu, Y., Lin, T. R., Fan, Y., \& Mulholland, M. W. (2005). Stimulation of neurogenesis in rat nucleus of the solitary tract by ghrelin. Peptides, 26(11), 2280-2288.

Zhang, W., Lin, T. R., Hu, Y., Fan, Y., Zhao, L., Stuenkel, E. L., \& Mulholland, M. W. (2004). Ghrelin stimulates neurogenesis in the dorsal motor nucleus of the vagus. The Journal of Physiology, 559(3), 729-737.

Zigman, J. M., Jones, J. E., Lee, C. E., Saper, C. B., \& Elmquist, J. K. (2006). Expression of ghrelin receptor mRNA in the rat and the mouse brain. Journal of Comparative Neurology, 494(3), 528-548.

Zigman, J. M., Nakano, Y., Coppari, R., Balthasar, N., Marcus, J. N., Lee, C. E., . . Elmquist, J. K. (2005). Mice lacking ghrelin receptors resist the development of diet-induced obesity. The Journal of Clinical Investigation, 115(12), 35643572. doi:10.1172/JCl26002 [doi] 